\title{
Pressure and osmotically driven membrane processes: A review of the benefits and production of nano-enhanced membranes for desalination
}

\author{
Basma Al-Najar ${ }^{*}, 1$, Christian D. Peters ${ }^{*}, 2$, Hanan Albuflasa ${ }^{1}$, and Nicholas P. Hankins ${ }^{2}$ \\ ${ }^{1}$ Department of Physics, University of Bahrain, P.O. Box 32038, Kingdom of Bahrain \\ ${ }^{2}$ Department of Engineering Science, The University of Oxford, Parks Road, OX3 1PJ, \\ Oxford, UK
}

June 2019

\section{Abstract}

This review focuses on current research attempts to develop nano-enhanced polymeric desalination membranes. The novel contribution made by this work as 5 compared to many recent reviews on membrane enhancement is that a critical review is made of the effect that the morphological, optical and magnetic properties of the applied nanomaterials have on the efficiency of desalination membranes. The focus on nanomaterials in this review is on both applying new chemical compositions at various concentrations, and also on altering the nanomaterials' morphology and other properties to reach the optimal membrane efficiency for desalination applications. The synthesis route has

15 a major role of tuning the physical and chemical properties of the nanomaterials, and hence, the membrane morphological parameters can be altered, all of which are summarised in this review. The review surveys different types of nanomaterials used for membrane fabrication, such as single elements, metal oxides and nanotubes. Furthermore, mixed oxide composites and polymer/nanomaterial combinations are also considered for membrane enhancement. A wide application range is investigated for modified membranes in pressure and osmotically driven membrane processes for desalination, including reverse osmosis, forward osmosis, osmotically assisted reverse osmosis and pressure assisted forward osmosis.

\section{Introduction}

30 Freshwater scarcity is a globally growing threat that is further aggravated by population growth, economic development and increasing consumption. These global trends are predicted to result in a continuously growing water demand of $1 \%$ per annum, but is expected 35 to accelerate in the next two decades (UNESCO 2018). Only $2.5 \%$ of the global water quantity can be qualified as freshwater, whereas the rest is saline (Alkaisi et al. 2017). Water desalination processes extract freshwater from these saline sources and therefore offer a viable alternative to the natural freshwater sources.

While there are several technologies available for desalination, the primary separation technology used for these applications are now membrane processes (Wang et al. 2014). This review article focuses on pressure and osmotically driven membrane processes that are capable of removing feedwater solutes in the ionic range (e.g. monovalent and divalent ions, maximum dissolved solids and smaller disinfection by-product precursors (Du et al. 2018)). Reverse osmosis (RO), being the most well-known of these technologies, revolutionised the desalination market and is now widely commercialised as the chosen low-energy method. Besides RO, processes such as forward osmosis (FO), osmotically assisted reverse osmosis (OARO) and pressure assisted forward osmosis (PAFO) are discussed.

In these processes, the membrane is often susceptible to fouling, ageing, oxidation and deformation/tearing, which result in non-ideal operation and increase operating and capital expenditures. Therefore, membrane development has been an intensive research focus (Boretti et al. 2018, Du et al. 2018, Le \& Nunes 2016, Giwa et al. 2016, Lee et al. 2011, Ulbricht 2006). In this review article, the application range is limited to desalination using state-of-the-art nano-enhanced flatsheet polymeric membranes.

Nanomaterials (NMs) have been used in a wide range of applications due to their large effective surface area that enhances their physical and chemical properties. The controllable shape and design of NMs (Wang, Gu, An \& Cai 2018), such as rods (Truppi et al. 2019), particles (Gallo et al. 2019), thin film, and 3D-shapes, allow them to be applied in a wide variety of environmental, industrial and biomedical applications. In water applications (Bethi et al. 2016, Santhosh et al. 2016), NMs have been used intensively in adsorption of heavy metals and as effective catalyst of organic pollutants, such as dyes and acids (Khin et al. 2012). They have also shown a significant anti-bacterial activity (Kumar et al. 2017). Due to the capabilities of NMs, they have become a good candidate to develop water desalination membranes (Daer et al. 2015, Ong et al. 2016).

In recent studies, NMs have been widely incorporated within the membrane matrix or as surface modifiers. These nano-enhanced membranes have shown great potential in improving the whole process performance by either raising the achievable water flux, increasing the salt rejection or lowering the membrane fouling propensity (Fathizadeh et al. 2019). The investigated NMs range from single elements (e.g. $\mathrm{Ag}$ and $\mathrm{Cu}$ ), oxides (e.g. $\mathrm{SiO}_{2}, \mathrm{TiO}_{2}, \mathrm{ZnO}$ and $\left.\mathrm{GO}\right)(\mathrm{Ab}-$ baszadeh et al. 2019)), to mixed oxides and polymer 
composites (Shafiq et al. 2018), and to nano fibers (e.g. carbon and titania nanotubes (Li et al. 2016)).

Earlier review papers that discuss the incorporation of NMs in desalination membranes mainly focus on a specific type of NM and the effect their concentration has on the pressure and/or osmotically driven membrane processes. For example, Teow \& Mohammad (2019) discuss the effectiveness of carbon nanotubes zeolite NMs at various loadings in $\mathrm{RO}, \mathrm{FO}$ and membrane distillation. The focus of Karkooti et al. (2018) is rather on the application of graphene nanoribbons and nanosheets at various concentrations in water treatment membranes to improve the membranes' hand, the latest developments in two-dimensional (2D) nanoporous membranes for RO desalination are reviewed by $\mathrm{Xu}$ et al. (2019). Other review articles discuss a broader range of NMs in membranes with a spefocus on membrane materials and their fabrication (Nasir et al. 2019). However, based on our knowledge, none of these reviews consider the fabrication route, morphology and properties of these nano-enhancers as a potential parameter to optimise the membrane for 115 different pressure and osmotically driven membrane process.

In this work we review recent publications that investigate the nano-enhancement of membranes with a special focus on the NMs' synthesis route, morphology and its physical properties. We have included a theoretical background on different membrane processes. Furthermore, we briefly discuss the effect of the NMs' synthesis route on their properties and hence on their application as anti-bacterial, adsorbent and catalytic importance of the NM's morphology and properties in modifying the membrane properties in order to achieve more affordable and energy efficient membrane desalination processes.

\section{Current pressure and osmot- ically driven membrane pro- cesses for desalination}

Figure 1 has been adapted from Kim et al. (2018) and visualises the conceptual dependency of the water flux $J_{W}$ on the transmembrane hydraulic pressure difference $\Delta P$ for the five main pressure and/or chemically driven membrane processes. Pressure retarded osmosis $(\mathrm{PRO})$ is not a purification process and thus not discussed in this review. The other four membrane main driving force, which is responsible for water transport across the semi-permeable membrane.

\section{$2.1 \quad$ Reverse osmosis}

Of the currently available desalination technologies,

$\mathrm{RO}$ is the most widely employed desalination process in terms of globally installed capacity (Mezher et al.
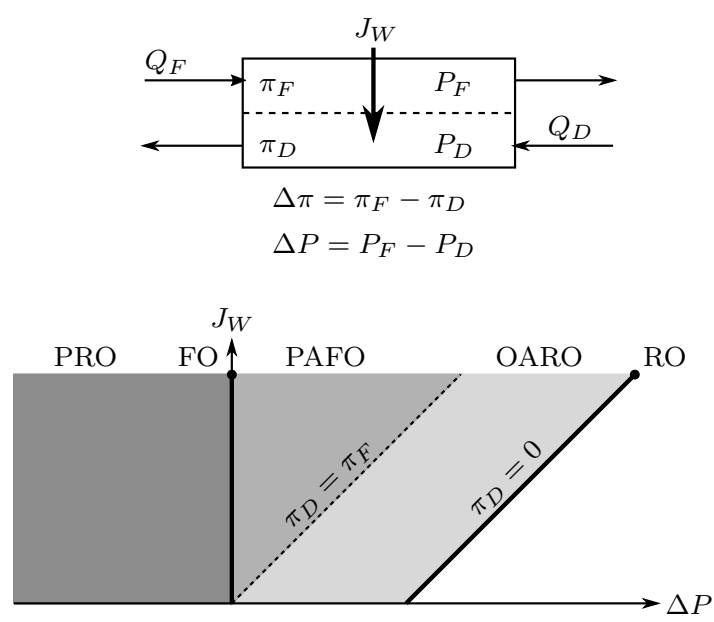

Figure 1: Water flux $J_{W}$ with respect to $\Delta P$ for $\mathrm{RO}$, FO, OARO, PAFO and PRO. Adapted from Kim et al. (2018).

2011). It is a purely pressure driven membrane process in which the feed stream $\left(Q_{F}\right)$ is pressurised to overcome the osmotic pressure of the RO feed solution $(\Delta P>\Delta \pi)$. In principle, only water is permitted to pass through the RO membrane. Thus, the osmotic pressure of the RO permeate is negligible $\left(\pi_{D}=0\right)$ compared to that of the feed stream, as no draw solution is employed $\left(Q_{D}=0\right)$.

Compared to thermal desalination methods, RO can operate closer to the thermodynamic minimum energy of separation, as it is a pressure driven process and no irreversible losses associated with a phase transition of the product water are incurred (Tong \& Elimelech 2016). Furthermore, RO is more energy efficient than the other presented membrane-based desalination techniques, as the water transported across the membrane is not firstly mixed with a draw solution, as done for example in FO, but directly constitutes the final product (Cai \& Hu 2016). Mixing of the permeated water with a draw solution diminishes the net energy efficiency due to (1) mixing entropy and (2) the additional energy consumption of the secondary purification process required to produce freshwater (Chen \& Yip 2018).

Although RO is the most energy efficient and an exceedingly robust desalination technology, the maximum operating pressure, required to overcome the feed osmotic pressure, is limited by the membrane burst pressure (Bartholomew et al. 2017). This limits the maximum recovery of $\mathrm{RO}$, especially at higher feed concentrations $(>75 \mathrm{~g} / L)$ (Tsai et al. 2017).

\subsection{Forward osmosis}

FO is a purely osmotically (chemically) driven membrane process where spontaneous freshwater permeation from the feed $Q_{F}$ to the draw $Q_{D}$ solution requires that the osmotic potential of the draw solution is higher than that of the feed solution $(\Delta \pi<0)$, as $\Delta P$ is negligible. Unlike $\mathrm{RO}$, the $\mathrm{FO}$ product is not freshwater, but rather a diluted draw solution. As a result, a secondary separation process is required to 
(1) regenerate the draw solution for reuse in the FO process and (2) to produce freshwater.

As mentioned, desalination with forward osmosis as initial pre-treatment process, such as in FO-RO, is more energy intensive than seawater desalination with RO alone (Cai \& Hu 2016). Nevertheless, the use of a suitable FO draw solution can potentially lower the cost of desalination as cheaper forms of energy (i.e. low-grade waste heat) can replace expensive electricas energy source for the draw solute regenerat process (McGinnis et al. 2013). In addition, other advantages of FO can include (1) low and reversible membrane fouling (Wang 2016), (2) possibility of achieving high process recoveries and minimising brine volume and (3) multi-barrier protection against feedwater contaminants for in-series membrane processes (Nguyen et al. 2019). These advantages make FO applicable to a wider range of applications. An example of a high recovery process is the full-scale FO plant operated at the Changxing power plant in China, which efficiently concentrates a RO brine stream $(60 \mathrm{~g} / \mathrm{L})$ to $220 \mathrm{~g} / \mathrm{L}$ prior to entering the brine crystalliser (Pendergast et al. 2016). Other examples of the wider application range of FO include its direct use as anaerobic and aerobic membrane bioreactor in municipal wastewater treatment (Eyvaz et al. 2016) or for water recovery from oily wastewater (Ge et al. 2017).

\subsection{Osmotically assisted reverse osmo- sis}

has also been referred to as draw solution assisted reverse osmosis (DSARO), osmotically-enhanced dewatering (OED), and split-feed reverse osmosis (SFRO). OARO ensures water transport across the membrane by incorporating both the $\mathrm{FO}$ and $\mathrm{RO}$ working principles. However, compared to FO, the draw solution is less concentrated than the feed solution $\left(\pi_{D}<\pi_{F}\right)$, and is only utilised to lower $\Delta \pi$ (Kim et al. 2018). Therefore, the use of an additional draw solution in OARO reduces the required hydraulic presto achieve an $\mathrm{RO}$ equivalent water flux $(\Delta P>$ $\Delta \pi)$. This also permits dewatering of more saline feed streams without exceeding the maximum allowable hydraulic pressure of the membrane module.

Similar to FO and other chemically driven membrane processes, a secondary purification process is required to produce freshwater. Therefore, OARO is more energy intensive than stand-alone RO or multi-stage RO, but can operate at lower hydraulic pressures (Peters \& Hankins 2019, Chen \& Yip 2018). However, less en35 ergy is consumed in comparison to FO. As described in Elimelech \& Phillip (2011), the minimum energy of separation increases with an increase in the osmotic pressure of the feed solution. Therefore, the secondary purification process is more energy intensive for $\mathrm{FO}$, 240 as the diluted FO draw solution to be regenerated is more concentrated. In comparison to thermal desalination methods, which are the predominant high recovery processes, OARO is more energy efficient and is a promising solution for brine volume minimisation and for water recovery from high-salinity waters. For example, Bouma \& Lienhard (2018) compare a six-stage SFRO process with a mechanical vapour compression (MVC) process with an equivalent number of stages for brine concentration up to $200 \mathrm{~g} / \mathrm{kg}$. The specific energy consumption (SEC) for the SFRO and MVC process are $3.9 \mathrm{kWh} / \mathrm{m}^{3}$ and $14.1 \mathrm{kWh} / \mathrm{m}^{3}$, respectively.

\subsection{Pressure assisted forward osmosis}

In PAFO a negative osmotic pressure difference $(\Delta \pi<$ $0)$ and positive hydraulic pressure difference $(\Delta P>0)$ are utilised. Generally, the FO water flux is lower than that of $\mathrm{RO}$, which is mainly due to the internal concentration polarisation (ICP) phenomena occurring in FO (Oh et al. 2014). The additional hydraulic pressure in PAFO has the benefit of increasing the water flux and reducing the reverse solute transport (RST) of the draw solution into the feed stream.

Although PAFO is more energy intensive than the stand-alone FO process, the higher water flux reduces the required membrane area for the same recovery (i.e. reduction in capital expenditures) and the lower RST minimises feed stream contamination and loss of draw solute (i.e. reduction in operational expenditures).

As shown in figure 1, at an equivalent water flux: $\Delta P_{R O}>\Delta P_{O A R O}>\Delta P_{P A F O}>\Delta P_{F O}$ and $\pi_{D, F O}>$ $\pi_{D, P A F O}>\pi_{D, O A R O}>\pi_{D, R O}$. Useful work done by the process is reduced by entropy generation associated with (1) mechanical losses in the energy recovery devices, (2) pressure losses in the membrane module and (3) mixing streams of different concentrations (Bouma \& Lienhard 2018). Therefore, a higher draw solute concentration results in a lower second law efficiency $\eta_{I I}$ of the overall process. Thus, $\eta_{I I, R O}>\eta_{I I, O A R O}>$ $\eta_{I I, P A F O}>\eta_{I I, F O}$

\section{Optimal membrane properties for desalination}

The ideal membrane is (1) highly water permeable (high water permeability coefficient $A$ ), (2) selective (low solute permeability $B$ ), (3) not significantly affected by ICP (low structural parameter $S$ ), (4) fouling resistant, (5) mechanically and chemically stable, (6) easily manufacturable, (7) produced from cheap and abundant materials, and (8) recyclable. Utilising such an ideal membrane will improve the process efficiency and reduce capital and operational costs by minimising for example pre-treatment requirements, membrane replacements, pressure loss due to fouling and chemical consumption.

\subsection{Water permeability}

Development of ultrapermeable membranes, which include the incorporation of Aquaporin (Zhao et al. 2012), nanoporous graphene (Cohen-Tanugi \& Grossman 2012) and densely packed carbon nanotubes 
(Corry 2008), foreshadow membranes with permeabilities exceeding those of current thin film composite membranes. However, enhancing the water permeability of membranes beyond those achieved by current TFC polyamide membranes will lead to insignificant improvements in $\mathrm{RO}$ and $\mathrm{FO}$ process efficiencies (e.g. lower SEC and/or lower capital and operational - Convincing arguments supporting this statement are offered by Werber et al. (2016) and are here shortly summarised.

Firstly, membrane permeability would solely affect the energy consumption in the desalination step. Intake, pre-treatment, post-treatment and brine discharge remain unaffected and can in total contribute to more than $1 \mathrm{kWh} / \mathrm{m}^{3}$ of the total desalination energy consumption (Elimelech \& Phillip 2011).

Secondly, energy savings achieved by employing ultra permeable membranes are limited to reducing the over-pressurisation required to achieve an acceptable water flux in pressure driven membrane processes. In essence, the minimum energy consumption in RO is limited by thermodynamics even when using ultra pershown in figure 2, the total energy consumption of RO can be subdivided into three regions. The first region (shaded dark grey) represents the theoretical minimum energy of desalination, which is dependent on the process recovery $Y$ and on $\pi_{F}$. For a single-stage RO process, the operating pressure must supersede the final brine osmotic pressure to ensure water permeation throughout the entire membrane module/pressure vessel. The second region (shaded yellow) indicates irreversible energy losses that are dependent on the minimum hydraulic pressure required to overcome the osmotic pressure of the exiting brine. RO cannot be operated at the minimum hydraulic pressure to achieve the desired recovery, because there are pressure losses (e.g. in the feed channels) and a sufficient driving force is required to achieve economically viable water fluxes in the entire RO membrane module/pressure vessel. The energy cost associated with this over-pressurisation is indicated in orange, which for currently employed TFC ings arising from utilising ultra permeable membranes are insignificant.

Thirdly, Cohen-Tanugi et al. (2014) show that ultra permeable membranes require less pressure vessels to produce the same total permeate output under nonfouling conditions. However, concentration polarisation is directly dependent on the water flux and hinders the increase of the water flux $J_{W}$ for membranes with higher $A$ values. Although external concentraion polarisation (ECP) in RO can be minimised using better feed spacer designs or higher cross-flow velocities, the increase in turbulence leads to higher channel pressure losses and increases the SEC. Furthermore, for real feedwaters containing contaminants, fouling is more severe at higher water fluxes, which also hinders the increase of $J_{W}$. Fouling is discussed in greater detail in section 3.3. Due to increased concentration polarisation and fouling, only minor savings in terms of

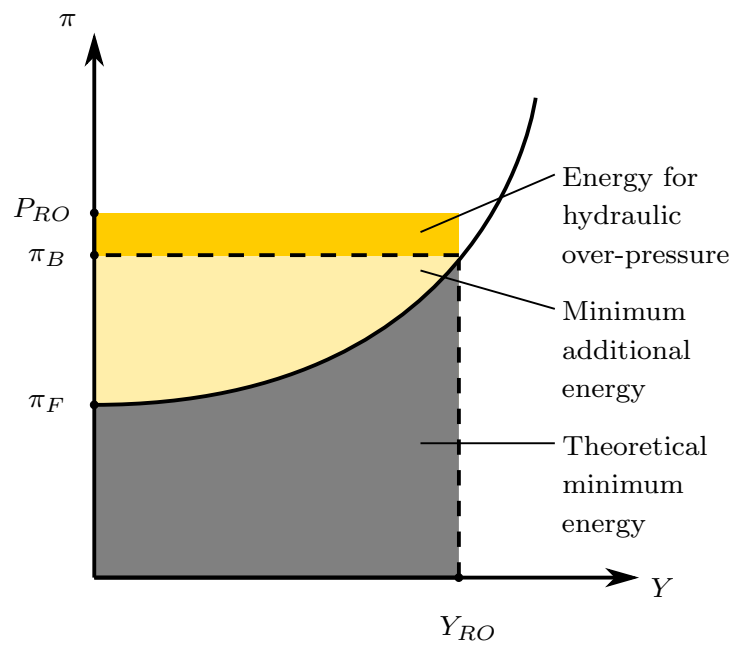

Figure 2: Representation of the energy consumption for a single-stage RO process with recovery $Y_{R O}$, final brine osmotic pressure $\pi_{B}$ and operating pressure $P_{R O}$. Adapted from Werber et al. (2016).

RO membrane area can be achieved at higher water permeabilities. This also applies to FO, although it is typically operated at much lower water fluxes of approximately $3 \mathrm{LMH}$ (Werber et al. 2016). The main FO water flux resistance is due to the support layer with a high structural parameter $S$ (i.e. due to internal concentration polarisation (ICP)) and not due to the active layer permeability. The FO water flux can be significantly improved if $S$ is minimised, while the water flux plateaus at water permeabilities exceeding those of current TFC membranes.

This discussion is focused around FO and RO, but the findings are also applicable to the intermediary processes (i.e. OARO and PAFO). To conclude, there is little benefit in further enhancing the membrane permeability beyond that of current TFC membranes.

\subsection{Selectivity}

For dense polymeric membranes, the water permeability coefficient $A$ and its salt permeability coefficient $B$ are not independent and demonstrate a permeabilityselectivity trade-off (Werber et al. 2016). According to Yip \& Elimelech (2011), the relationship is given by $B \propto A^{3}$ for TFC membranes. Therefore, tweaking the polyamide structure of the membrane's active layer to be more water permeable results in a simultaneous and significant increase in solute permeability. It can be concluded that more permeable membranes offer negligible improvements to the desalinantion process. Thus, Werber et al. (2016) argue that current membrane research should focus on developing more selective than more permeable membranes.

The development of more selective membranes will offer several advantages in terms of improving the water purification process. Firstly, better retention of feed impurities offers a more efficient process and a higher purity permeate. Improved process efficiency originates from a higher second law efficiency, as a 
higher selectivity results in more useful work being done (Bouma \& Lienhard 2018). Furthermore, if a draw solution is employed that differs from the feed solution, a better rejection of solutes by the membrane results in a lower cross-contamination of the two streams. This lowers the loss of draw solutes in the purification process (e.g. FO, PAFO), which can be valuable and must be continuously replenished, and thus reduces the operational costs of the process. Secondly, a higher solute removal in the desalination step eliminates pretreatment and post-treatment steps that are otherwise required to ensure an adequate permeate quality. This could lead to significant chemical, energy, and cost efficiency gains (Werber et al. 2016).

The complete retention of small neutral solutes, such as urea or disinfection by-products, is difficult due to their charge neutrality and small hydrodynamic radii (Werber et al. 2016). Furthermore, retention of boron and silica is often inadequate to meet product water specifications, as these only form weak acids and do not disassociate at neutral $\mathrm{pH}$. However, species, such as $\mathrm{SiO}_{2}$ and boron, become highly ionised at higher $\mathrm{pH}$ $(p H \geq 10.5)$, which reduces their membrane passage by a factor of ten or more (Morillo et al. 2014). The varying degree of selectivity towards different species depend on their interaction with the membrane.

Figure 3 displays the three exclusion mechanisms by which charged solutes (e.g. salt, organic acid) are rejected by mainly porous membranes. Steric exclusion, or size exclusion, hinders charged or uncharged species with large hydrated radii to pass through smaller membrane pores. Furthermore, the larger the hydrated particle size, the lower its permeability due to more drag and friction force when it diffuses inside the membrane matrix (Zaidi et al. 2015)

The Donnan effect describes the attraction or repulsion occurring between charged species and the membrane, whose surfaces often contain charged functional groups. Thus, the stronger interaction between the with monovalent ions leads to a better retention or higher diffusivity, if the membrane and divalent ion have the same or opposite charge, respectively (Zaidi et al. 2015). Wadley et al. (1995) however, found that the retention of negatively charged organic solutes and divalent ions by the negatively charged nanofiltration membrane is lower than expected due to the high concentrations of $\mathrm{NaCl}$ in the feed solution $(50 \mathrm{~g} / \mathrm{L}$ to $100 \mathrm{~g} / \mathrm{L}$ ). The strong presence of monovalent ions are found to shield the charge of the membrane and thus reduces its selectivity.

Lastly, dielectric exclusion occurs due to the resistance arising from the solute having to shed its hydration shell in order to enter the membrane pore. This exclusion mechanism is found to be partially responsible for the high retention of divalent ions (Roy et al. 2017).

Until recently, it was generally assumed that water and solute transport are solely dependent on the characteristics of the membrane's active layer (Wang et al. 2014). However, several studies found that the influ-

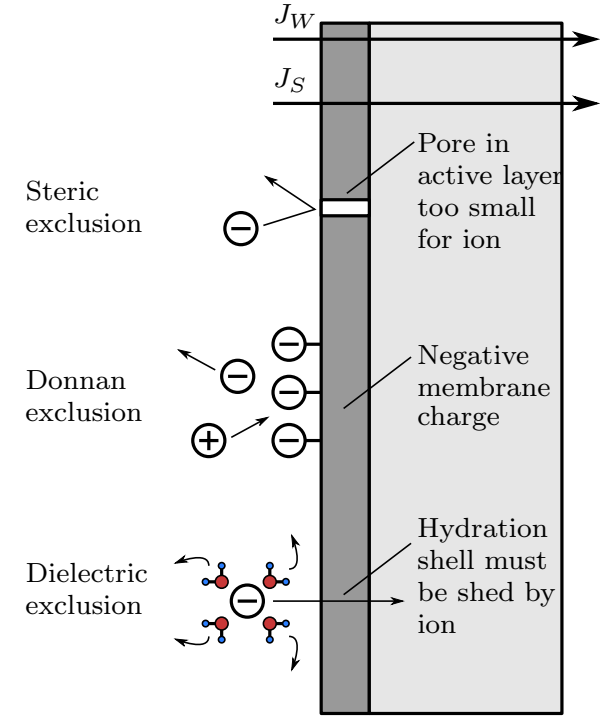

Figure 3: Representation of solute exclusion mechanisms in porous membranes. Adapted from Roy et al. (2017).

ence of the support layer structure cannot be neglected (Du et al. 2018). For example, Ghosh \& Hoek (2009) varied the pore structure and hydrophilicity of the polysulfone support layer and recorded variations in the membranes water permeability and selectivity. The experimental findings indicate that more hydrophobic and rough polysulfone support layers result in an overall higher water permeability whereas membranes with large pores in the support layer showed a higher salt permeability. More porous, hydrophilic support layers allowed for the formation of polyamide within the pores during the interfacial polymerisation process. Therefore, the path length of water and solute through the polyamide layer are longer and thus a lower water permeability is observed. Hydrophobic and non-porous support layers are however not beneficial for FO (or any other process employing a draw solute), as the membrane support layer is ideally hydrophilic and porous to reduce ICP.

\subsection{Fouling propensity}

Membrane fouling can cause operational instabilities and increases operational costs (e.g. more frequent membrane module replacement and cleaning, higher chemical usage, and higher specific energy consumption) and capital expenditures. It is common practice to over-design the water purification/desalination plant and allow for additional membrane modules to counteract the expected water flux reductions associated with membrane fouling and ageing.

In order to enhance membranes using nanomaterials to be fouling resistant, it is important to understand the types and underlying mechanisms of fouling. Therefore, the rest of this subsection focuses on these aspects. 


\subsubsection{Fouling types and mechanisms}

The four types of fouling are categorised as (1) scaling (formation of mineral deposits), (2) particulate and colloidal fouling, (3) organic fouling and (4) biofouling.

495 Each individual fouling type is represented in figure 4 using scanning electron microscope (SEM) images of model foulants.

Fouling is a complex process and feedwaters often contain several different types of contaminants.

500 Thus, the four presented forms of fouling often occur simultaneously and can also initiate or aggravate each other (Badruzzaman et al. 2019). According to Voutchkov (2018) and Chesters et al. (2013), particulate/colloidal/organic fouling and biofilm formation are most pronounced in the first and second membrane module of the RO pressure vessel, while scale formation is most likely to occur in the last two membrane modules.

Biofouling is considered the most difficult to eradicate (Fane 2018, Badruzzaman et al. 2019, Jiang et al. 2017), as it is practically impossible to keep large water treatment plants sterile and prevent the growth of microorganisms in stagnant flow regions. Microbial contamination of the membrane system occurs by microbes entering the system via the feed stream or by spreading from their upstream growth sites, which can be located in any prior process equipment, such as piping and storage tanks. Even the pre-treatment process itself can be the origin of downstream biofouling. For are, if flocculants are used in the pre-treatment process, these can provide a suitable habitat for microbial growth (Franken 2009).

The mechanism by which biofouling develops on the membrane surface is illustrated in figure 5. Biofouling initiated by adsorption of dissolved organic matter on the membrane surface. The organic conditioned surface enhances the rate by which first colonists (microorganisms) approaching the membrane surface loosely attach themselves (Ben-Dov et al. 2016). In the sec530 ondary step, cell adhesion structures are formed, which ensure a more permanent microbial attachment to the membrane surface. After the microorganisms have attached themselves more permanently, the first and secondary maturation stages take place. In the first 55 maturation stage, the originally attached microbes offer new and diverse adhesion sites for additional microbes arriving from the feed stream. Together the microbes form the biopolymer matrix, which holds together the biofilm. In the secondary maturation step biofilm growth is ensured by microbial reproduction and by the recruitment of new microbes from the feedwater. For microbial proliferation, nutrients in the water are consumed at higher rates and extracellular polymeric substances (EPS) are excreted by the microbes. EPS can improve the biofilm structure and make its removal more difficult (Jiang et al. 2017). In the last step, microbes detach themselves from the biofilm or die-off due to the high population density and lack of nutrients. Thus, an equilibrium stage is reached where detached microorganisms migrate to new growth sites and the process depicted in figure 5 repeats itself.

\subsubsection{Reversible and irreversible fouling}

Reversible and irreversible fouling are differentiated by the degree of foulant attachment to the membrane surface. More precisely, reversible fouling is defined as a loosely attached fouling layer that is removable via physical cleaning methods, which is not the case for irreversible fouling (Nguyen et al. 2019).

According to the critical flux theory, which is first developed for pressure-driven membrane processes, fouling is insignificant (i.e. reversible) if the membrane process is operated below the critical flux, but noticeable and irreversible fouling are observed once this flux is exceeded (Bacchin et al. 2006, Du et al. 2018, Nguyen et al. 2019). Higher water flux operation requires less initial membrane area (lower capital expenditures) for a certain total permeate output, but irreversible membrane fouling will increase downtime due to membrane cleaning and replacement. Thus, operation below the critical flux is favoured to ensure economical operation of the membrane process (Bacchin et al. 2006). The exact value of the critical flux varies for every single operation and depends on membrane properties (surface charge, membrane orientation, roughness, hydrophilicity), concentration of foulants present, feedwater characteristics ( $\mathrm{pH}$, temperature, crossflow velocity), and operational time (Bacchin et al. 2006).

The formation of a fouling/cake layer induces a third type of concentration polarisation, namely cakeenhanced concentration polarisation (CECP), which is depicted in figure 6 for both $\mathrm{RO}$ and $\mathrm{FO}$ operation. This concept is particularly relevant for colloidal fouling and biofouling (Lee et al. 2010). CECP arises as the cake layer prevents cross/tangential flow in its 'porous' structure and hinders solute back diffusion (Hoek \& Elimelech 2003). Thus, the solute concentration in the membrane's vicinity is enhanced due to the cake layer. This is similar to ICP where the membrane's porous support layer restricts enhanced mass transfer by convection.

CECP causes an elevated osmotic pressure at the membrane's feed side and thus lowers the effective driving force for $J_{W}$ (Chong et al. 2008). Another side effect is that the high feed side solute concentration causes a higher forward solute transport, which lowers the membrane's selectivity. Furthermore, the negative effects of CECP on the water and solute flux are more pronounced for higher selectivity membranes and thus is an important phenomenon to consider for tight nanofiltration and RO/FO membranes (Hoek \& Elimelech 2003).

As shown in the figure, CECP is more pronounced in FO than in RO. In forward osmosis, reverse solute transport from the draw to the feed solution causes a higher solute concentration within the cake layer. The accumulated mass on the membrane's surface entraps the dissolved draw solutes and causes a higher water flux reduction by raising the feed side osmotic pressure 


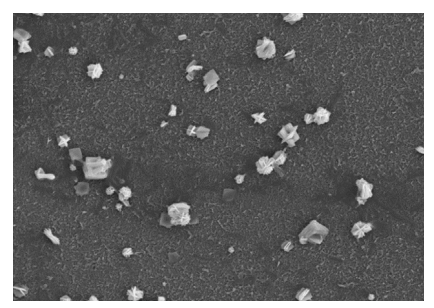

(a)

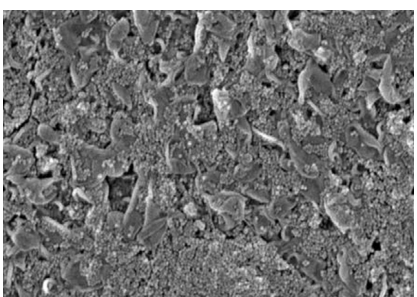

(b)

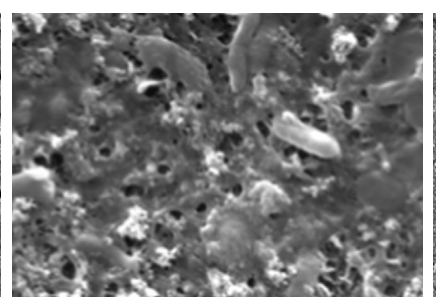

(c)

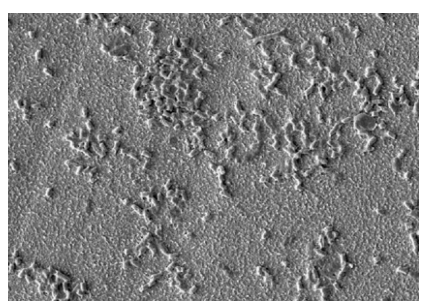

(d)

Figure 4: SEM images of (a) $\mathrm{CaSO}_{4}$ scale (Hu et al. 2014), (b) colloidal silica fouling (Ho et al. 2016), (c) organic sodium alginate fouling (Shafi et al. 2017), and (d) E.Coli biofouling (Xu et al. 2013).

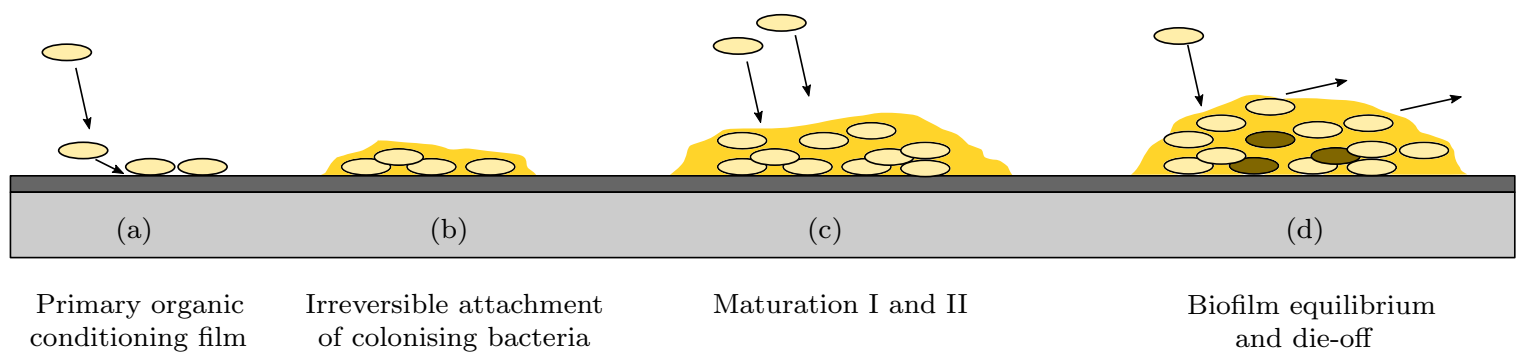

Figure 5: Conceptual illustration of the biofouling mechanism on the membrane surface. Adapted from (Badruzzaman et al. 2019).

(Du et al. 2018). As CECP in FO is dependent on the reverse solute flux of the draw solution, it is stated by Lee et al. (2010) that draw solutes with a greater hydrated radius (dextrose rather than $\mathrm{NaCl}$ ) cause less CECP due to their lower reverse solute flux.

Although FO is more affected by CECP, the fouling layer is rather loosely attached to the membrane due to the lack of hydraulic pressure. In RO, organic and deformable gel-like fouling layers are compacted by the hydraulic pressure, which increases the hydraulic rethe other hand, cake layer compaction by the hydraulic pressure in $\mathrm{RO}$ is less pronounced for colloidal fouling, as the layer cannot be further compressed than the maximum packing density of hard, rigid particles (Lee et al. 2010).

Of all the presented processes, forward osmosis has the lowest fouling propensity and shows the highest fouling reversibility (Cai \& Hu 2016). Lee et al. (2017) found that organic fouling in forward osmosis operation is almost fully reversible. On the other hand, the origical cleaning when PAFO is operated at a hydraulic pressure of 7.5 bar. Lotfi et al. (2017) explains that at higher applied hydraulic pressures, the deposition and build-up of a fouling cake layer is enhanced. Additionhydraulic pressures and is therefore more difficult to remove. In Mi \& Elimelech (2010), water flux reduction due to gypsum scaling is investigated for forward osmosis and reverse osmosis operation. The reverse osmosis and the forward osmosis process uses a $4 \mathrm{M} \mathrm{NaCl}$ draw solution while both are fed the same scaling solution. It is found that the water flux reduction rate is equivalent for both processes, but an almost complete flux ing. Meanwhile, the flux is only restored to $90 \%$ for the reverse osmosis process. The difficult gypsum scale removal in reverse osmosis operation can be attributed to scale compaction at high hydraulic pressures. Furthermore, it is found that gypsum scaling affects the thin film composite membrane more severely than the cellulose acetate membrane. It is hypothesized that surface chemistry and/or topology of the TFC membrane induce more severe heterogeneous crystallization than the cellulose acetate membrane (Mi \& Elimelech 2010). Thus, low pressure operations, such as in FO and PAFO, are more likely to show signs of reversible fouling than high pressure operations (OARO and RO).

\subsection{Mechanical and chemical stability}

Developing membranes with a superior mechanical and chemical stability will allow for membrane processes to be applied to a wider range of applications. The membrane material plays a vital role in the application choice. The nano-enhancement of organic (polymeric) membranes, such as polyamide TFC and cellulose triacetate (CTA) membranes, is the main focus of this review but these membranes are generally limited to non-oxidative and low temperature applications. However, organic membranes have already been employed for certain extreme applications, such as treating radioactive liquid wastes (Combernoux et al. 2017).

Limitations of polymeric membranes become especially evident for both chemically and pressure driven membrane processes, such as PAFO, OARO, and PRO. Chemically driven membrane processes require a support layer with a low structural parameter to minimise the internal concentration polarisation phenomenon, but this impairs the membrane's mechanical stability. This complicates high pressure operation of FO mem- 


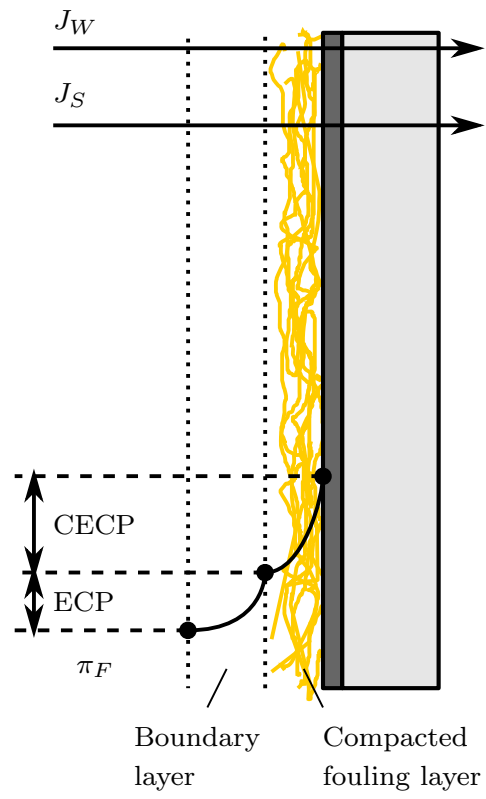

(a) Reverse osmosis

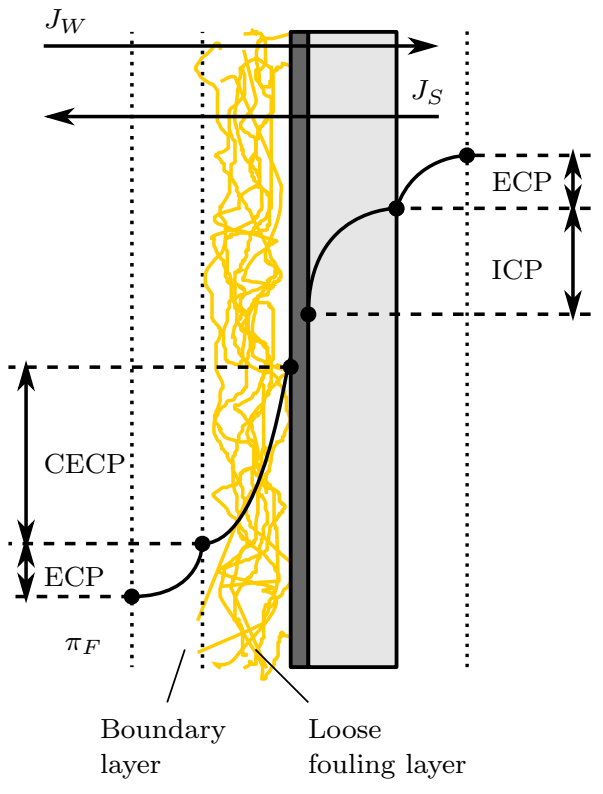

(b) Forward osmosis

Figure 6: Illustration of cake-enhanced, internal and external concentration polarisation for RO and FO with AL-FS membrane orientation. membranes can withstand higher hydraulic pressures, while TFC FO membranes are less stable.

In spiral wound modules, the choice of the permeate spacer (for OARO and PAFO processes) and the consideration to prevent membrane deformation under high operating pressures (Oh et al. 2014). For example, Kim \& Elimelech (2012) found that in PRO operation, the feed channel is compressed during high pressure operation which led to a higher flow resistance. The membrane is also subjected to concave and convex deformation due to the feed spacer. It is therefore stated that the design of the spacer is also of paramount importance. Furthermore, F de Roever et al. (2009) found that spacer intrusion into the RO membrane is a common phenomenon due to year-long operation, which gradually leads to creep-like deformation of the RO membrane. This phenomenon is also more likely at the high end of the normal temperature and pressure operation range. This proves that membranes are generally subjected to localised deformation, which can lead to membrane failure if not minimised.

As discussed in section 5, the inclusion of certain NMs can prevent mechanical and chemical degradation, such as aging, oxidation and plastic deformation, and prolong and enhance the membrane process.

\section{Synthesis, properties and ap- plications of nanomaterials for membrane modification}

With the emergence of NMs (unit size of less than $100 \mathrm{~nm}$ ), significant amounts of research investigate their efficiency in different applications, such as technology (Gajanan \& Tijare 2018), environment (Sharma et al. 2015) and biomedicine (Qu et al. 2018). Due to their small size and high surface area to volume ratio, their physical and chemical properties are enhanced in comparison to their bulk state (Lisjak \& Mertelj 2018). Within such small size units, the effective surface area becomes very large, owing NMs unique optical (Bhalla \& Tyagi 2018), magnetic (Hu et al. 2018) and mechanical properties (Vivar Mora et al. 2018).

In figure 7, a schematic diagram demonstrates the importance of NMs in the applications of water treatment and purification. Besides their large surface area, the enhanced magnetic properties make some NMs good candidates for adsorption of heavy metals from wastewater (Ge et al. 2018). This allows for a stronger attachment to heavy metal ions, as well as for easier separation from water. NMs are also involved in the photocatalysis of organic materials due to their good optical properties (Tatarchuk et al. 2018). They also own distinguishable antibacterial properties and are therefore widely applied in wastewater treatment (Khan et al. 2016). Due to the above-mentioned perks of NMs, they have also been incorporated into membranes to enhance the membrane properties (Mayyahi 2018), such as roughness (Ma et al. 2016), porosity (Rabiee et al. 2015) and mechanical strength (Lu et al. 2016). 


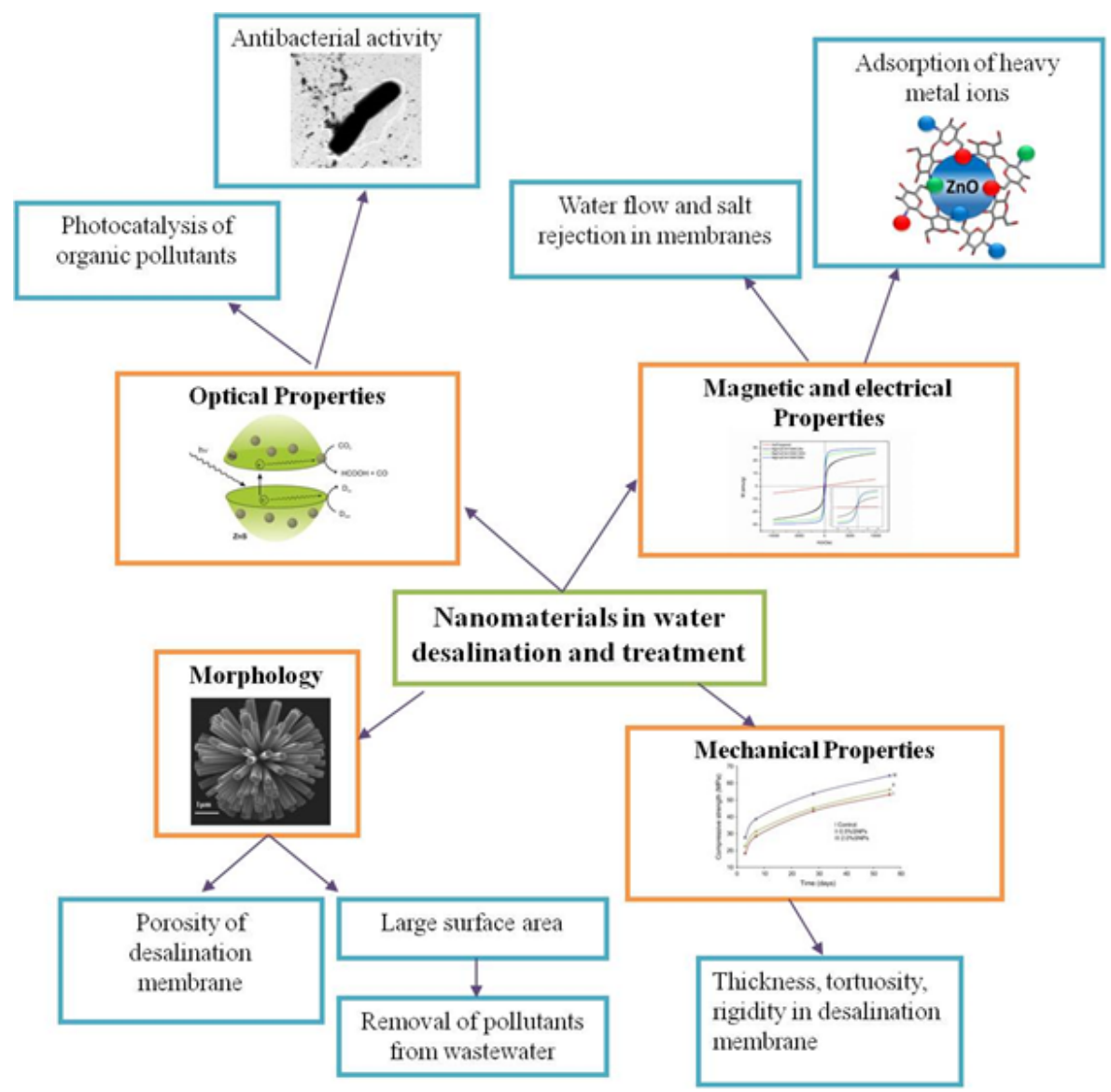

Figure 7: Properties of NMs and their applications in desalination and water treatment. Copyrights for figures in scheme obtained from Urgessa et al. (2013), Saad et al. (2018), Palla et al. (2017), Mitra et al. (2014) and Bououdina, Al-Najar, Falamarzi, Judith Vijaya, Shaikh \& Bellucci (2019).

NMs heve been synthesised using different routes, which can be mainly classified as either chemical (Zhu, $\mathrm{Ju}, \mathrm{Xu}$, Yang, Gao \& Hou 2018), mechanical (Ostovari Moghaddam et al. 2018) or green (Abdelghany et al. 2018). Accordingly, different shapes and sizes of NMs are created. This includes particles (Pattnaik et al. 2018), rods (Khot et al. 2018), tubes (Liao et al. 2018), films (Mujeeb Rahman et al. 2018) and even unique structures, such as flower-like structures (Wang, Ding, Liu, Zhu, Li, Xia, Fu \& Li 2018).

The chemical NM fabrication routes are the most common and involve various chemical steps. The solgel method is one of the well-known chemical based methods (Hasnidawani et al. 2016). In this method, two precursors are mixed together in water until a uniform solution is created. This is followed by a prolonged polymerisation phase and hence, nano-chains are created. Separation of the NMs from the solution can be done through heating, which ultimately results in nanopowders. Other separation methods can shape the NMs into other structures, such as tubes and films (Behnajady et al. 2011). It is shown that the sol-gel experimental conditions, such as the chosen precursors, water percentage, temperature and polymerisation time affect the structure and the behaviour of the nanoparticles (NPs) (Mutuma et al. 2015). Size and surface area of NMs can also be altered by changing the $\mathrm{pH}$ of the solution in the sol-gel process (SalavatiNiasari et al. 2016).

Other chemical routes can be applied to obtain unique multi dimensional structures, such as the hydrothermal route, which mainly depends on chemical interactions under high temperature (Zhu, Li \& Zeng 2018). It was shown that the high concentration of the surfactant applied during this chemical process leads to the formation of flower-like $\mathrm{ZnO}$ structures. Such structures provide a high surface area that can be utilized for different applications. Other factors during the hydrothermal process, such as the $\mathrm{pH}$ of the solution, were also shown to influence the shape of the NMs. Additionally, the hydrothermal method was applied to combine $\mathrm{ZnO}$ and $\mathrm{CuO}$ NPs in core shell design structures, where $\mathrm{CuO}$ NPs are coated with ZnO NPs (Mansournia \& Ghaderi 2017).

Co-precipitation is another chemical synthesis route, that was used to coat NPs with polymers. The coprecipitation method works by mixing two reacting liquids together to create solids within the mixed solution. This precipitate is usually removed from the bulk liquid by adsorption or filtration (Harvey 2000). Other chemical routes can also be utilised for NMs fabrication, which include combustion (Kaur et al. 2016), microwave (Nahas et al. 2016), microemulsion (Pineda-Reyes \& Olvera 2018) and solvothermal meth- 
ods (Atchudan et al. 2016). These NM synthesis routes either be applied separately or even combined with other chemical methods to give unique structures and complicated chemical phases of NMs. They are less commonly used in the preparation of NMs for water purification due to their high price and complexity.

The most well-known mechanical route to synthesise NMs is ball milling, which depends on the continuous milling of bulk material until it reaches nanosize. The milling process is done in a mechanical mill that contains several metal balls. The rotation time of the ball mill averages between several hours to a few days. The number and the size of the balls can be varied to affect the NP structure (Orge et al. 2017). Milling time, milling speed and precursor ratios have been shown to influence the properties of the fabricated NMs (Petrović et al. 2018). Ball milling can also be combined with other chemical routes, such as the hydrothermal method (Bazazi et al. 2018) and microwave method (Chen et al. 2016).

Green synthesis is one of the emerging environmentally friendly approaches to produce NMs by involving natural agents, such as organic constituents found in plants and/or agricultural waste (Tatarchuk et al. 2018). During the synthesis process, the amount of green extract affects the morphology and the structure of NPs. This is because the green extracts act as alternative reducing agents to produce NPs. Therefore, green synthesis is claimed to produce the desired NMs without producing toxic residuals that are harmful to the environment (Kombaiah et al. 2018). Furthermore, this synthesis method is known to be cheap, safe and efficient (Jamdagni et al. 2018).

The increasing demand for NMs requires large scale synthesis while most of the laboratory synthesis routes are time and labour intensive (Kombaiah et al. 2018), which may not be practical for future commercial practice. Therefore, researchers have been investigating various options for large scale synthesis. For example, solid state routes can be used for batch scale fabrication of NMs (Galizia et al. 2017) and green synthesis of Ag has potential for large scale fabrication as shown by Shende et al. (2017). Furthermore, the synthesis of $\mathrm{TiO}_{2}$ (Asiah et al. 2015, Mahy et al. 2016), ZnO (Liu, Shan, Zhou, Zhao \& Shen 2017), Cu (Xia et al. 2017), graphene oxide (GO) (Liu et al. 2016), core-shell 840 design of $\mathrm{SiO}_{2} / \mathrm{Co} @ \mathrm{Fe}_{2} \mathrm{O}_{3}$ (Jithendra Kumara et al. 2018), and carbon nanotubes (Zhang et al. 2016) are all reported to be produced on a large scale.

Electrospinning is one of the most attractive ways to create unique designs of fibrous nano structures that 845 can be considered for large scale and cost effective production (Anis et al. 2017). It allows for the formation of interconnected pores that facilitate the flow of water (Ahmed et al. 2015, Tian et al. 2013). During the electrospinning process, nanofibers are created ${ }_{850}$ from a polymeric liquid jet which are elongated under an electrical field. The forces, including surface tension, Coulombic repulsion force, electrostatic force, viscoelastic force, gravity, and air drag force, affect the charged fluid jet to form and bend the polymeric jet into loops and spirals. This creates a fibrous structure layer with a high porosity of up to $90 \%$ that can be controlled by varying the applied forces. Electrospinnings main advantage is the high versatility that allows for the creation of nanofibers over various diameters, structures and arrangements (Tian et al. 2017).

As mentioned earlier, the synthesis route has a major effect on the shape, size and properties of NMs (Teimouri et al. 2018). Accordingly, this affects their behaviour in various water purification and treatment applications such as antibacterial treatment (Khan et al. 2016), photocatalysis of dyes and adsorption of heavy metals (Bououdina, Alwqyan, Khezami, AlNajar, Shaikh, Gill, Modwi, Taha \& Lemine 2019). These applications are briefly discussed below:

\subsection{Photocatalysis of pollutants:}

NMs have shown great catalytic activity, especially under certain irradiation wavelengths, such as solar light and ultraviolet (UV) (Tatarchuk et al. 2018). Such behaviour is very useful in the degradation of some materials that cannot be biodegraded in water. The enhanced optical properties of NMs led to a faster and stronger photocatalytic process. $\mathrm{TiO}_{2} \mathrm{NMs}$ are therefore applied in wastewater treatment to degrade different types of dyes (Kaplan et al. 2016). Size and surface area can be altered by changing the $\mathrm{pH}$ of the solution during the sol-gel fabrication of $\mathrm{TiO}_{2}$ NPs. Studies have shown that $\mathrm{TiO}_{2}$ NPs fabricated at different $\mathrm{pH}$ have noticeably different photocatalysis efficiencies in the degradation of Methylene Blue (MB) dye, which is a well-known water pollutant (SalavatiNiasari et al. 2016). Further structural manipulation of $\mathrm{TiO}_{2}$ NPs is achieved by the sol-gel method by assisting it with ultrasound and other chemical additives to promote the NPs photocatalytic behaviour (Pinjari et al. 2015). The morphology of more complex chemical compositions such as $\mathrm{ZnTiO}_{3} \mathrm{NPs}_{\text {can }}$ also be controlled by the synthesis calcination temperature and $\mathrm{pH}$, achieving different efficiencies in the degradation process of pollutant dyes (Salavati-Niasari et al. 2016). Core-shell $\mathrm{Cu}$ NPs have also shown good photocatalytic effects (Ghosh et al. 2015). Ag- Cu/ZnO (Modwi et al. 2019), carbon NMs (Yi et al. 2018), ZnO nano-flowers (Saikia et al. 2015) are also used as an efficient photocatalyst in wastewater treatment.

\subsection{Antibacterial behaviour:}

Generally, the antibacterial effect is accompanied with photocatalytic activity as the latter generates toxic Reactive Oxygen Species (ROS). Studies have shown that combining $\mathrm{Ag}$ NPs with $\mathrm{TiO}_{2}$ NPs resulted in a dual photocatalytic and antimicrobial effect, which can be effective in wastewater treatment. Such antibacterial activity is shown to be related to the Ag particle size, as smaller NPs possessed a stronger antibacterial effect(Zielińska-Jurek et al. 2015). The size effect has also been confirmed by Maddinedi et al. (2017) when the green synthesis solution was applied at different $\mathrm{pH}$ 
values to alter the Ag NPs sizes. Figure 8 shows that by altering the $\mathrm{pH}$ value from 11 to 13 , the size of the created Ag NPs reduces from $22 \mathrm{~nm}$ to $5 \mathrm{~nm}$. This afthe antibacterial properties of the Ag NPs. Figure 8 shows the results of cytotoxicity assays of the synthesised Ag NPs. The percentage of viable bacteria is shown to be affected by the concentration of the applied Ag NPs. With larger concentrations (80 ppm), the percent viability reached its minimum $(50 \%)$. Figure 8 also shows that the size of Ag NPs affected its antibacterial behaviour, as $5 \mathrm{~nm}$ sized Ag NPs caused more bacterial death, leading to a low viability percentage (Maddinedi et al. 2017).

${ }_{925}$ Furthermore, antibacterial $\mathrm{ZnO}$ NPs were arranged in a unique flower-like shape design through utilising the sol-gel method (Khan et al. 2016). With different stirring conditions, flower-like $\mathrm{ZnO}$ NPs were formed with different sizes. Higher stirring speeds, led to the 930 formation of smaller NPs, which resulted in a more powerful antibacterial behaviour. The process and resulting crystal structure are displayed in figure 9 .

\subsection{Removal of heavy metals:}

The large surface area of NMs, as well as their magnetic behaviour, make them a good candidate for adsorption processes. $\mathrm{TiO}_{2}$ nanotubes prepared via the sol-gel method have shown to be an efficient adsorbent of $\mathrm{Pb}^{2+}, \mathrm{Cu}^{2+}$ and $\mathrm{Cd}^{2+}$ heavy metal ions ( $\mathrm{Fu}$ et al. 2019). Many researchers have included NMs in are $\mathrm{NiFe}_{2} \mathrm{O}_{4}$ /graphene oxide composites (Lingamdinne et al. 2017), carbon nanotubes (Xu et al. 2018), Alumina $\mathrm{Al}_{2} \mathrm{O}_{3}$ (Wang et al. 2019), $\mathrm{ZnO}$ (Bozorgi et al. 2018), Magnetite $\mathrm{Fe}_{2} \mathrm{O}_{3}$ (Darezereshki et al. 2018) and core-shell Fe-MgO (Ge et al. 2018). Composites of $\mathrm{MgO} / \mathrm{Fe}_{2} \mathrm{O}_{3}$ are also shown to have a considerable adsorption capacity of heavy metals. (Bououdina, AlNajar, Falamarzi, Judith Vijaya, Shaikh \& Bellucci 2019) found that the experimental synthesis parameters, such as the annealing temperature, lead to crystal growth that increases the grain size of the NMs. This in turn affected the adsorption efficiency of the samples, as smaller NPs owned a better adsorption capacity. Such effects are also reported in Da'na (2017) and Xiao et al. (2015).

Moreover, the adsorption capacity of polyethylene glycol (PEG) coated $\mathrm{Fe}_{2} \mathrm{O}_{3}$ NPs are influenced by their crystallite size. When the PEG weight is changed from $1 \mathrm{~g}$ to $2 \mathrm{~g}$ and $3 \mathrm{~g}$, during synthesis, the crystallite size spectively. This is found to enhance the NPs saturation magnetization, which increases their potential to effectively remove metals from wastewater (Anbarasu et al. 2015).

For the aforementioned properties of NMs, they are also included in desalination and water treatment membranes. The following section reviews the latest research on including NMs in TFC and CTA membranes.

\section{Nano-enhanced membranes for desalination}

NMs have shown potential to improve conventional desalination membranes due to their unique characteristics. Membrane enhancement can be performed with different NMs and via various routes. In TFC membranes, NMs can be incorporated in the active layer (Li, Li \& Zhang 2017), in the support layer (Tian et al. 2017), or as a surface modifier for conventional membranes (Lu et al. 2017). Usually, surface coatings with NMs resulted in stronger anti-fouling properties, as well as in enhanced membrane hydrophilicity (Saleh \& Gupta 2012). The incorporation of NMs in the Polyamide (PA) active layer was also proven to enhance the membrane's anti-fouling properties, its water permeability and its selectivity. On the other hand, the addition of NMs in the support layer matrix or as a nanofiber texture (Lu et al. 2016) improved the support layer's structural parameter (Rastgar et al. 2017).

From table 1, it can be perceived that the applied NMs can be classified as (1) single element particles, such as carbon dots (Li, Valladares Linares, Bucs, Fortunato, Hélix-Nielsen, Vrouwenvelder, Ghaffour, Leiknes \& Amy 2017), Ag NPs (Ben-Sasson et al. 2014) and $\mathrm{Cu}$ NPs (Ma et al. 2016), (2) oxide NPs and nanosheets and (3) carbon nanotubes (CNT) (Chan et al. 2016) and titania nanotubes (TNT) (Padaki et al. 2015). Furthermore, (4) different types of NMs can be combined to produce more efficient composites (Dong et al. 2015). Some studies also investigate (5) combining NMs with polymers (Shafiq et al. 2018). This section discusses the influence of these different NMs on the properties of the TFC and CTA membranes that are mainly utilised in desalination.

\subsection{Single element nanoparticles}

Single element NPs, such as carbon dots (CDs), have been applied to enhance the active layer of TFC membranes. Figure 10 demonstrates the process of including carbon dots during the interfacial polymerisation of the PA active layer on the (Polysulfone) PSF substrate. The extremely small carbon dots (average size of $6.8 \mathrm{~nm}$ ) caused a major difference in the membrane's surface by creating a valley structure with projections that were clearly shown in the cross-sectional SEM images as well as on the Atomic Force Microscopy (AFM) images. The concentration of the incorporated dots was increased from $0.01 \mathrm{wt} \%$ to $0.08 \mathrm{wt} \%$ leading to a higher rigid valley structure. Figure 10 shows the difference in the surface structures of the virgin membrane (figure 10b) and the modified membrane with $0.08 \mathrm{wt} \%$ carbon dots (figure 10c), where the highest roughness parameter was obtained. The measured contact angle of the membranes was shown to decrease from $78^{\circ}$ for the virgin membrane to $63^{\circ}$ for the $0.08 \mathrm{wt} \%$ carbon enhanced membrane indicating a more hydrophilic surface. Such a change in surface structure with the ${ }_{1025}$ addition of carbon dots were mainly due to their in- 


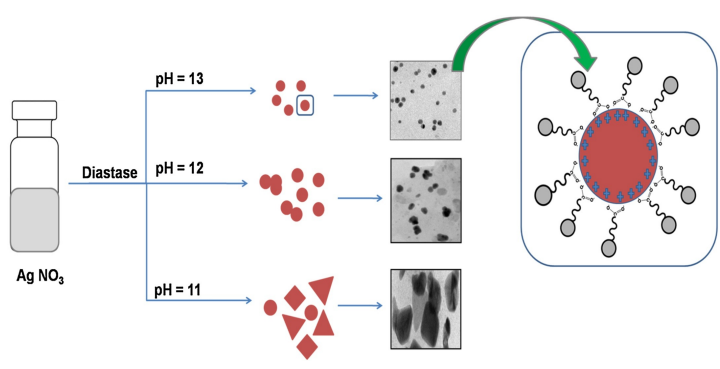

(a)

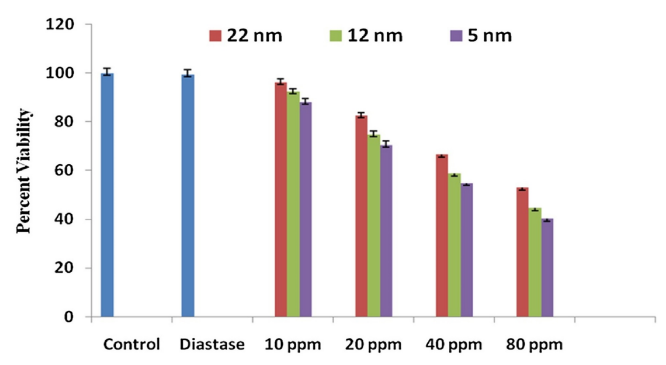

(b)

Figure 8: (a) The effect of the pH value on the obtained size and shape of Ag NPs and their (b) corresponding antibacterial activity. Copyrights obtained from Elsevier (Maddinedi et al. 2017).

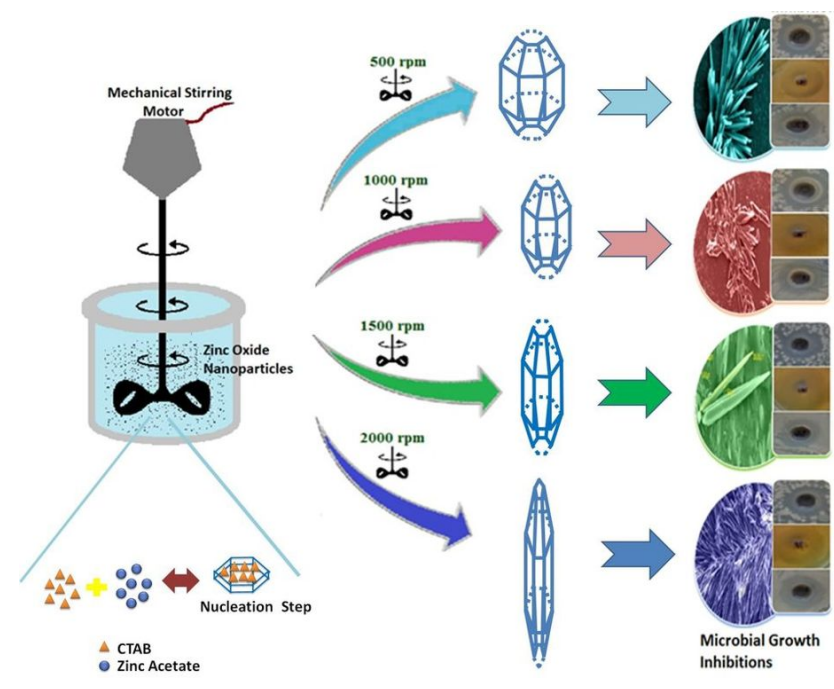

Figure 9: The effect of the stirring speed during the sol-gel method on the obtained size and shape of $\mathrm{ZnO}$ NPs and their anti-bacterial properties (Khan et al. 2016).

teraction with PA during the interfacial polymerisation. A noticeable improvement in $J_{W}$ of the enhanced membranes was found for membranes enhanced with wt $\%$ to 0.03 wt $\%$ carbon, as the flux increased from $72 \mathrm{LMH}$ (virgin membrane) to $88 \mathrm{LMH}$ with $0.03 \mathrm{wt} \%$ carbon. However, adding more carbon NPs resulted in a decline in the water flux, reaching $65 \mathrm{LMH}$ with $0.08 \mathrm{wt} \%$ carbon. This was related to the increase in A active layer thickness with the additional concentration of carbon, as well as due to the agglomeration of the carbon NPs (Li, Li \& Zhang 2017). As mentioned in section 3.1, the enhancement of the membrane's water permeability, in this case using carbon NPs, offers only an insignificant improvement with respect to the overall desalination process, as only the membrane over-pressurisation can be minimised.

In addition, $\mathrm{Ag}$ NPs with $15 \mathrm{~nm}$ size were incorporated to enhance the surface of TFC membranes (Benin situ Ag NPs on the surface of the RO TFC membranes using different concentrations of $\mathrm{AgNO}_{3}$ and $\mathrm{NaBH}_{4}$ as precursors. With the small size of the obtained Ag NPs $(15 \mathrm{~nm})$, the surface roughness and hy-

drophilicity of the membrane was varied. As a result,

the intrinsic properties of the membrane was affected, as the $\mathrm{A}$ and $\mathrm{B}$ coefficient decreased by $17 \%$ and $25 \%$, respectively. This has been related to the change of the PA active layer characteristics due to the added $\mathrm{NaBH}_{4}$, which was revealed to influence the fabrication parameters of the membrane's structure and function. ALthough the membrane permeability is compromised in this work, the enhanced membrane has shown considerable antibacterial properties to three types of bacteria (E. coli, P. Aeruginosa and S. aureus). The number of living bacteria in the enhanced membrane decreased by $78 \%, 91 \%$ and $96 \%$, respectively, compared to the virgin membrane. However, dynamic fouling tests were not performed in this work. Other studies include this test, as it assists in assessing the behavior of the bacterial foulant during the separation process (Padaki et al. 2015).

Due to their strong antibacterial effect, Ag NPs are still considered in recent studies Yang et al. (2019). To overcome the flux decline, Ag NPs were incorporated in the support layer of a RO TFC membrane. Different Ag concentrations were added during the phase inversion process of the PSF support layer. This caused the formation of $\mathrm{Ag}$ nanochannels (2 $\mathrm{nm}$ to $3 \mathrm{~nm}$ ), which facilitated water flow within the membrane and decreased its hydraulic resistance. At a certain concentration $(20 \mathrm{mM})$, the enhanced membrane showed an increased water flux reaching $50 \mathrm{LMH}$ in comparison with only $20 \mathrm{LMH}$ for the plain TFC membrane. Additionally, the membrane selectivity improved, as the enhanced Ag membrane showed a better rejection towards solutes, such as boron, ethylene glycol, diethylene glycol, pentaerythritol, norfloxacin and ofloxacin. A further increase in the Ag NPs concentration within the substrate caused a noticeable decline in the water flux and salt rejection. This was mainly due to the agglomeration of Ag NPs, as most of the NPs tend to agglomerate at high concentrations.

Recent studies also investigated the incorporation of Ag NPs in membrane distillation membranes (Politano et al. 2019). Chemically reduced Ag NPs with an average particle size of $30 \mathrm{~nm}$ were applied during the fabrication of polyvinylidene fluoride (PVDF) microporous films. Different weight concentrations $(15 \%, 25 \%$ and $30 \%$ ) of $\mathrm{Ag}$ have shown to affect the thickness, porosity, pore size, roughness and the contact angle of the 


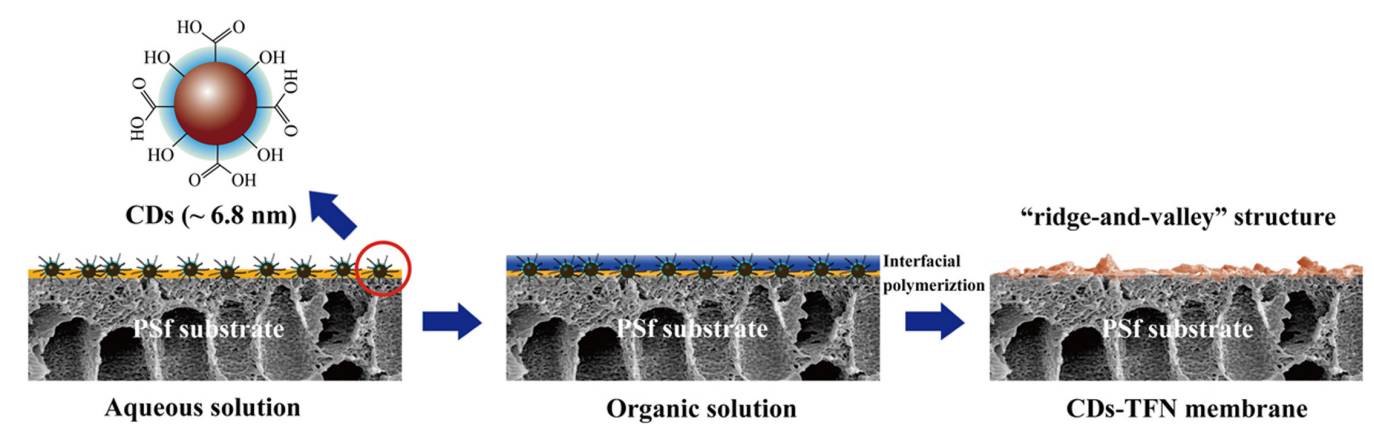

(a)

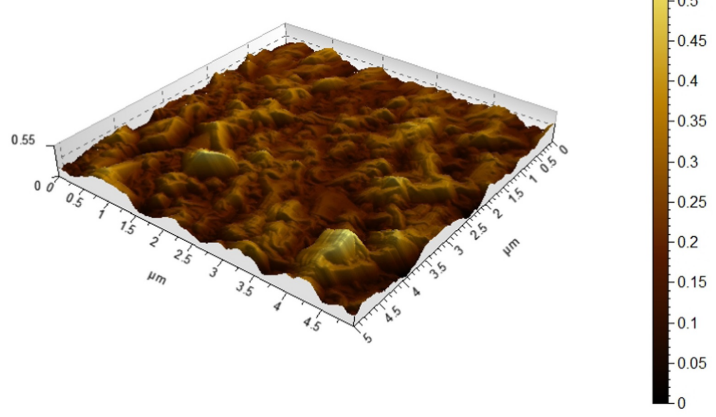

(b)

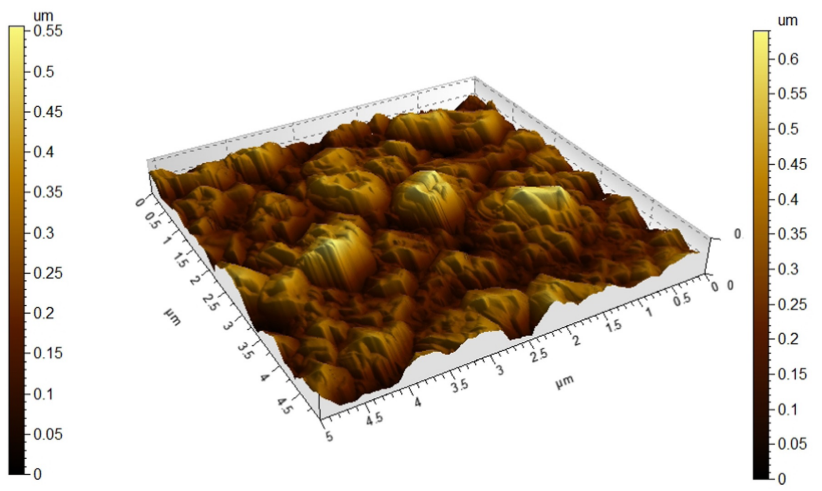

(c)

Figure 10: (a) The schematic process of CDs-TFN membrane fabrication. Three dimensional AFM images of (b) the virgin TFC membrane and (c) the TFC membrane modified with 0.08 wt\% carbon dots. Copyrights obtained from Elsevier(Li, Li \& Zhang 2017).

membrane. In this case, the water flux could be increased by up to $19 \%$ at a $\mathrm{Ag}$ weight concentration of $25 \%$.

Copper $(\mathrm{Cu})$ NPs have also been considered in the enhancement of RO TFC membranes using sprayand spin-assisted layer-by-layer fabrication (Ma et al. 2016). Figure 11a demonstrates the process of sprayand spin-assisted layer-by-layer fabrication. $\mathrm{Cu}$ NPs coated with polyethylenimine (PEI) were applied on the surface of the membrane as alternating layers with polyacrylic acid. As shown in figure 11a, the formation of each layer mainly includes polycations. Such designs with alternating charges (the positively charged PEI$\mathrm{Cu}$ NPs and negatively charged poly acrylic acid) have shown to improve the membrane's anti-fouling properties with only a slight decline in the water permeability. With the addition of more PEI-Cu bilayers $(2,4,6$ and 10 bilayers), the surface properties changed noticeably, as shown in the SEM images. Figure 11b shows the SEM images of the rigid-valley structure of the enhanced membrane surface with only two bilayers of PEI $\mathrm{Cu}$. Figure $11 \mathrm{c}$ shows that this rigid-valley structure was covered completely with ten bilayers. This caused ened hydrophilicity of the enhanced membrane, as the contact angle increased by $12 \%$. Thus, a slight decline in the membrane water and salt permeability was found. The change in $\mathrm{A}$ and $\mathrm{B}$ with the addition of PEI $\mathrm{Cu}$ bilayers is shown in figure 11d. Furthermore, the membrane enhanced with coated $\mathrm{Cu}$ bilayers was found to strongly affect the antibacterial properties of the membrane. Static bacterial inactivation tests revealed a high antibacterial activity on the $\mathrm{Cu}$ modified membranes with different numbers of bilayers. Figure 11e shows the amount of bacteria found on the pristine membrane compared to the enhanced membrane with only PEI and with bilayers of $\mathrm{Cu}$-PEI. The amount of bacteria was almost reduced by $20 \%$ with the PEI enhancement. Meanwhile the bacterial load dropped by more than $90 \%$ in the 2 bilayers $\mathrm{Cu}-$ PEI membrane. Further decreases in the amount of bacteria was found with more bilayers. Dynamic fouling tests, using RO-cross flow cells, revealed that the enhanced membrane flux slightly decreased as a result of the added $\mathrm{Cu}$-PEI bilayers. However, the enhanced membrane showed good anti-biofouling properties when a bacterial suspension solution was applied. A lower water flux reduction rate was achieved for the enhanced membrane (38\% reduction after 24 hours) in comparison to the pristine membrane $(66 \%$ reduction after 24 hours). This was mainly due to the antibacterial properties of the $\mathrm{Cu}$ NPs in the enhanced membranes (Ma et al. 2016).

Other metal based NPs have also been recently applied in TFC membranes. This includes UiO-66 NPs (Liu et al. 2019), which were mainly based on $\mathrm{Zr}$ (II) ions and other acid additives. The $50 \mathrm{~nm}$ particles were synthesized through hydrothermal routes and then applied as a surface enhancer of the PA active layer of an RO TFC membrane. Different concentration of UiO66 were applied $(0.025 \%, 0.05 \%, 0.075 \%$ and $0.1 \%$ $(\mathrm{w} / \mathrm{v}))$ to the coating solution, which resulted in four different nano-enhanced TFC membranes. The surface 


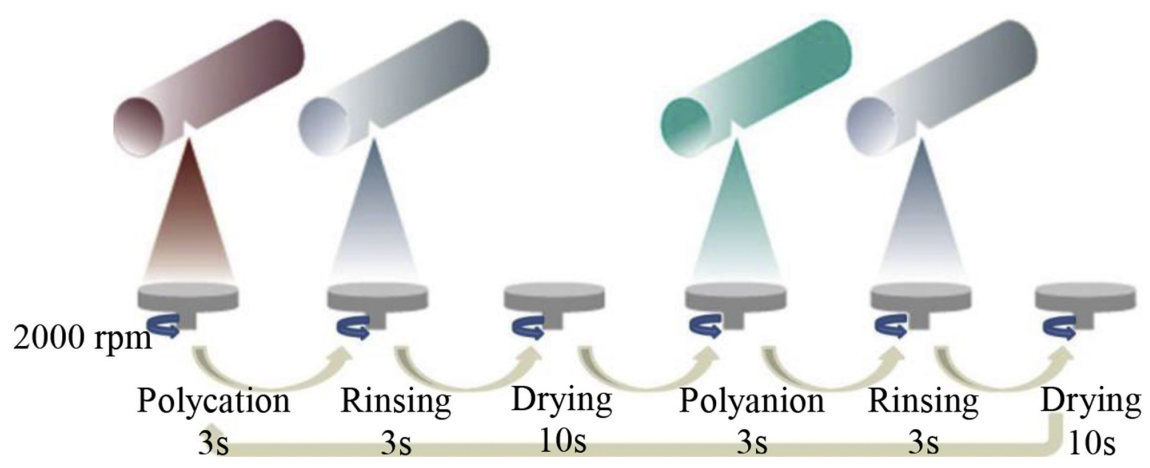

(a)

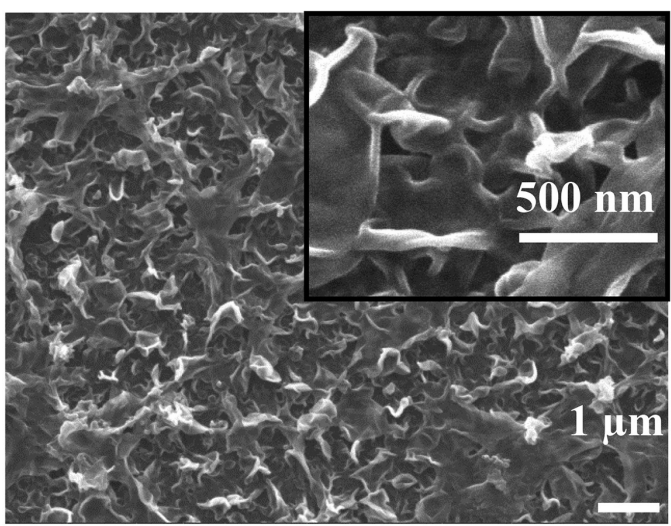

(b)

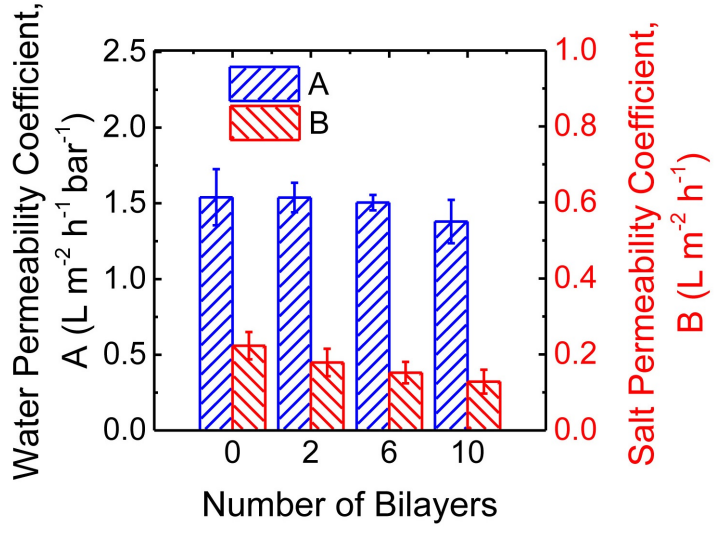

(d)

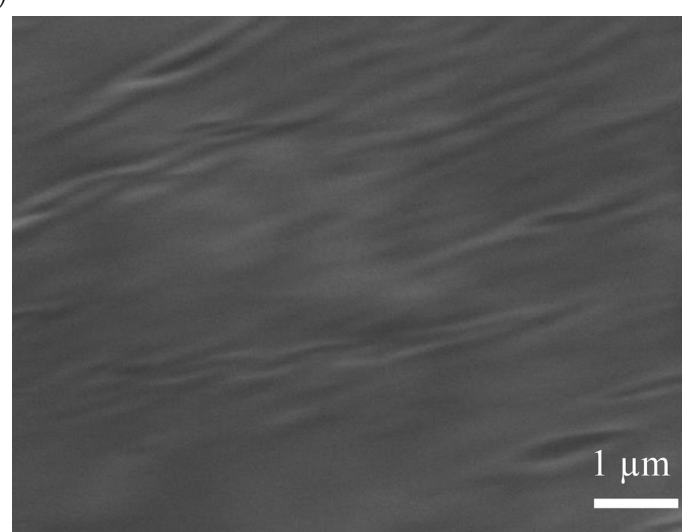

(c)

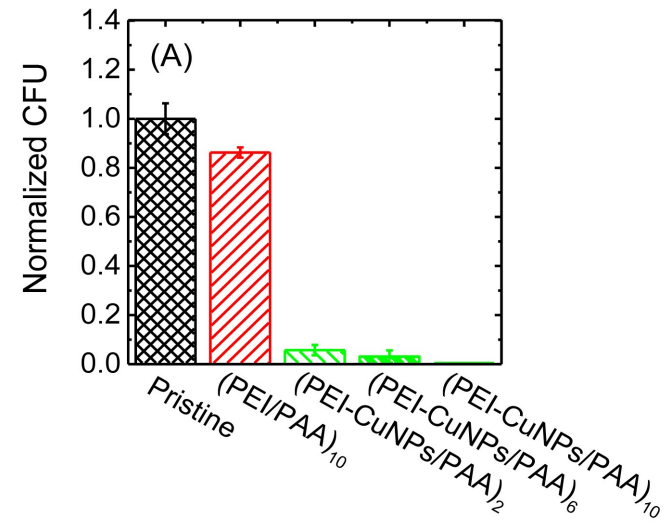

(e)

Figure 11: (a) Spray- and spin-assisted layer-by-layer fabrication. (b) SEM images of the TFC enhanced membrane with 2 PEI-Cu bilayers and (c) 10 PEI-Cu bilayers. (d) Performance parameters of the enhanced membranes with different bilayers of PEI-Cu NPs. (e) Normalized CFU that corresponds to the amount of bacteria present on the modified and unmodified membranes. Copyrights obtained from Elsevier (Ma et al. 2016).

charge of the membranes were shown to be more negative with the addition of UiO-66 NPs from $-25 \mathrm{mV}$ for the plain TFC membrane to $-37 \mathrm{mV}$ for the enhanced TFC membrane with $0.1 \%$ NPs. This led to a reduced contact angle, which indicates a change in the hydrophilicity of the membrane with the NPs enhave been observed for each enhanced membrane. Although the membrane with $0.1 \% \mathrm{UiO}-66$ was the most hydrophilic, the RO water flux was not considerably enhanced from that of the plain membrane. The membrane enhanced with only $0.05 \%$ shows the highest wa- ter flux increase of $36 \%$ during neutral $\mathrm{pH} 7$ testing. Additionally, the boron rejection improved from $80 \%$ for the plain membrane to $90 \%$ for the $0.05 \%$ UiO-66 NPs enhanced membrane.

\subsection{Oxide nanoparticles and nano- ${ }_{1175}$ sheets}

The inclusion of oxide NMs in desalination membranes was widely investigated due to their unique atomic structure that allows to enhance the physical and chemical membrane properties. Recently, $\mathrm{TiO}_{2} \mathrm{NPs}_{1180}$ 
were applied to modify the surface of a commercial CTA and Aquaporin FO membrane (Xue et al. 2018). The contact angle of the $\mathrm{TiO}_{2}$ enhanced CTA membrane was reduced by $34 \%$ in comparison to the unmodified CTA membrane. However, the modification with the same $\mathrm{TiO}_{2}$ NPs caused a $31 \%$ increase in the contact angle of the Aquaporin membrane. This was explained by the possible blockage of Aquaporin channels by $\mathrm{TiO}_{2} \mathrm{NPs}$, which led to the reduction of the membrane's hydrophilicity. Nevertheless, in both cases the addition of the $\mathrm{TiO}_{2}$ NPs led to a performance enhancement, as the FO water flux increased by $73.4 \%$ and $13.6 \%$ for the CTA and Aquaporin membranes, respectively. The reverse solute flux $J_{S}$ slightly decreased for the modified CTA membrane while it slightly increased for the modified Aquaporin membrane.

In order to enhance UF membranes made out of polyvinyl chloride (PVC), ZnO NPs were added during the fabrication process using different concentra( 0.3 wt \% 1 wt \% 2 wt\% 3 wt\% and 4 wt\%) (Rabiee et al. 2015). This led to a lower contact angle that reached $52.2^{\circ}$ for the $4 \mathrm{wt} \% \mathrm{ZnO}$ enhanced membrane in comparison to $67.5^{\circ}$ for the virgin membrane. Additionally, the maximum increase in porosity and ified membrane and reached $79.85 \%$ and $12.1 \mathrm{~nm}$, respectively. The change in the porous structure of the membrane was clearly shown in the SEM images. Figure $12 \mathrm{a}$ and figure $12 \mathrm{~b}$ show the difference between 1210 the pore structure of the virgin membrane and the enhanced membrane with $3 \mathrm{wt} \% \mathrm{ZnO}$, respectively. Pores were shown to be less tortuous and more uniform for the modified membrane. Accordingly, the water flux was shown to increase with the addition of the $\mathrm{ZnO}$

1215 NPs, reaching its maximum value at $401.9 \mathrm{LMH}$ with the $3 \mathrm{wt} \% \mathrm{ZnO}$ enhanced membrane. The change in the water flux at different $\mathrm{ZnO}$ concentrations is shown in figure 12c. It was shown that the addition of more ZnO NPs (4 wt\%) slightly decreased the permeate flux to $378.7 \mathrm{LMH}$. This was related to agglomeration of the NPs at high concentrations, which caused pore blockage, and hence resulted in the reduction of the water flow. Anti-fouling experiments showed a higher fouling reversibility for the $3 \mathrm{wt} \% \mathrm{ZnO}$ membrane. This is shown in figure $12 \mathrm{~d}$. In the fouling experiment, the pure water fluxes were obtained for the first 90 minutes. In the second 90 minute interval, the membranes were tested in a Bovine Serum Albumin (BSA) fouling solution, in which the $3 \mathrm{wt} \% \mathrm{ZnO}$ membrane also achieved the highest water flux. Finally, the membranes were washed and tested again in pure water. The $3 \mathrm{wt} \% \mathrm{ZnO}$ enhanced membrane showed the highest water flux recovery of $97 \%$ (Rabiee et al. 2015).

$\mathrm{SiO}_{2} \mathrm{NPs}_{\mathrm{s}}$ were also applied to enhance TFC membranes. $\mathrm{SiO}_{2}$ NPs were incorporated in the PA active layer of FO membranes with different concentrations $(0.01 \mathrm{wt} \%, 0.05 \mathrm{wt} \%$ and $0.1 \mathrm{wt} \%)$ in order to improve the membrane water flux in both orientations. It was found that the water flux increased remarkably with $\mathrm{SiO}_{2} \mathrm{NPs}$ loading, while the solute flux decreased. This refers to the increase in membrane roughness as a re- sult of the involvement of NPs within the PA active layer. $\mathrm{SiO}_{2}$ NPs can also disrupt the chain packing in the active layer polymer causing an improved water flux (Niksefat et al. 2014).

$\mathrm{SiO}_{2}$ NPs can also be applied within the substrate of the FO membrane (Tian et al. 2017). Commercial $\mathrm{SiO}_{2}$ NPs were added to the mixed solvent of $\mathrm{N}$ dimethylformamide (DMF $>99.5 \%$ ) and N-Methyl2-pyrrolidone during the electrospinning process. This resulted in a thicker substrate layer that increased with the $\mathrm{SiO}_{2}$ concentration $(0 \%, 0.16 \%, 0.8 \%$ and $1.6 \%)$. As all prepared samples were covered with a PA active layer, the surface morphology was very similar, and the contact angle remained almost unchanged. On the other hand, the porosity, thickness and pore size of the substrate was altered. The porosity increased from $60 \%$ to $83 \%$, while the pore size increased from $0.55 \mu \mathrm{m}$ to $1.28 \mu \mathrm{m}$ for the virgin and the $1.6 \% \mathrm{SiO}_{2}$ enhanced membranes, respectively. Therefore, the calculated structural parameter considerably decreased from $523 \mu \mathrm{m}$ (virgin membrane) to $174 \mu \mathrm{m}$. The tensile modulus decreased to $173 \mathrm{MPa}$ for the $1.6 \% \mathrm{SiO}_{2}$ membrane in comparison with $295 \mathrm{MPa}$ for the virgin membrane. Such structural changes in the support layer of the TFC membranes resulted in the reduction of the ICP phenomenon and enhanced the membrane's flow properties. The water permeability coefficient A increased by $26.5 \%$, and similarly the salt permeability coefficient B increased by $24 \%$.

The use of $\mathrm{SiO}_{2}$ as a surface modifier for commercial FO membranes was also shown to be efficient (Liu, Lee, Small, Ma \& Elimelech 2017). Commercial $\mathrm{SiO}_{2}$ NPs were used to graft FO TFC membranes using the dip coating method. This was compared with a zwitterionic polymer surface modification of the FO TFC membrane. Figure 13a shows a schematic diagram of the two applied methods. Membrane permeability tests showed a slight change in performance between the enhanced membranes and the virgin membrane. Figure $13 \mathrm{~b}$ shows that the water permeability coefficient A reduced slightly for the two enhanced membranes. The salt permeability coefficient $\mathrm{B}$ reduced slightly for the $\mathrm{SiO}_{2}$ NPs enhanced membrane. However, it increased for the polymer enhanced membrane. The structural parameter increased slightly for both enhanced membranes. The hydrophilicity was shown to increase for both enhanced membranes by around $50 \%$ in comparison to the virgin membrane, while the roughness parameter was found to slightly decrease for the two enhanced membranes. Although the two enhanced membranes show similar structural characteristics, they showed different anti-fouling behaviours. As shown in figure 13c, the amount of E-coli bacteria found on the $\mathrm{SiO}_{2}$ membrane surface was much greater than for the polymer modified membrane and the virgin membrane. This indicates that the $\mathrm{SiO}_{2} \mathrm{NPs}$ actually assisted bacterial adhesion in this experiment by $45 \%$. This was related to the positive surface charge of the $\mathrm{SiO}_{2}$ NPs that attracted the negatively charged bacteria. This also explains the low adhesion of bacteria on the negatively charged zwitterionic membrane. 


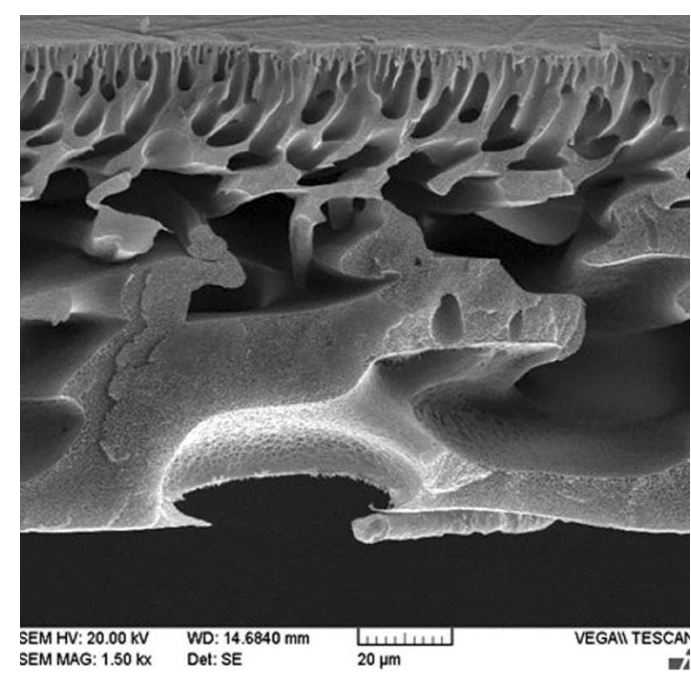

(a)

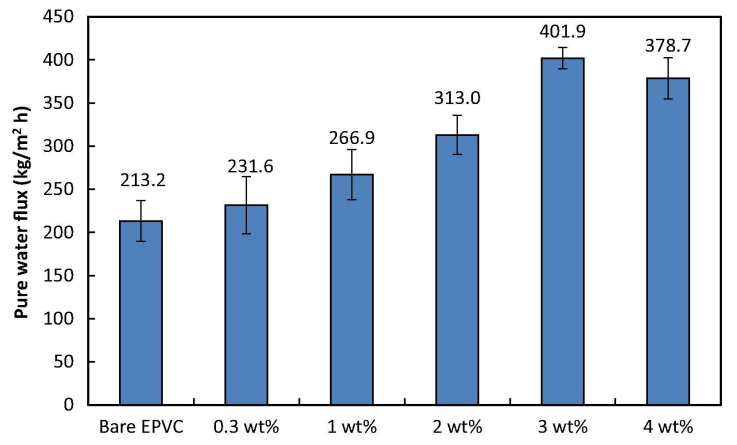

(c)

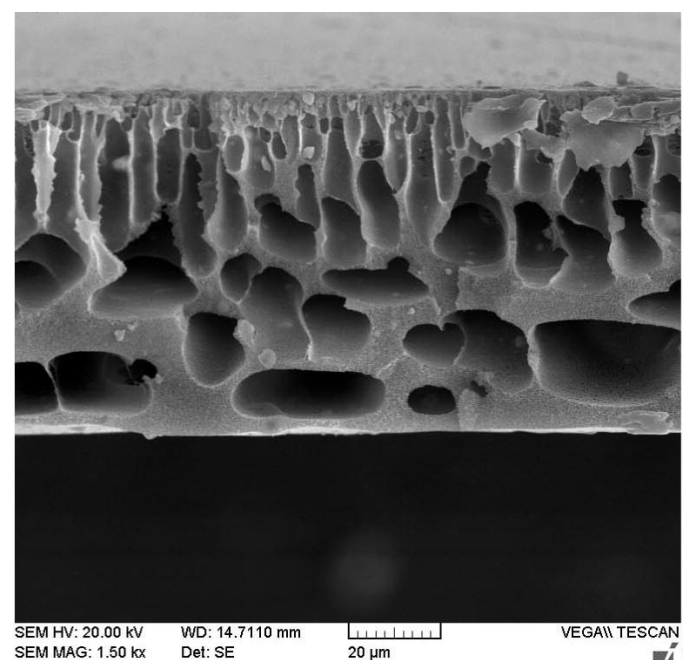

(b)

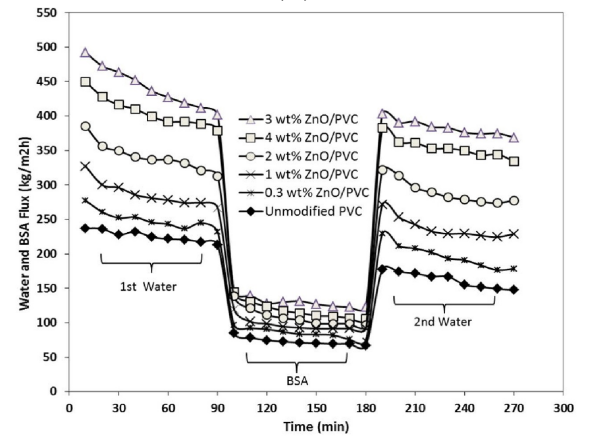

(d)

Figure 12: Cross-sectional SEM images of the (a) virgin PVC UF membrane and (b) the enhanced membrane with $3 \mathrm{wt} \% \mathrm{ZnO}$ NPs. (c) Pure water flux obtained for the enhanced membranes with different concentrations of ZnO NPs. (d) Permeate flux for feed solutions containing pure water and BSA in three 90 min intervals: First for pure water, then for the BSA solution and lastly for pure water again after washing the membranes for 30 min. Copyrights obtained from Elsevier (Rabiee et al. 2015).

Chen et al. (2018) applied graphene oxide (GO) to modify CTA RO composite membranes for wastewater treatment. Samples with different GO contents (0.02 wt\%, $0.05 \mathrm{wt} \%$ and $0.1 \mathrm{wt} \%)$ showed different surface morphologies and the structural rigidity increased with the incorporation of more GO. Under different operational pressures, a noticeable flux enhancement membrane with the maximum GO content $(0.1 \mathrm{wt} \%)$, compared with only 1.6 LMH for the virgin membrane at equivalent operating pressures. The salt rejection was however reduced. This flux enhancement was related to the improved membrane hydrophilicity, as the contact angle decreased by $13 \%$ for the modified membrane. However, the thermal stability of the membrane was found to decline. The GO membranes showed faster degradation rates than the virgin membrane. ity, which created degradation centers on the surface of the membrane. Moreover, stress-strain curves showed an increased tensile strength at the cost of a lower flexibility. This makes the membrane more fragile and in-
Layer double hydroxyl (LDH) $\mathrm{Mg}_{3} \mathrm{Al}-\mathrm{CO}_{3} \mathrm{NPs}$ (Lu et al. 2017) were prepared using the coprecipitation method and were added to the TFC membranes as an external coat via Polydopamine (PDA) self-polymerisation. This process included the immersion of the membrane in a PDA aqueous solution, which was followed by coating it with the LDH NPs at different experimental parameters. Figure 14a illustrates the steps of the LDH coating of the TFC membrane. Herein, the LDH suspension time of the membrane was varied, where one sample was suspended for 1 hour (dip-coating) and the second sample was kept until desiccation (deposition). This created different surface morphologies, as seen in the SEM images, which indicated different binding mechanisms. In the deposition method, the LDH NPs were dispersed uniformly and formed a compact layer over the PA active layer. The amount of LDH loaded on the surface was even doubled (8.96 wt\%) compared to $4.93 \mathrm{wt} \%$ for the dip-coated sample. Consequently, the deposit offered an extremely high chlorine protection to the PA active layer. In comparison to the virgin and dip-coated membrane, the chlorine resistance of the deposited membrane increased by approximately 96 times, as shown 


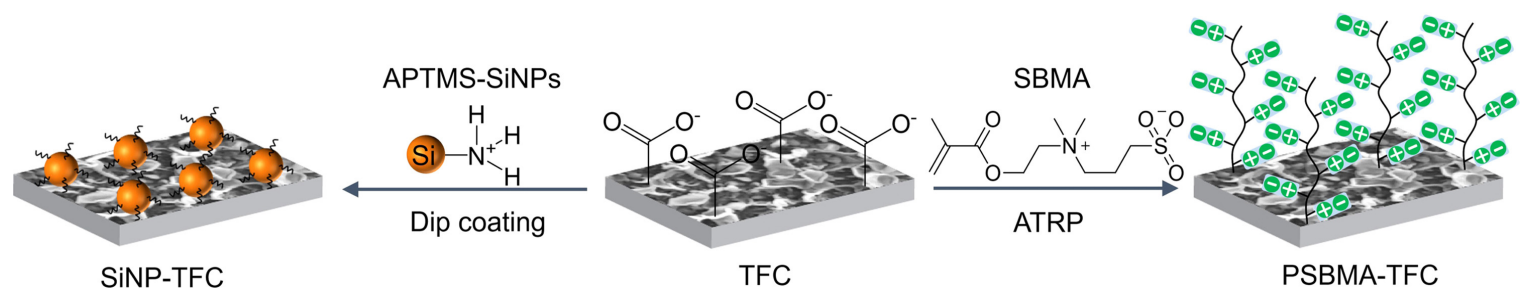

(a)

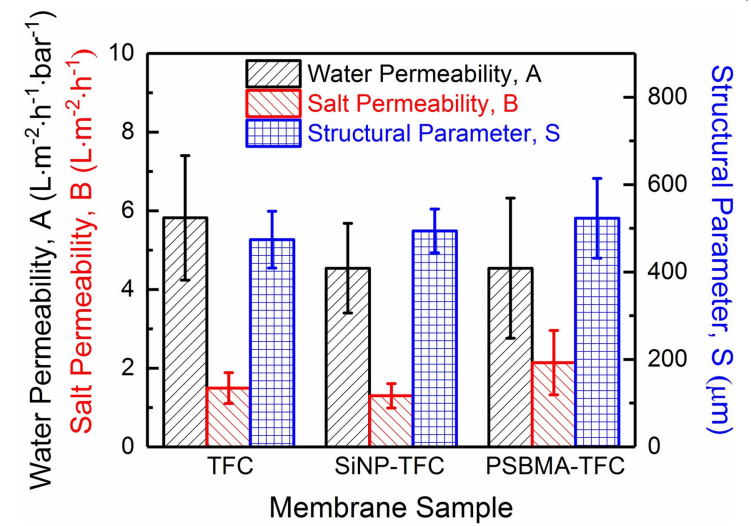

(b)

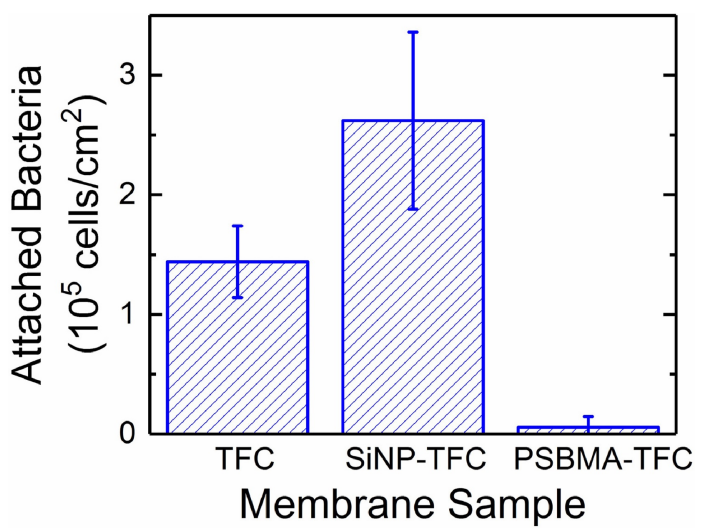

(c)

Figure 13: (a) A schematic diagram showing the modification of the TFC membrane surface using $\mathrm{SiO}_{2} \mathrm{NPs}_{\mathrm{S}}$ and a zwitterionic polymer. (b) Transport parameters of the virgin and the enhanced membranes. (c) Average fluorescence intensity that corresponds to the concentration of E-coli bacteria on the surface of the virgin and enhanced membranes. Copyrights obtained from Elsevier (Liu, Lee, Small, Ma \& Elimelech 2017).

in figure 14b. Moreover, the contact angle decreased, reaching $65,45,35$ and 30 degrees for the virgin membrane, the PDA coated membrane, the dip-coated and the deposited membranes, respectively. However, the 355 flux of the enhanced membranes decreased in both FO and PRO tests; i.e. the water flux decreased by $20 \%$ for the PDA coated membrane and decreased even further for the $\mathrm{LDH}$ deposited membrane, as shown in figure 14c. This flux reduction was due to the compact LDH layer, which created an additional hydraulic resistance ( $\mathrm{Lu}$ et al. 2017).

On the other hand, incorporating LDH NPs in the PSF support layer showed a noticeable improvement in the FO and PRO water fluxes ( $\mathrm{Lu}$ et al. 2016). With different concentrations (1 wt\%, 2 wt\%, 3 wt $\%$ and $4 \mathrm{wt} \%$ ), LDH NPs were introduced during the fabrication of the PSF support layer, which significantly altered the porosity and pore orientation of the substrate. With a higher LDH weight, the pores were better aligned with the water flow direction, which improved the water flux by reducing the ICP effect. In both membrane orientations the water flux improved, as shown in figure 15a. The reduction of ICP is beneficial for any osmotically driven membrane process, as her water flux can be achieved for the same draw solute concentration. The enhanced membranes were also shown to better maintain their mass at higher temperatures. The membrane's thermal stability increased with the addition of LDH NPs. This was linked to the

LDH NPs inhibiting the diffusion of oxygen molecules to the membrane, which delayed its thermal degradation. Furthermore, as shown in figure 15b, the addition of LDH NPs enhanced the membrane strength, as the membrane tensile strength and its elongation increased with LDH loading up until $2 \mathrm{wt} \%$. A further increase in LDH loading reduced the membrane flexibility and made it more fragile ( $\mathrm{Lu}$ et al. 2016).

Modified oxide NPs have shown to be efficient in enhancing desalination membranes. Amino acid modified $\mathrm{ZnO}$ NPs were incorporated during the preparation of the FO TFC membrane substrate (Darabi et al. 2019). Two amino acid modifiers were applied to the $\mathrm{ZnO}$ nanofillers, which were 1,3-phenylendiamine (M.ZnO) and Triethylenetetramine (T.ZnO)), at three different concentrations $(0.1 \% \mathrm{w}, 0.3 \% \mathrm{w}$ and $0.5 \% \mathrm{w})$. The membrane S-value changed with the different modifier and its concentration. The lowest S-value was obtained with T.ZnO $(0.5 \% \mathrm{w})$. This corresponded to a lower contact angle and a slightly higher porosity of $88 \%$. In the FO experiment, the T.ZnO $(0.5 \% \mathrm{w})$ modified membrane achieved the highest water flux of $12 \mathrm{LMH}$ in comparison to only 5.5 LMH for the plain TFC membrane. However, the salt rejection dropped for the T.ZnO membrane $(0.5 \% \mathrm{w})$ by $8 \%$. This decrease in salt rejection was explained by the lower PA active layer and support layer interlinkage caused by the nano-modification of the substrate.

The introduction of the discussed oxide NMs into the membrane has shown to enhance its properties with most studies reporting an increased water flux. As mentioned in section 3.1, achieving a higher water flux by altering the membrane's active layer does not lead to significant improvements of the membrane process. However, improving (1) the membrane's anti- 


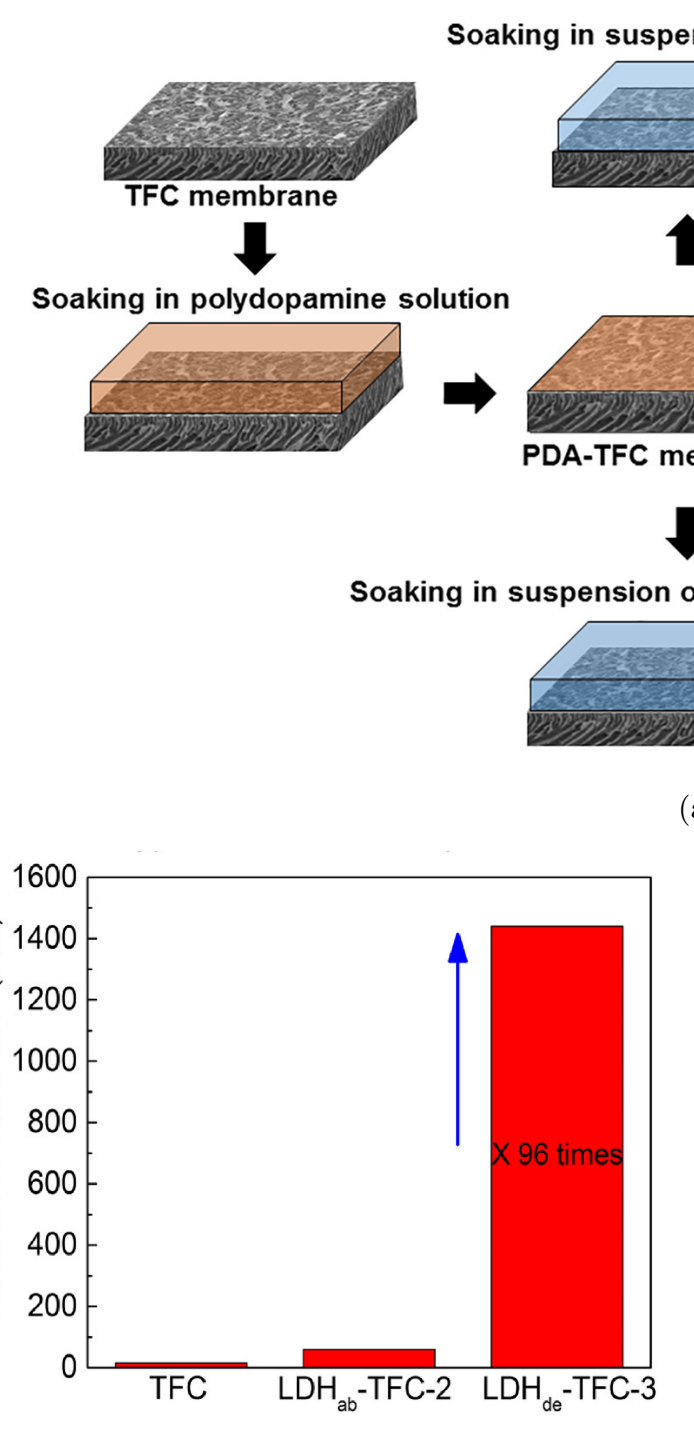

(b)

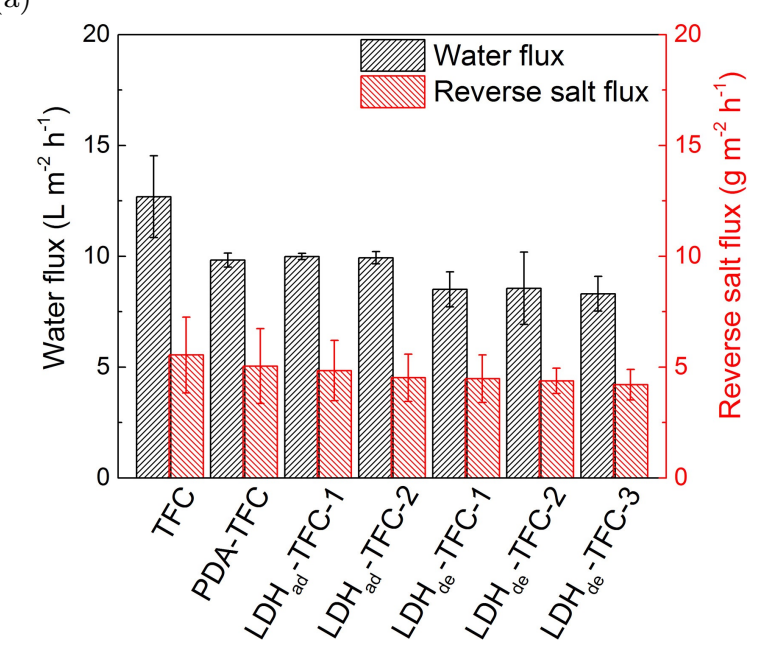

(c)

Figure 14: (a) A schematic diagram of coating TFC membranes with LDH NPs via two different experimental conditions; dip coating and deposition coating. (b) Chlorine resistance time for the virgin and the enhanced membranes. (c) Water flux and reverse solute flux in the FO experiment for the virgin and the enhanced membranes. Copyrights obtained from Elsevier (Lu et al. 2017)

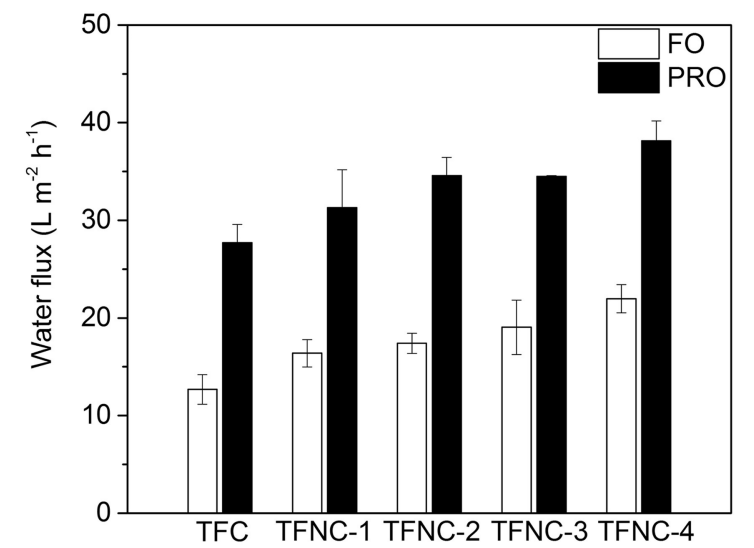

(a)

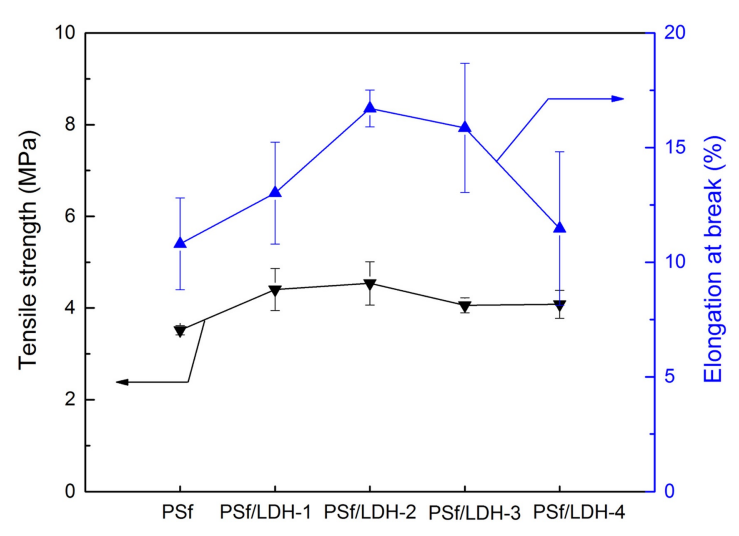

(b)

Figure 15: (a) Water flux in both FO and PRO modes and (b) mechanical properties of the virgin TFC membrane and the TFC membranes enhanced with $1 \mathrm{wt} \%, 2 \mathrm{wt} \%, 3 \mathrm{wt} \%, 4 \mathrm{wt} \%$ of LDH NPs. Copyrights obtained from Elsevier (Lu et al. 2016). 
fouling properties, (2) its selectivity, (3) its mechanical and chemical strength and (4) lowering the ICP effect in osmotically driven membrane processes can lead to significant improvements in the membrane process. Other studies have shown attempts to further enhance oxides (Fathizadeh et al. 2019) or with polymers (Ang et al. 2019). Examples of these NM combinations will be discussed in the following subsections.

\subsection{Carbon and Titania Nanotubes}

Carbon Nanotubes (CNT) have been incorporated during the preparation of the PA active layer of RO TFC membranes. SEM and AFM results showed the difference in structure between the plain PA and the CNT PA membranes. As a result of the CNT involvement, smaller bundles were created within the PA active layer whereas the roughness remained constant as seen from the AFM topography. The enhanced membrane with $2 \mathrm{wt} \%$ CNT showed an improved water flux for different solutions of KCL, $\mathrm{NaCl}, \mathrm{CaCl}_{2}, \mathrm{MgCL}_{2}$ and $\mathrm{MgSO}_{4}$. $36 \mathrm{LMH}$ for the $\mathrm{KCl}$ solution, whereas the water flux increased from $15 \mathrm{LMH}$ to $35 \mathrm{LMH}$ for the $\mathrm{NaCl}$ solution. The biofouling resistance of the CNT enhanced membrane (Z-CNT-20\%) was tested using an RO flow experiment with a bovine serum albumin (BSA) solution. The water flux reduction rate was lower for the enhanced membrane due to a lower accumulation of biomass on the membrane. Even after cleaning, the enhanced membrane experienced a complete flux recovery $(100 \%)$. This confirmed that irreversible fouling was prevented due to the weaker attachment of the created foulant. This was explained by the addition of Z- functional groups that offer both negative and positive charges, which created a hydration layer that prevented the foulant from binding onto the membrane surface (Chan et al. 2016).

Titanium nanotubes (TNT) were incorporated in the PSF substrate of an RO TFC membrane to enhance its anti-fouling properties (Padaki et al. 2015). Different concentrations of TNT (0.1 wt \%, $0.3 \mathrm{wt} \%, 0.5 \mathrm{wt} \%)$ were magnetically dispersed in the casting solution of the prepared PSF support layer. This resulted in changes of the membrane's hydrophilicity, pore structure and porosity. The contact angle reduced from ${ }_{1460} 72^{\circ}$ to $60.3^{\circ}$ while the porosity percentage increased from $71^{\circ}$ to $79^{\circ}$. Though the PSF surface had the same smoothness, the pores size and structure were shown to be altered with higher TNT concentrations. As revealed from the cross-sectional SEM images, that was constructed of an upper layer with vertical pores and a lower layer of larger horizontal pores. With the addition of $0.1 \mathrm{wt} \% \mathrm{TNT}$, the lower pores became smaller and more aligned with the vertical pores. This ment increased with the addition of $0.3 \mathrm{wt} \%$ TNT. When the TNT concentration reached $0.5 \mathrm{wt} \%$ TNT, the alignment between the upper and the lower pores became more visible. This aligned pore structure fa- cilitated water transport through the membrane and resulted in an enhanced water flux, as well as in an improved flux recovery during the anti-fouling tests. Figure 16b shows the flux change with time during anti-fouling tests in a BSA solution. A huge water flux increase was achieved with the $0.3 \mathrm{wt} \%$ and $0.5 \mathrm{wt} \%$ TNT enhanced membranes, in comparison with the virgin membrane and the $0.1 \mathrm{wt} \%$ TNT membrane. A sharp decrease in flow occurred for the $0.3 \mathrm{wt} \%$ and $0.5 \mathrm{wt} \%$ membranes at around $70 \mathrm{~min}$ due to foulant accumulation. However, the flux reduction was not as significant as for the virgin membrane. Furthermore, an almost complete flux recovery was observed after cleaning although figure $16 \mathrm{c}$ reveals that more foulant accumulated on the TNT membranes due to the enhanced water flux. This large foulant concentration explains the sharp decrease in the water flux during the fouling tests.

Composites of CNT and TNT were also investigated (Wan Azelee et al. 2017). CNT-TNT were prepared using hydrothermal routes and then underwent acid treatment (HCL solution) to improve the surface charge of the nanotubes. This resulted in a better interaction with the PA active layer. TEM images showed that the acid treatment helped in reducing the agglomeration of the nanotubes and hence increased the membrane's hydrophilicity. The enhanced CNT-TNT-TFC membrane without acid treatment and the plain TFC membrane showed higher contact angles $\left(72.12^{\circ}\right.$ and $76.2^{\circ}$, respectively) than the acid treated CNT-TNT-TFC membrane $\left(66.7^{\circ}\right)$. Moreover, AFM and Field Emission Scanning Electron Microscope (FESEM) images showed valley surface microstructures of the fabricated membranes with the highest rigids for the acid treated sample indicating a higher surface roughness. Such microstructures led to an improved water flux in the RO performance experiments (0.74 $\mathrm{LMH} \mathrm{bar}^{-1}$ ) as when compared to the plain TFC membrane $\left(0.47 \mathrm{LMH} \mathrm{bar}^{-1}\right)$ and the other enhanced TFC membranes using only CNT-TNT (0.62 $\left.\mathrm{LMH} \mathrm{bar}^{-1}\right)$, only TNT (0.52 $\mathrm{LMH} \mathrm{bar}^{-1}$ ) and only CNT (0.50 LMH bar $\left.{ }^{-1}\right)$. This reflects on how the choice of NM combination as well as its fabrication parameters and additives affect the performance of the membrane during the separation process (Wan Azelee et al. 2017). In this study, only the increase in membrane permeability was investigated and thus no information was offered as to whether more important membrane properties, such as the membrane selectivity, were optimised.

Recent studies suggest that CNT can effectively replace the PSF support layer (Li et al. 2019). Vertical aligned CNT were used as a support layer for RO TFC membranes and were compared with the classic TFC membrane with a PSF support layer. It was shown that a very high permeability of $4.7 \mathrm{LMH} /$ bar could be achieved in comparison with only $0.4 \mathrm{LMH} /$ bar for the classic TFC membrane. This was explained by the structure of the formed PA active layer on top of the support layer. As shown in figure 17, the PA active layer that forms above the conventional PSF 

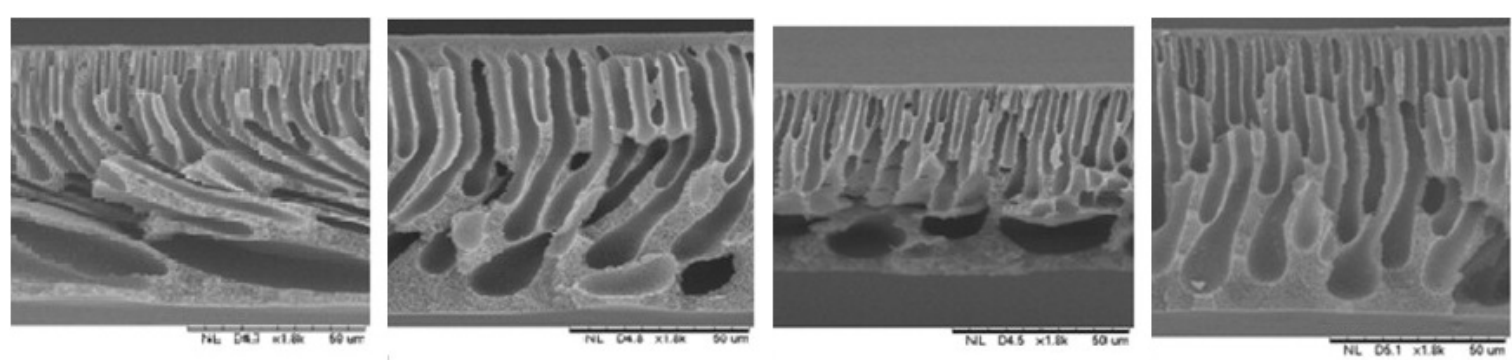

(a)

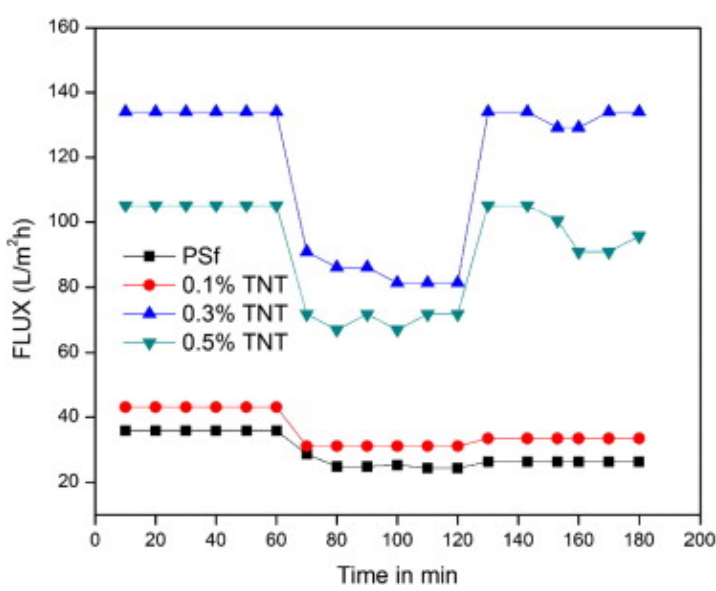

(b)

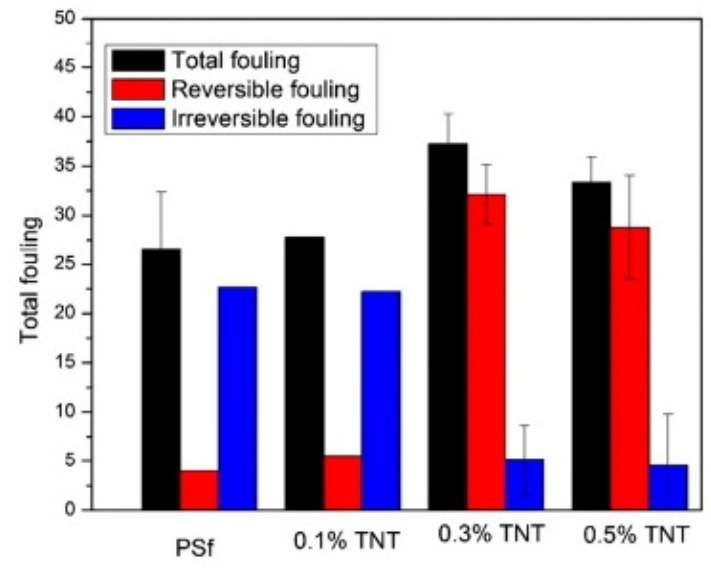

(c)

Figure 16: Cross-sectional SEM images of (a) the virgin PSF membrane, $0.1 \mathrm{wt} \%$ TNT, $0.3 \mathrm{wt} \%$ TNT and $0.5 \mathrm{wt} \%$ TNT enhanced membranes (From left to right). (b) Membrane fouling study at 1 bar and washing at 120 min with a $0.1 \mathrm{M} \mathrm{NaCl}$ solution for $30 \mathrm{~min}$. The washing period was excluded from the displayed filtration time. (c) Fouling resistance ratios of the various membranes. Copyrights obtained from Elsevier (Padaki et al. 2015).

support layer was thicker with a more ridged valley structure in comparison with the PA active layer above the CNT support, which was thinner and smoother. The CNT support layer also led to a smoother and more aligned water transfer through the membrane. CNT support layers may also be beneficial for osmotically driven membrane processes, as the improved flow structure may minimise the ICP effect occurring in the membrane support layer. Unfortunately, this enhanced membrane was not investigated for osmotically driven membrane processes.

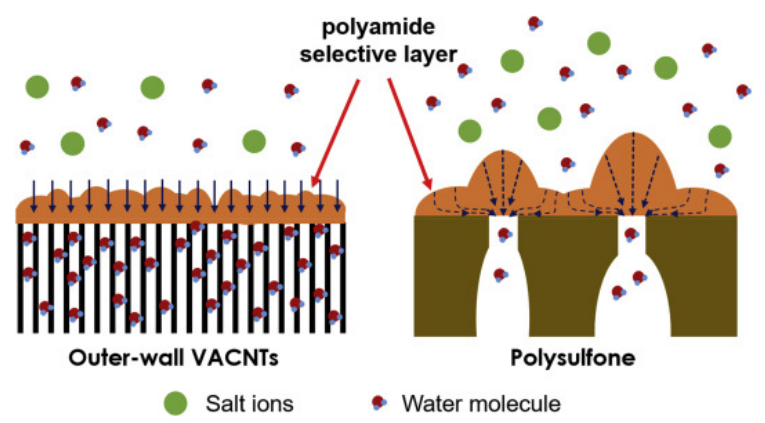

Figure 17: Comparison of the water molecule transport between a polyamide/CNT membrane and a classic polyamide/polysulfone membrane. Copyrights obtained from Elsevier (Li et al. 2019).

\subsection{Mixed oxide composites of nano- materials}

Mixed oxide composites have been widely and successfully applied for various water purification processes, as shown in section 4 . Therefore, the incorporation of mixed oxide composites into desalination membranes was widely investigated. For example, the inclusion of Zeolite NPs during the fabrication of TFC membranes was tested by Kim et al. (2013). The Zeolite NPs were synthesised using hydrothermal routes and then functionalized by amine groups. A solution of prepared NPs was poured onto the surface of a sulfonated poly (arylene ether sulfone) UF membrane during the interfacial polymerisation step. This enhanced UF membrane was used as a RO support layer. The enhanced membrane with the aminated Zeolite NPs was compared with another enhanced membrane with only Zeolite and a plain PA TFC membrane. AFM results showed a lower surface roughness parameter for the aminated Zeolite TFC membrane with an RMS of $27 \mathrm{~nm}$, in comparison with $31 \mathrm{~nm}$ and $55 \mathrm{~nm}$ for the Zeolite enhanced and the plain TFC membranes. Contact angle measurements indicated an improved hydrophilicity of the aminated Zeolite TFC membrane, as the contact angle reduced by around $26 \%$ in comparison with the plain TFC membrane. This caused a noticeable increase in the $\mathrm{RO}$ water flux from $23.2 \mathrm{LMH}$ 
for the PA TFC membrane to $39.2 \mathrm{LMH}$ for the aminated Zeolite TFC membrane. The latter even showed Zhe chlorine resistance. This confirmed the role of NPs in protecting the structure of the PA active layer from chlorine.

Similar results were obtained from Dong et al. (2015) when they incorporated Zeolite NPs with different conthe PA active layer of the RO TFC membrane. SEM images showed similar thicknesses for both membranes. However, the cross-sectional SEM images revealed the difference in the surface morphology and the pore structure of the enhanced and the 1585 plain membrane. The plain PA active layer had a typical leaf structure as shown in figure 18a, whereas the modified PA active layer had a more flourish structure as displayed in figure 18b. TEM images also confirmed a more leaf-type microstructure for the Zeolite NPs enhanced TFC membranes. The incorporated Zeolite NPs can be observed as black dots in the TEM image in figure 18c. With the increase of Zeolite loading from $0.05 \mathrm{wt} \%$ to $0.2 \mathrm{wt} \%$, the contact angle decreased by $27 \%$, leading to a noticeable flux increase. Figure 18d with respect to the Zeolite loading. As the concentration of Zeolite increased, the water flux noticeably increased while the salt rejection decreased slightly. This trend was caused by the nanogaps that were formed in incorporation. The small pore size of the Zeolite NPs might also contribute to the water flux enhancement.

Furthermore, oxide NMs were also successfully combined with other single elements in a recent study. An (Nguyen et al. 2014). This altered the surface morphology of the membrane since the $\mathrm{TiO}_{2} / \mathrm{Ag}$ coating formed a rougher layer with more surface projections. This was confirmed via SEM and AFM analysis. Furachieved a lower bacterial accumulation concentration $(2 \mu \mathrm{g} / \mathrm{L})$ in comparison to the untreated commercial membrane $(23.5 \mu \mathrm{g} / \mathrm{L})$. This membrane modification also resulted in a $40 \%$ increase in the water flux during FO operation.

$\mathrm{TiO}_{2}$ was also combined with GO to modify the RO TFC membrane surface using the layer-by-layer coating method. After the preparation of the PA active layer, the membrane was soaked in $\mathrm{aTiO}_{2}$ solution folof $\mathrm{TiO}_{2} / \mathrm{GO}$ bilayers was increased from $2,4,6,8,10$ to 12 bilayers. The optimum number of bilayers was chosen to be 6 , as a further increase in bilayers resulted in the reduction of the $\mathrm{RO}$ water flux. A biofouling analysis was performed of both the 6 bilayers enhanced membrane and the virgin membrane. During the antifouling experiments under UV radiation, the water flux of the enhanced TFC remained more steady with time, which indicated a lower accumulation of foulant on the 1630 membrane surface. This anti-fouling behaviour was explained by the photocatalytic ability of $\mathrm{TiO}_{2} \mathrm{NPs}$.

According to Mayyahi (2018), the combination of $\mathrm{GO}$ and $\mathrm{ZnO}$ showed a considerable improvement of the investigated TFC RO membrane. $\mathrm{ZnO}$ and GO NPs were added to the MPD solution during the interfacial polymerisation process of the PA active layer. TEM images of the enhanced membrane surface showed an increase in roughness with the addition of the $\mathrm{ZnO}-\mathrm{GO}$ nanocomposites. These NMs affected the reaction between the PA active layer and the substrate, which led to a different surface microstructure. Six concentrations of the composites were applied $(0.02 \mathrm{wt} \%, 0.04 \mathrm{wt} \%, 0.06 \mathrm{wt} \%, 0.08 \mathrm{wt} \%$, $0.10 \mathrm{wt} \%$ and $0.12 \mathrm{wt} \%)$. It was found that the minimum contact angle was obtained at $0.08 \mathrm{wt} \%$, as it decreased from $57^{\circ}$ for the virgin membrane to $30^{\circ}$ for the $0.08 \mathrm{wt} \%$ enhanced membrane. Higher concentration $(0.1 \mathrm{wt} \%)$ caused the contact angle to increase, which indicated a decline in the membrane's hydrophilicity. Water permeability tests showed that the highest water flux was achieved with the $0.08 \mathrm{wt} \%$ doped membrane. Water flux and salt rejection showed a gradual increase with the loading of the NPs. The water flux increased from 27.1 LMH (virgin membrane) to $42.5 \mathrm{LMH}$ for the $0.08 \mathrm{wt} \%$ doped membrane. A further increase in the concentration caused a considerable decline in the water flux. This trend was also observed for the change in salt rejection. The high concentration of NPs led to their agglomeration; and their effective surface area decreased. Hence, both hydrophilicity and water flux decreased. The $0.08 \mathrm{wt} \% \mathrm{ZnO}-\mathrm{GO}$ enhanced membrane was also examined in fouling tests. In comparison to the virgin membrane, the water flux reduction was less severe under these fouling conditions. The water flux of the modified membrane could be retrieved by up to $98 \%$ of its initial value after rinsing, while the virgin one reached a flux recovery of $80 \%$. Lastly, the composite of $\mathrm{ZnO}-\mathrm{GO}(20 \mathrm{~nm})$ showed a better performance than the individual $\mathrm{ZnO}(100 \mathrm{~nm})$ and GO $(200 \mathrm{~nm}$ to $500 \mathrm{~nm})$ NPs. This reveals the synergy of combining different NMs. The use of larger NPs led to the creation of micro-holes within the PA active layer, which affected its salt rejection.

Furthermore, ZnO NPs were combined with silica $\left(\mathrm{ZnO}-\mathrm{SiO}_{2}\right)$ (Rastgar et al. 2017) in a core-shell nanostructure by utilising the sol-gel process. These NPs were dispersed in the PSF solution during the fabrication of the support layer of a FO TFC membrane. The characteristics and performance of the modified membrane were compared with the unmodified membrane and also with a membrane modified with only $\mathrm{ZnO}$ NPs. The obtained results showed a variation in the thickness and porosity of the enhanced membranes. As shown in figure 19a, the porosity and thickness of the membrane increased with the addition of $\mathrm{ZnO}$ NPs. With the incorporation of the $\mathrm{ZnO}-\mathrm{SiO}_{2}$ NPs at different loadings, the porosity decreased considerably while the thickness increased. This led to a different S-value for the modified membranes. For the $\mathrm{ZnO}$ NPs enhanced membrane, the S-value decreased dramatically to $300 \mu \mathrm{m}$, compared with $723 \mu \mathrm{m}$ for the virgin membrane. In the case of the modified membrane with the core-shell $\mathrm{ZnO}-\mathrm{SiO}_{2}$, the concentration of NPs influenced the S-value, giving it a minimum 


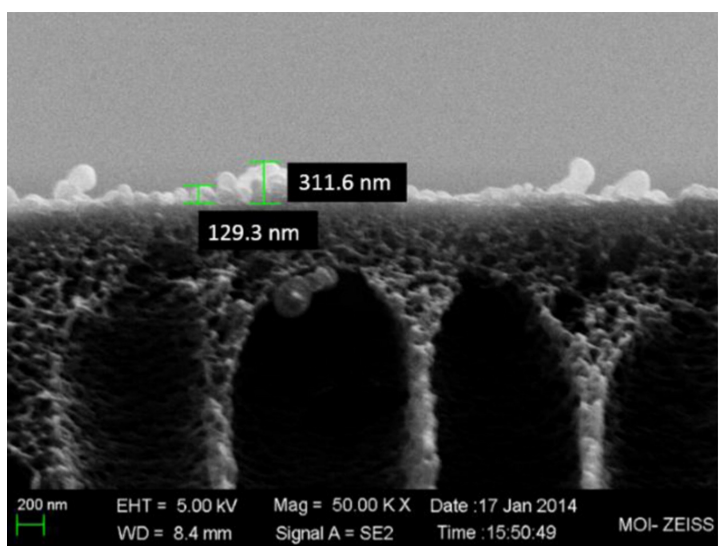

(a)

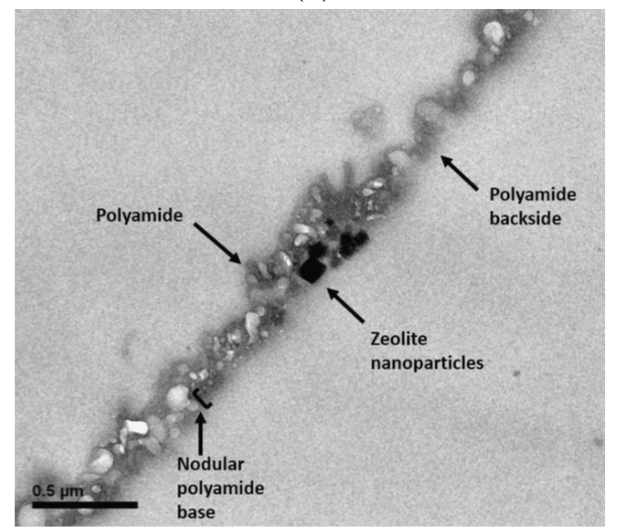

(c)

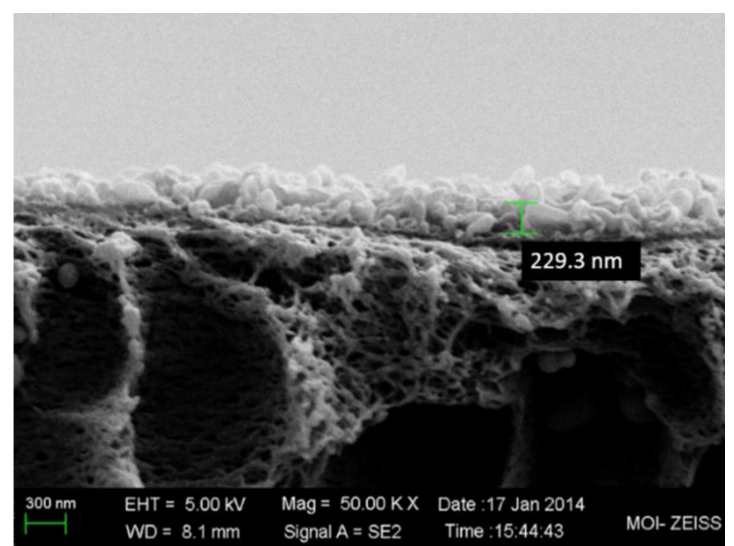

(b)

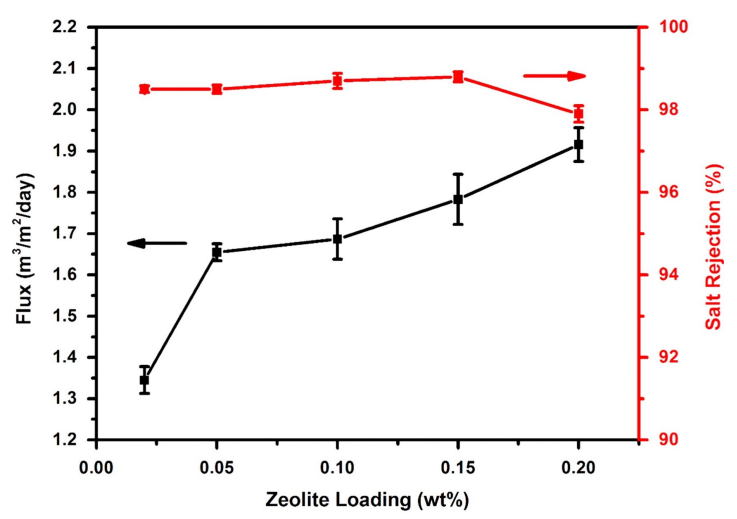

(d)

Figure 18: Cross-sectional SEM images of the (a) plain TFC membrane and the (b) 0.1 wt\% Zeolite enhanced TFC membrane. (c) TEM image of the PA active layer of the enhanced TFC membrane. (d) Effects of Zeolite loading on the water flux and salt rejection (adding NaY Zeolite nanoparticles into the amine solution; 2000 ppm $\mathrm{NaCl}$ solution, 225 psi). Copyrights obtained from Elsevier (Dong et al. 2015).

value of $271 \mu \mathrm{m}$ at $2 \mathrm{wt} \% \mathrm{ZnO}-\mathrm{SiO}_{2}$. The contact angle, which was depicted in figure $19 \mathrm{~b}$, also reached its minimum value at $2 \mathrm{wt} \% \mathrm{ZnO}-\mathrm{SiO}_{2}$. Cross-sectional SEM images that appear in figure $19 \mathrm{c}$ show a noticeable change in the pore structure, as a result of the NPs modification. The unmodified membrane showed a non-uniform pore structure while the $\mathrm{ZnO}$ modified substrate formed longer and larger pores. Furthermore, the $\mathrm{ZnO}-\mathrm{SiO}_{2}$ modified membrane showed a longer and more aligned pore structure. This facilitated water flux, especially in PRO mode, where the water flux reached $50 \mathrm{LMH}$ compared with $43 \mathrm{LMH}$ and $26 \mathrm{LMH}$ for the $\mathrm{ZnO}$ modified and the unmodified membranes, respectively (figure 19d). Although the total surface area of the $\mathrm{ZnO}-\mathrm{SiO}_{2} \mathrm{NPs}$ was 10 times less than that of the $\mathrm{ZnO} \mathrm{NPs}_{\mathrm{s}}$, the water flux was greater for the $\mathrm{ZnO}-\mathrm{SiO}_{2}$. This was related to the high hydrophilicity, as well as the aligned pore structure that facilitated water flow. However, figure $19 \mathrm{e}$ shows that the reverse salt flux increased with the $\mathrm{ZnO}-\mathrm{SiO}_{2}$ modified membrane (Rastgar et al. 2017). The comparison between the single oxide and the mixed oxide composites in the above article reveals the effect of the mixed oxides on the enhancement of the membrane properties. However, investigating the effect of varying the percentage weight of the two ox- ides within the composite may be useful for further membrane enhancements.

\subsection{NMs-polymer composites}

Polyaniline (PANI) nanostructures were synthesised through interfacial polymerisation, and were added alongside $\mathrm{Cu}$ NPs to the surface of a RO commercial TFC membrane (Khajouei et al. 2018). The contact angle was found to decrease with the addition of the $\mathrm{Cu}$ NPs. A further decrease in the contact angle was observed when the combination of PANI and $\mathrm{Cu}$ was applied. Such a metal-polymer combination was very effective in reducing the hydrophilicity of the membrane. Zeta potential measurements of the PANI/Cu enhanced membrane showed the stability of charge over $\mathrm{pH}$, whereas the charge of the virgin membrane changed with $\mathrm{pH}$ alterations. This stable charge confirms the continuous positive charge of the enhanced membrane as a consequence of the added NPs. This was one of the factors that might prevent bacterial adhesion on the membrane surface. Therefore, the E-coli bacterial inhibition zone was shown to increase in the PANI/Cu enhanced membrane. The enhanced membrane showed a slight increase in water flux and maintained an almost similar salt rejection as the virgin 

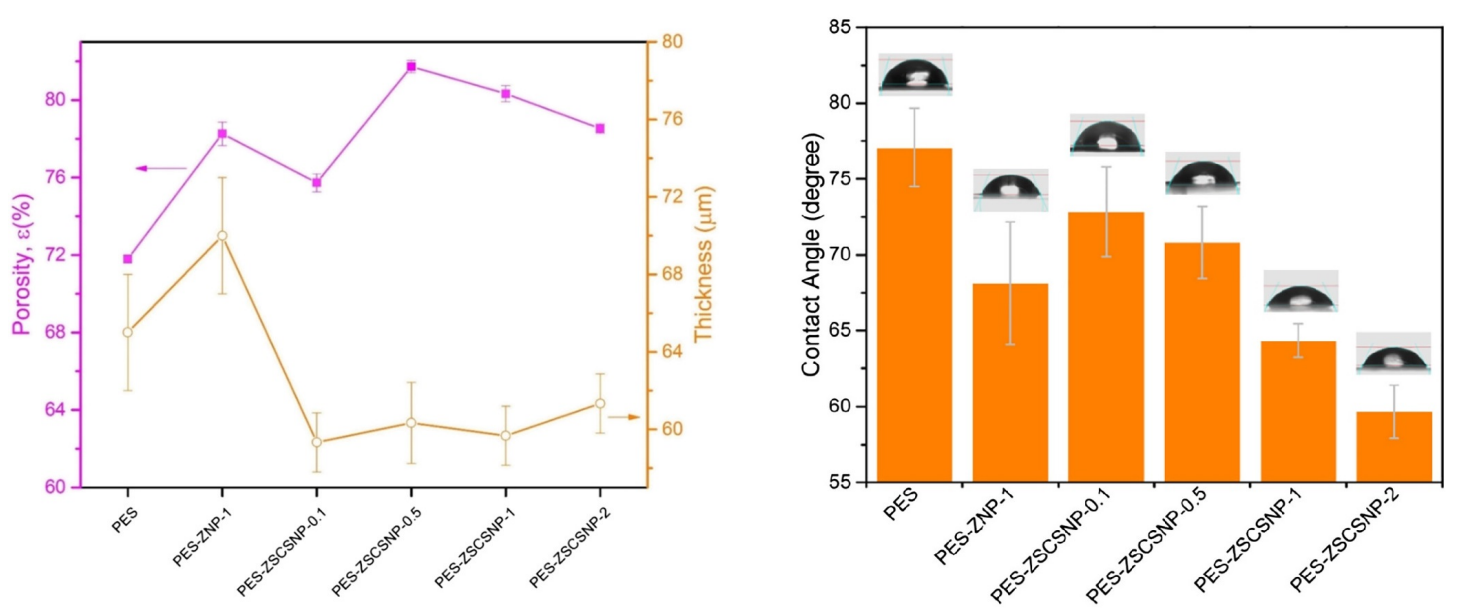

(a)
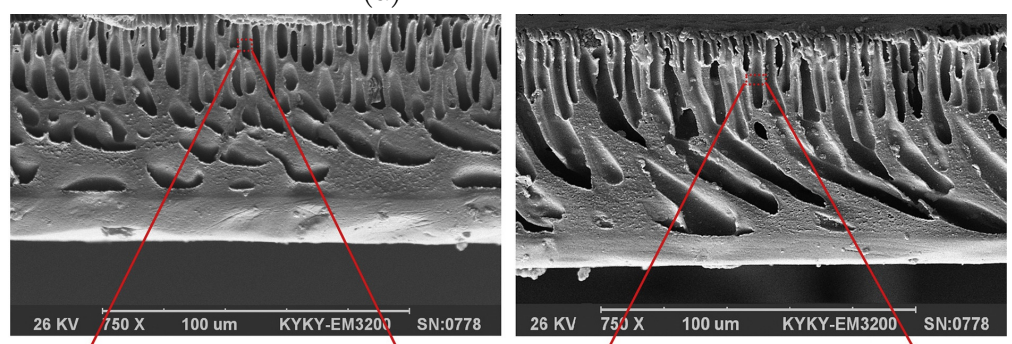

(b)
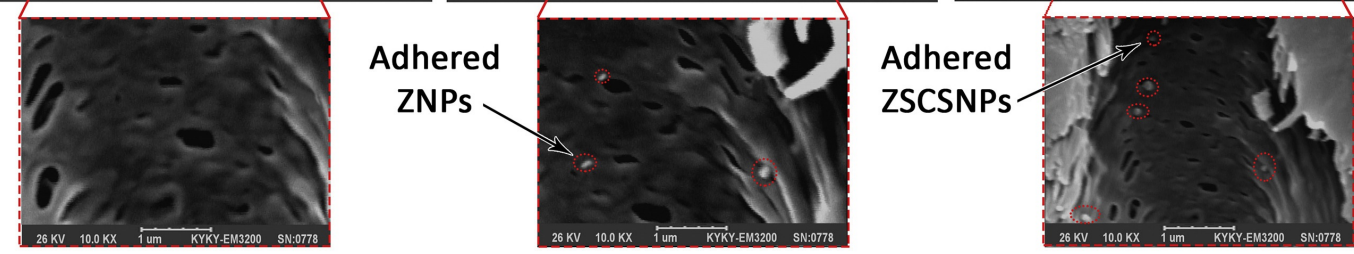

(c)

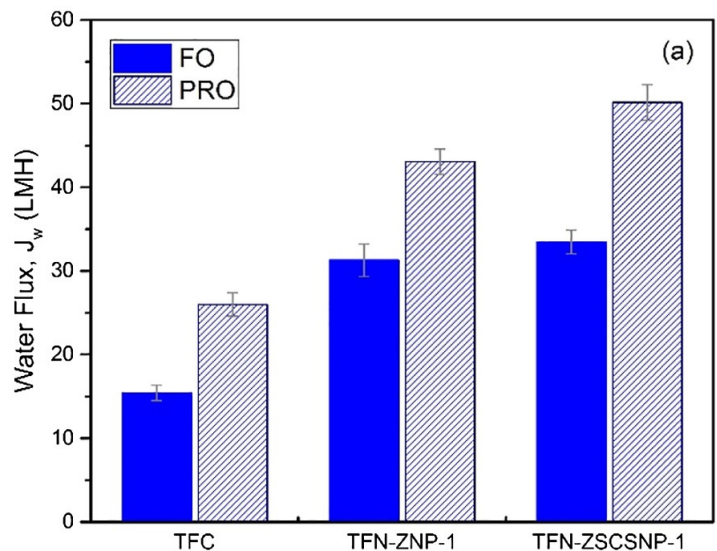

(d)

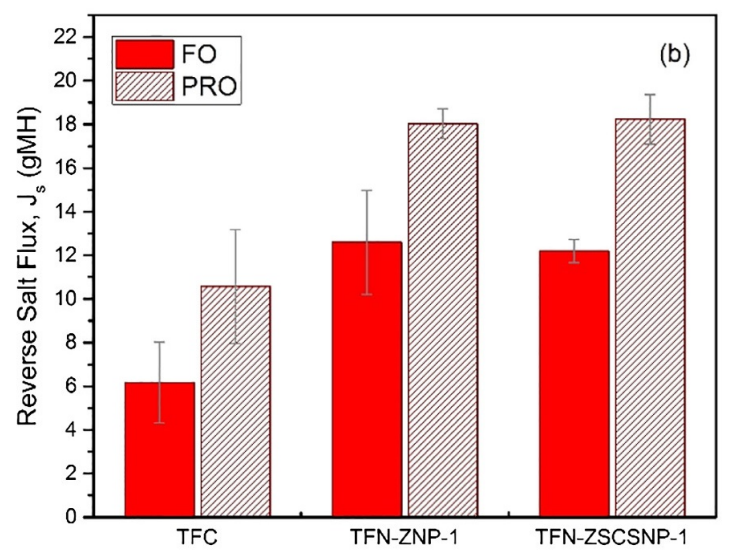

(e)

Figure 19: (a) Porosity, thickness and (b) contact angle measurements for the unmodified, the $\mathrm{ZnO}$ and $\mathrm{ZnO}-\mathrm{SiO}_{2}$ modified TFC membranes. (c) TEM images for the unmodified membrane (left), $\mathrm{ZnO}$ modified membrane (middle) and $\mathrm{ZnO}-\mathrm{SiO}_{2}$ modified membrane (right). (d) Achieved water fluxes for the $\mathrm{FO}$ and PRO modes. (e) Reverse salt flux for FO and PRO mode. Copyrights obtained from Elsevier (Rastgar et al. 2017).

membrane. The long-term biofouling test revealed a more stable water flux with time, which indicates a lower fouling accumulation rate.

Another example of an efficient NP and polymer combination was the addition of PEG and $\mathrm{TiO}_{2}$. A recent study combined the PEG polymer, which was known for its high hydrophilicity, flexibility and thermal stability, with commercial $\mathrm{TiO}_{2} \mathrm{NPs}$ to enhance a CTA membrane for RO applications (Shafiq et al. 2018). The PEG-400 polymer was combined with different weight percentages of $\mathrm{TiO}_{2}\left(5 \%, 10 \%, 15 \%,{ }_{1755}\right.$ $20 \%$ and $25 \%$ ) and added to the casting solution of the 


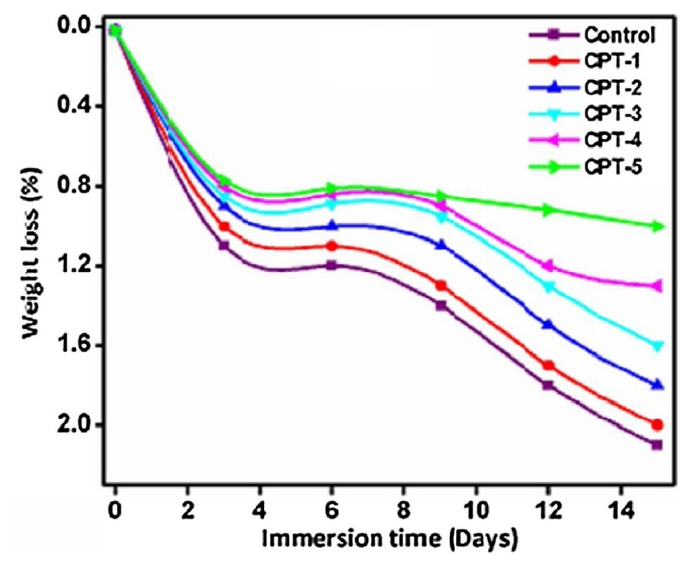

(a)

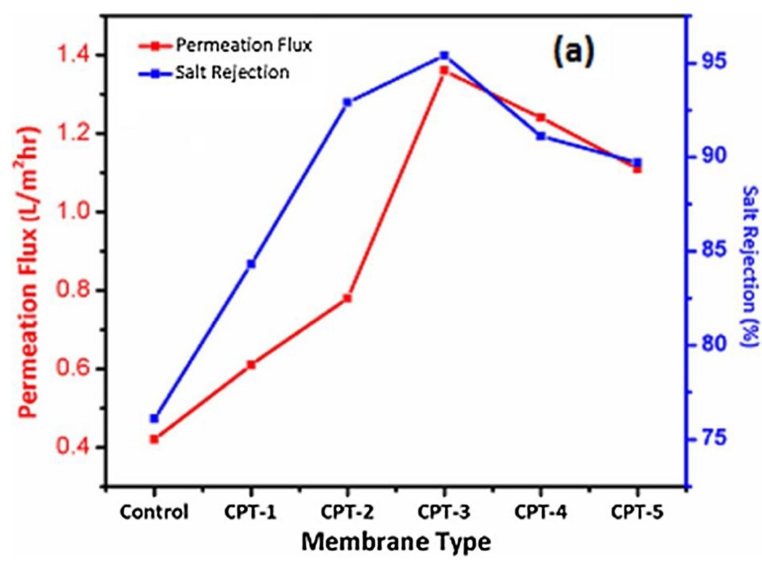

(b)

Figure 20: (a) The degradation of the virgin and modified CTA membranes at $\mathrm{pH} 7.4$ with $\mathrm{TiO}_{2}$ at different weight percentages: CPT-1 : $5 \mathrm{wt} \%$, CPT-2: $10 \mathrm{wt} \%$, CPT-3: $15 \mathrm{wt} \%$, CPT-4: $20 \mathrm{wt} \%$ and CPT-5: $25 \mathrm{wt} \%$ ). (b) A comparison of permeation flux with salt rejection. Copyrights obtained from Elsevier (Shafiq et al. 2018)

CTA membrane. The modified membrane showed signs of a good thermal stability up to temperatures reaching $250^{\circ} \mathrm{C}$. All of the prepared membranes showed a dense ure 20a, chemical stability tests at a constant $\mathrm{pH}$ of 7.4 showed that the rate of membrane weight loss over 14 days decreased with a weight increase of $\mathrm{TiO}_{2}$. The membrane with the maximum amount of $\mathrm{TiO}_{2} \mathrm{NPs}$ enhanced membranes also showed a bacterial inhibition that reached its maximum value with the highest NP percentage $(25 \%)$. However, this high $\mathrm{TiO}_{2}$ loading did not result in the optimum RO performance. $\mathrm{TiO}_{2}$ loading from $5 \%$ to $10 \%$, reaching its maximum with $15 \%$ (1.4 LMH). At higher $\mathrm{TiO}_{2}$ concentrations, the water flux started to reduce and finally reached $1.1 \mathrm{LMH}$ at $25 \% \mathrm{TiO}_{2}$. A similar trend was observed this trend was related to the hydrophilicity of $\mathrm{TiO}_{2}$, which facilitates water flow within the enhanced membrane. It is important to note that enhancing the water permeability of CTA membranes is beneficial to the ally have a significantly lower water permeability than their TFC counterparts.

Recently, a composite of polyamide/nitrogen-doped GO quantum dots were effectively applied to enhance the active layer of a RO TFC membrane (Fathizadeh et al. 2019). The composite was synthesised through the hydrothermal route and this resulted in welldispersed nanoparticles with sizes ranging from $3 \mathrm{~nm}$ to $8 \mathrm{~nm}$. The concentration of the nano-composites was during the interlinking process, as ten different concentrations were used ranging from $0.0025 \mathrm{wt} \%$ to $0.1 \mathrm{wt} \%$. The roughness parameter and the effective surface area of the membrane were found to decrease with the concentration of the nano-enhancer composite. On the other hand, thermal stability tests showed an almost constant temperature effect of the enhanced and the plain membranes. Desalination RO tests showed that the water flux and salt rejection depended on the nano-composite concentration. As the nanocomposite concentration was increased to $0.02 \mathrm{wt} \%$, the flux increased by $60 \%$ in comparison with the plain membrane. As the concentration reached $0.4 \mathrm{wt} \%$, the water flux and salt rejection did not show any considerable changes. A further increase in the concentration caused a decline of approximately $60 \%$ in the water flux and salt rejection, which was argued to occur due to particle agglomeration (Fathizadeh et al. 2019).

During the last years, the agglomeration effect of high NMs loadings was reported in most of the published articles that focused on the enhancement of desalination and water purification membranes using NMs. While this phenomena was widely discussed and understood, the membrane enhancement effect of the other properties of the NM have not been widely investigated. In the following section, the focus lies on the rare publications that investigate other NM properties and their effect on the desalination process. 
Table 1: Examples of NMs that are applied for water purification membrane enhancement

\begin{tabular}{|c|c|c|c|c|c|c|c|c|}
\hline $\begin{array}{l}\text { NM chemical } \\
\text { composition }\end{array}$ & $\begin{array}{l}\text { Synthesis } \\
\text { route of NM }\end{array}$ & $\begin{array}{l}\mathrm{NM} \\
\text { size }\end{array}$ & $\begin{array}{l}\text { Membrane } \\
\text { type }\end{array}$ & $\begin{array}{l}\text { Targeted } \\
\text { membrane layer }\end{array}$ & Performance & $\begin{array}{l}\text { Optimum } \\
\text { concentration }\end{array}$ & $\begin{array}{l}\text { App- } \\
\text { lication }\end{array}$ & Reference \\
\hline Carbon & Commercial & $8 \mathrm{~nm}$ & TFC & Active layer & $J_{W}$ increased by $25 \%$ & $0.03 \mathrm{wt} \%$ & $\mathrm{RO}$ & Li, Li \& Zhang (2017) \\
\hline $\mathrm{Ag}$ & $\begin{array}{l}\text { In-situ } \\
\text { fabrication }\end{array}$ & $15 \mathrm{~nm}$ & $\mathrm{TFC}$ & Surface coating & $\begin{array}{l}\text { Enhanced anti- } \\
\text { bacterial properties } \\
\text { A decreased by } 17 \% \\
\text { B decreased by } 25 \%\end{array}$ & $0.64 \mathrm{wt} \%$ & RO & Ben-Sasson et al. (2014) \\
\hline $\mathrm{Ag}$ & $\begin{array}{l}\text { In-situ } \\
\text { chemical reduction }\end{array}$ & $2 \mathrm{~nm}$ to $3 \mathrm{~nm}$ & $\mathrm{TFC}$ & Support layer & $\begin{array}{l}J_{W} \text { increased by } 150 \% \\
\text { Boron rejection increased }\end{array}$ & $\begin{array}{l}20 \mathrm{mM} \text { of } \\
\mathrm{AgNO}_{3} \text { solution }\end{array}$ & $\mathrm{RO}$ & Yang et al. (2019) \\
\hline $\mathrm{Ag}$ & Chemical reduction & $30 \mathrm{~nm}$ & PVDF & $\begin{array}{l}\text { Within membrane } \\
\text { matrix }\end{array}$ & $J_{W}$ increased by $19 \%$ & $25 \%$ & $\begin{array}{l}\text { Membrane } \\
\text { distillation }\end{array}$ & Politano et al. (2019) \\
\hline $\mathrm{Cu}$ & $\begin{array}{l}\text { Wet chemical } \\
\text { reduction }\end{array}$ & $39.4 \mathrm{~nm}$ & $\mathrm{TFC}$ & Layer by layer & $\begin{array}{l}J_{W} \text { decreased by } 13 \% \\
\text { Enhanced anti- } \\
\text { bacterial properties }\end{array}$ & 10 bilayers & $\mathrm{RO}$ & Ma et al. (2016) \\
\hline $\mathrm{UiO}-66$ & $\begin{array}{l}\text { Hydrothermal } \\
\text { routes }\end{array}$ & $50 \mathrm{~nm}$ & $\mathrm{TFC}$ & Active layer & $\begin{array}{l}J_{W} \text { increased by } 36 \% \\
\text { Boron rejection } \\
\text { increased by } 10 \%\end{array}$ & $0.05 \%$ & $\mathrm{RO}$ & Liu et al. (2019) \\
\hline $\mathrm{TiO}_{2}$ & Commercial & & CTA & $\begin{array}{l}\text { Surface } \\
\text { modification }\end{array}$ & $\begin{array}{l}J_{W} \text { increased by } 73 \% \\
J_{S} \text { decreased by } 50 \%\end{array}$ & & $\mathrm{FO}$ & Xue et al. (2018) \\
\hline $\mathrm{Al}_{2} \mathrm{O}_{3}$ & Sol-gel & & $\mathrm{TFC}$ & Active layer & $J_{W}$ increased by $44 \%$ & $1 \%$ & RO & Saleh \& Gupta (2012) \\
\hline $\mathrm{ZnO}$ & Commercial & $20 \mathrm{~nm}$ to $30 \mathrm{~nm}$ & UF & Within matrix & $\begin{array}{l}J_{W} \text { increased by } 73 \% \\
\text { Improved anti-fouling properties }\end{array}$ & $3 \mathrm{wt} \%$ & UF & Rabiee et al. (2015) \\
\hline $\mathrm{SiO}_{2}$ & Commercial & $15 \mathrm{~nm}$ to $20 \mathrm{~nm}$ & $\mathrm{TFC}$ & Active layer & $\begin{array}{l}J_{W} \text { increased by } 100 \% \\
J_{S} \text { decreased by } 150 \%\end{array}$ & $0.1 \mathrm{wt} \%$ & $\mathrm{FO}$ & Niksefat et al. (2014) \\
\hline $\mathrm{SiO}_{2}$ & Commercial & $5 \mathrm{~nm}$ to $15 \mathrm{~nm}$ & $\mathrm{TFC}$ & $\begin{array}{l}\text { Electrospun } \\
\text { support layer }\end{array}$ & $\begin{array}{l}\text { A increased by } 26 \% \\
\text { B increased by } 24 \%\end{array}$ & $1.6 \%$ & $\mathrm{FO}$ & Tian et al. (2017) \\
\hline $\mathrm{SiO}_{2}$ & Commercial & $200 \mathrm{~nm}$ & $\mathrm{TFC}$ & Support layer & $\begin{array}{l}\text { A increased by } 135 \% \\
\text { B increased by } 135 \%\end{array}$ & $15 \%$ & RO & Bui \& McCutcheon (2016) \\
\hline $\mathrm{SiO}_{2}$ & Commercial & $200 \mathrm{~nm}$ & $\mathrm{TFC}$ & Support layer & $\begin{array}{l}J_{W} \text { increased by } 150 \% \\
J_{S} \text { was maintained }\end{array}$ & $10 \%$ & $\mathrm{FO}$ & Bui \& McCutcheon (2016) \\
\hline
\end{tabular}


Table 1: Examples of NMs that are applied for water purification membrane enhancement

\begin{tabular}{|c|c|c|c|c|c|c|c|c|}
\hline $\begin{array}{l}\text { NM chemical } \\
\text { composition }\end{array}$ & $\begin{array}{l}\text { Synthesis } \\
\text { route of NM }\end{array}$ & $\begin{array}{l}\mathrm{NM} \\
\text { size }\end{array}$ & $\begin{array}{l}\text { Membrane } \\
\text { type }\end{array}$ & $\begin{array}{l}\text { Targeted } \\
\text { membrane layer }\end{array}$ & Performance & $\begin{array}{l}\text { Optimum } \\
\text { concentration }\end{array}$ & $\begin{array}{l}\text { App- } \\
\text { lication }\end{array}$ & Reference \\
\hline $\mathrm{SiO}_{2}$ & Commercial & $25.4 \mathrm{~nm}$ & TFC & Dip-coating & $\begin{array}{l}\text { Amount of biofouling increased by } 66 \% \\
\text { A decreased by } 16 \%\end{array}$ & $20 \%$ & FO & Liu, Lee, Small, Ma \& Elimelech (201 \\
\hline $\begin{array}{l}\text { GO- } \\
\text { nanosheets }\end{array}$ & $\begin{array}{l}\text { Modified } \\
\text { Hummer's method }\end{array}$ & $6 \mathrm{~nm}$ to $8 \mathrm{~nm}$ & $\mathrm{TFC}$ & Support layer & $\begin{array}{l}J_{W} \text { increased by } 150 \% \\
J_{S} \text { increased slightly }\end{array}$ & $0.2 \mathrm{wt} \%$ & $\mathrm{FO}$ & Qin et al. (2015) \\
\hline GO & Commercial & & CTA & CTA matrix & $\begin{array}{l}J_{W} \text { increased by } 212 \% \\
\text { Thermal stability decreased } \\
\text { Mechanical strength decreased }\end{array}$ & $0.1 \mathrm{wt} \%$ & $\begin{array}{l}\mathrm{RO} \\
\text { waste water }\end{array}$ & Chen et al. (2018) \\
\hline $\mathrm{Mg}_{3} \mathrm{Al}-\mathrm{CO}_{3}$ & Co-Precipitation & $20 \mathrm{~nm}$ to $30 \mathrm{~nm}$ & $\mathrm{TFC}$ & Dip-coating & $\begin{array}{l}J_{W} \text { decreased by } 22 \% \\
J_{S} \text { decreased by } 9 \% \\
\text { Chlorine resistance increased }\end{array}$ & $8.96 \mathrm{wt} \%$ & FO & Lu et al. (2017) \\
\hline $\mathrm{Mg}_{3} \mathrm{Al}-\mathrm{CO}_{3}$ & Chemical routes & & TFC & Support layer & $\begin{array}{l}J_{W} \text { increased by } 42 \% \\
\text { Mechanical strength increased }\end{array}$ & $4 \mathrm{wt} \%$ & $\mathrm{FO}$ & Lu et al. (2016) \\
\hline $\begin{array}{l}\text { Boehmite } \\
\gamma \text { - } \mathrm{AlO}(\mathrm{OH})\end{array}$ & Sol-gel & $20 \mathrm{~nm}$ & CTA & CTA matrix & $\begin{array}{l}\text { A increased by } 140 \% \\
\text { Structural parameter decreased }\end{array}$ & $0.5 \mathrm{wt} \%$ & $\mathrm{FO}$ & Zirehpour et al. (2015) \\
\hline $\mathrm{ZnO}$ & $\begin{array}{l}\text { Chemical } \\
\text { routes }\end{array}$ & & $\mathrm{TFC}$ & $\begin{array}{l}\text { Support layer } \\
\text { with amino acid } \\
\text { modification }\end{array}$ & $\begin{array}{l}J_{W} \text { increased by } 118 \% \\
\text { Salt rejection decreased by } 8 \%\end{array}$ & $0.3 \mathrm{wt} \%$ & $\mathrm{FO}$ & Darabi et al. (2019) \\
\hline $\mathrm{CNT}$ & Commercial & $\begin{array}{l}\text { Diameter } 15 \mathrm{~A} \\
\text { Length } 1 \mu \mathrm{m}\end{array}$ & TFC & Active layer & $\begin{array}{l}J_{W} \text { increased by } 130 \% \\
\text { Biofouling decreased }\end{array}$ & $2 \mathrm{wt} \%$ & RO & Chan et al. (2016) \\
\hline TNT & $\begin{array}{l}\text { Hydrothermal } \\
\text { method }\end{array}$ & $\begin{array}{l}\text { Diameter } \\
20 \mathrm{~A} \text { to } 40 \mathrm{~A} \\
\text { Length } 1 \mu \mathrm{m}\end{array}$ & $\mathrm{TFC}$ & Support layer & $\begin{array}{l}J_{W} \text { increased by } 400 \% \\
\text { Anti-fouling properties increased }\end{array}$ & $0.3 \mathrm{wt} \%$ & RO & Padaki et al. (2015) \\
\hline CNT-TNT & Hydrothermal & $\begin{array}{l}10 \mathrm{~nm} \text { to } 20 \mathrm{~nm} \\
71 \mathrm{~nm} \text { to } 141 \mathrm{~nm}\end{array}$ & $\mathrm{TFC}$ & Support layer & A increased by $57 \%$ & & RO & Wan Azelee et al. (2017) \\
\hline Zeolite & $\begin{array}{l}\text { Hydrothermal } \\
\text { method }\end{array}$ & & $\mathrm{TFC}$ & Active layer & $\begin{array}{l}J_{W} \text { increased by } 68 \% \\
\text { Chlorine resistance increased }\end{array}$ & & RO & Kim et al. (2013) \\
\hline Zeolite & $\begin{array}{l}\text { Hydrothermal } \\
\text { method }\end{array}$ & $150 \mathrm{~nm}$ & TFC & Active layer & $J_{W}$ increased by $40 \%$ & $0.2 \mathrm{wt} \%$ & RO & Dong et al. (2015) \\
\hline
\end{tabular}


Table 1: Examples of NMs that are applied for water purification membrane enhancement

\begin{tabular}{|c|c|c|c|c|c|c|c|c|}
\hline $\begin{array}{l}\text { NM chemical } \\
\text { composition }\end{array}$ & $\begin{array}{l}\text { Synthesis } \\
\text { route of NM }\end{array}$ & $\begin{array}{l}\text { NM } \\
\text { size }\end{array}$ & $\begin{array}{l}\text { Membrane } \\
\text { type }\end{array}$ & $\begin{array}{l}\text { Targeted } \\
\text { membrane layer }\end{array}$ & Performance & $\begin{array}{l}\text { Optimum } \\
\text { concentration }\end{array}$ & $\begin{array}{l}\text { App- } \\
\text { lication }\end{array}$ & Reference \\
\hline $\mathrm{TiO}_{2}-\mathrm{Ag}$ & Sol-gel & & $\mathrm{TFC}$ & Dip-coating & $\begin{array}{l}\text { Anti-fouling properties increased } \\
J_{W} \text { increased by } 25 \%\end{array}$ & & $\mathrm{FO}$ & Nguyen et al. (2014) \\
\hline $\mathrm{TiO}_{2}-\mathrm{GO}$ & Commercial & $100 \mathrm{~nm}$ & $\mathrm{TFC}$ & Layer by layer & Anti-fouling properties increased & 6 bilayers & $\mathrm{RO}$ & Shao et al. (2017) \\
\hline $\mathrm{ZnO}-\mathrm{GO}$ & $\begin{array}{l}\text { Chemical } \\
\text { routes }\end{array}$ & $20 \mathrm{~nm}$ & $\mathrm{TFC}$ & Active layer & $J_{W}$ increased by $66 \%$ & $0.08 \mathrm{wt} \%$ & $\mathrm{RO}$ & Mayyahi (2018) \\
\hline $\mathrm{ZnO} @ \mathrm{SiO}_{2}$ & Sol-gel & $30 \mathrm{~nm}$ & TFC & Support layer & $J_{W}$ increased by $65 \%$ & $2 \mathrm{wt} \%$ & FO-PRO & Rastgar et al. (2017) \\
\hline $\mathrm{Cu}-\mathrm{PANI}$ & In situ & & $\mathrm{TFC}$ & Active layer & Anti-fouling properties increased & & $\mathrm{RO}$ & Khajouei et al. (2018) \\
\hline $\mathrm{TiO}_{2}-\mathrm{PEG}$ & Commercial & $25 \mathrm{~nm}$ & CTA & CTA matrix & $\begin{array}{l}J_{W} \text { increased by } 125 \% \\
\text { Chemical stability increased }\end{array}$ & $15 \%$ & $\mathrm{RO}$ & Shafiq et al. (2018) \\
\hline $\begin{array}{l}\text { GO } \\
\text { Quantum dots }\end{array}$ & $\begin{array}{l}\text { Hydrothermal } \\
\text { method }\end{array}$ & $10 \mathrm{~nm}$ & $\mathrm{TFC}$ & Active layer & $J_{W}$ increased by $60 \%$ & $0.02 \mathrm{wt} \%$ & $\mathrm{RO}$ & Fathizadeh et al. (2019) \\
\hline
\end{tabular}




\section{Effect of nanomaterial mor- phology and properties on the membrane efficiency}

Most of the recently published articles involving the enhancement of desalination membranes using NMs have considered the concentration of NMs as the main experimental variable for the different intrinsic properties of the membrane. However, NMs were shown to have different effects based on their morphological, physical and chemical properties, as discussed in section 4 . It was also reported that the overall desalination performance was influenced by the membrane's material soperties, such as the crystallite size of the polymer used to fabricate the desalination membrane ( $\mathrm{Lu}$ et al. 2019). During the fabrication of these membranes, the addition of p-nitrophenol showed the effect of the CTA membrane crystallization, as XRD peaks revealed the formation of smaller crystallite sizes in the enhanced membrane. As a result, the internal concentration polarization within the membrane decreased during the FO process, which lead to an enhanced desalination performance.

1840 Studies considering other membrane desalination applications, such as membrane distillation, have shown that the shape of the NMs enhancers also affect the membrane fouling propensity (Rajabi et al. 2015). In membrane distillation, the size of nano $\mathrm{TiO}_{2}$ enhancers 5 were shown to affect the permselectivity and antifouling performance of polyvinylidene fluoride (PVDF) membranes (Zhang et al. 2017), where two particle sizes $(5 \mathrm{~nm}$ and $21 \mathrm{~nm})$ were prepared using different preparation methods and then incorporated during the o membrane preparation process. These two sizes led to different membrane morphologies and characteristics (contact angle, porosity, roughness and surface energy). Accordingly, an improved anti-fouling performance was determined using the larger $\mathrm{TiO}_{2} \mathrm{NPs}$ $5(21 \mathrm{~nm})$ (Zhang et al. 2017). However, smaller sized NPs $(5 \mathrm{~nm})$ maintained a higher water flux, as they were easily incorporated within the membrane pores, whereas, the larger NPs blocked some membrane pores. This shows the significance of choosing the optimum (ize of the NM used to enhance polyneric nimembranes. Furthermore, the size effect of $\mathrm{ZnO}$ NMs in PVDF membranes were also reported in Jia et al. (2017). A recent study by Lee et al. (2019) has confirmed that the ZIF-8 (zeolitic) NPs particle size affected the TFC membrane properties. Three different particle diameters were applied $(60,150$ and $250 \mathrm{~nm})$ by changing the reaction time of the chemical synthesis. The change in size was confirmed using dynamic light scattering (DLS) analyser as shown in figure 21a. These NPs were incorporated during the phase inversion process of the PA active layer of the TFC membrane. The different sizes of NPs were found to affect the deposition of the PA active layer on the support layer which affected the interlinkage between the two layers in the 5 membrane composite. As seen in figure $21 \mathrm{~b}$, the deposition of the ZIF-8 NPs on the support was differ- ent for different particle sizes. The energy barrier was calculated to give an indication of the strength of the interlinkage between the two layers. The $150 \mathrm{~nm}$ particle size membrane was found to have the lowest energy barrier which indicated a lower interlinkage between the two layers. Therefore, in the RO experiment, this membrane showed the highest flux enhancement with a $43 \%$ increase in water permeance in comparison to the virgin membrane, as shown in figure 21c. This size effect was also related to the thickness of the PA active layer, as too large particles $(250 \mathrm{~nm})$ could not get within the PA matrix and thus caused defects that lowered the water flux and salt rejection of the modified membrane.

Nevertheless, the influence of the NMs size on the membrane modification does not repeal the importance of concentration in the modification process. Optimization of these two parameters and of the others mentioned earlier are required to achieve the optimum membrane characteristics for different desalination processes. Recent studies have shown that a specific size/concentration combination was related to the highest water flux for PVDF membranes (Karimi et al. 2019); ZIF-8 NPs within a size range of $80 \mathrm{~nm}$ to $100 \mathrm{~nm}$ and a $0.1 \mathrm{wt} \%$ concentration achieved a water flux of $310 \mathrm{LMH}$, which was an almost $100 \%$ increase in comparison with the virgin membrane. Smaller sizes of ZIF-8 NPs showed to have a considerable flux enhancement too ( $76 \%$ more than the virgin membrane) with a higher concentration of $0.2 \mathrm{wt} \%$ (Karimi et al. 2019).

All of these recent publications emphasize the importance of the inner structure of the membrane components. Therefore, the morphology and properties of the desalination membrane nano-enhancers can be considered as strong influencers of the membrane permeability, selectivity, its fouling propensity and its mechanical and chemical stability. It is essential to consider the NMs properties as a fundamental parameter during the membrane enhancement investigations.

Overall, the effect of the NMs morphology and its properties on the membrane desalination process have not yet been widely investigated. Thus, not only novel chemical compositions should be investigated but also the effect of varying the properties of the NMs, including their grain size, surface area and their optical and magnetic properties. Controlling the properties of NMs membrane enhancers would consequently allow to control the intrinsic properties of the desalination membranes based on the required process and techniques.

\section{Conclusions}

Nanomaterials are an intriguing way to enhance TFC and CTA membranes due to their unique characteristics. Studies show that NMs can be fabricated with different chemical compositions and with different shapes and sizes. The synthesis routes of these NMs are discussed in section 4 , and include various chemical and mechanical approaches. It is shown that the properties of NMs are sensitive to the experimental parameters of 


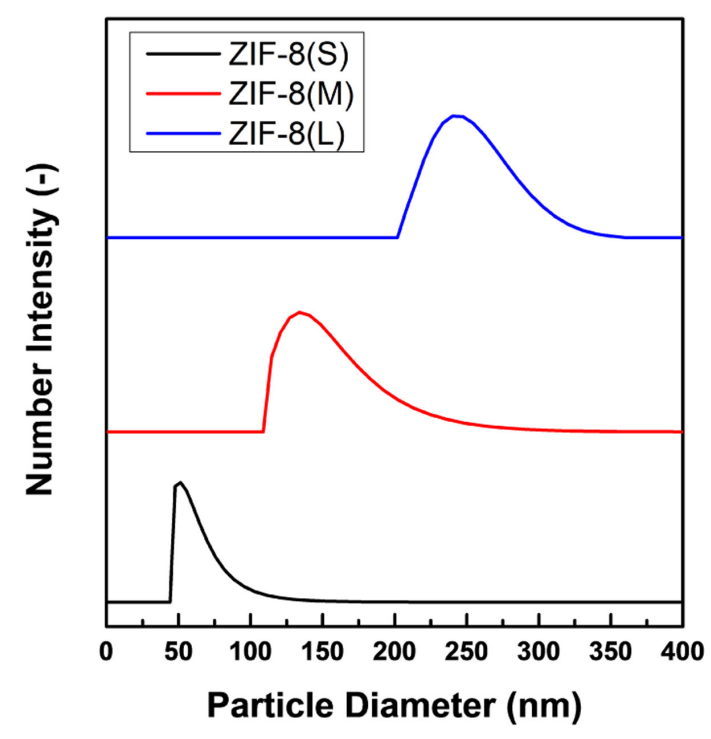

(a)

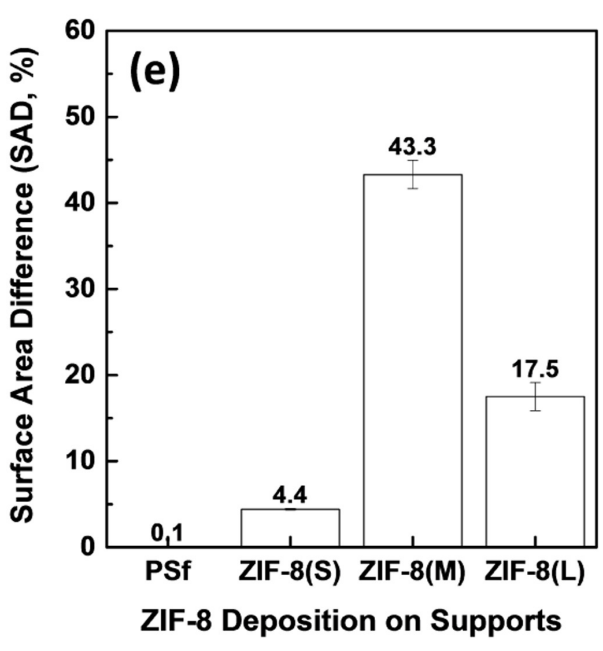

(b)

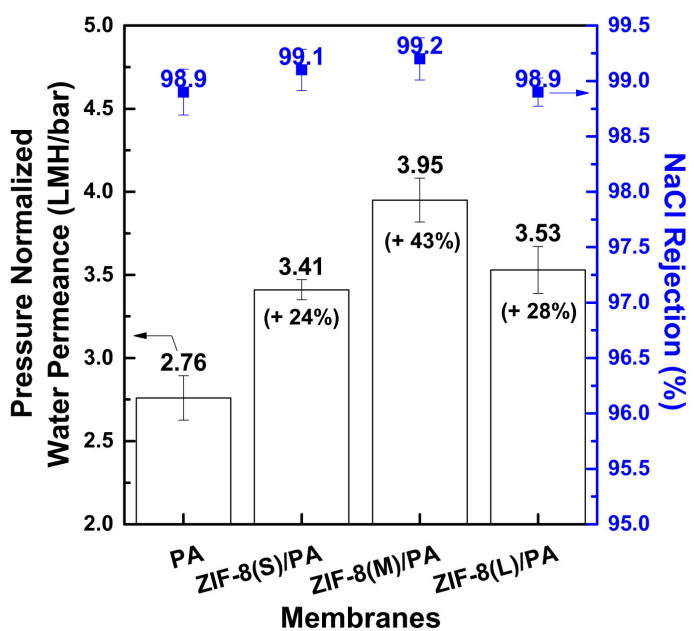

(c)

Figure 21: (a) Size distribution of the ZIF-8 nano-enhancers showing three different sizes with their (b) deposition on the enhanced PVDF membrane surface and (c) the achieved water permeance and salt rejection from these membranes. Copyrights obtained from Elsevier (Lee et al. 2019)

their synthesis route. Accordingly, their applications in water treatment are also affected by these parameters. For example, antibacterial activity, adsorption of heavy metal, and degradation of pollutant dyes from wastewater are all reported applications of NMs that are sensitive to the synthesis route. Membrane modifications using NMs, with different chemical compositions, are discussed in section 5 . These include single elements, oxides, nanotubes and mixed composites of oxides and polymers. Oxide NMs, such as $\mathrm{ZnO}$, $\mathrm{TiO}_{2}$ and $\mathrm{SiO}_{2}$ are found widely in research as membrane enhancers. Other chemical compositions, such as ferrites, are not as widely investigated, although they have shown potential in other water treatment applications. The modification processes that can be found in literature target either the membranes active layer or its support layer. NMs are most commonly incorpo- rated during the fabrication of these membrane layers. However, membrane surface modification can also be achieved by coating them with NMs post membrane fabrication. Most studies show an optimum concentration of NMs where the best performance is obtained, as NMs tend to agglomerate in high concentrations, which has a negative effect on their application. Composites of NMs or the combination of NMs and polymers show promising results, as their individual properties are joined together. The weight of each NMs within the composite is found to alter the membrane properties and its separation efficiency. Other chemical additives, such as acids and amine groups, show a considerable improvement in the enhancement process.

In water treatment applications of NMs, such as in adsorption and the photocatalysis of pollutants, the characteristics of NMs are widely studied. In these ap- 
plications, the NMs synthesis route is reported to have or effect on their properties, and hence also on their application in water treatment. However, studies considering NMs for the enhancement of water purification membranes are found to rarely investigate the effect of the NMs morphology and its properties, such ies are summarised that actually investigate the effect of the NM morphology on the membrane performance. In general, a knowledge gap exists as to how the NM synthesis route and the resulting NM properties and orphology affect the membrane performance.

The reported studies investigate the membrane performance mainly in terms of fouling propensity, chlorine resistance, water and salt permeability for RO and FO. As it appears in our search, no attempts have been made to investigate the performance of enhanced membranes in OARO and PAFO processes.

\section{References}

Abbaszadeh, M., Krizak, D. \& Kundu, S. (2019), 'Layer-by-layer assembly of graphene oxide nanoplatelets embedded desalination membranes with improved chlorine resistance', Desalination 470, 114116.

Abdelghany, T. M., Al-Rajhi, A. M. H., Al Abboud, M. A., Alawlaqi, M. M., Ganash Magdah, A., Helmy, E. A. M. \& Mabrouk, A. S. (2018), 'Recent Advances in Green Synthesis of Silver Nanoparticles and Their Applications: About Future Directions. A Review', BioNanoScience 8(1), 5-16.

Ahmed, F. E., Lalia, B. S. \& Hashaikeh, R. (2015), 'A review on electrospinning for membrane fabrication: Challenges and applications', Desalination 356, 15-30.

Alkaisi, A., Mossad, R. \& Sharifian-Barforoush, A. (2017), 'A Review of the Water Desalination Systems Integrated with Renewable Energy', Energy Procedia 110, 268-274.

Anbarasu, M., Anandan, M., Chinnasamy, E., Gopinath, V. \& Balamurugan, K. (2015), 'Synthesis and characterization of polyethylene glycol (PEG) coated Fe3O4 nanoparticles by chemical co-precipitation method for biomedical applications', Spectrochimica Acta Part A: Molecular and Biomolecular Spectroscopy 135, 536-539.

Ang, M. B. M. Y., Trilles, C. A., Guzman, M. R. D., Pereira, J. M., Aquino, R. R., Huang, S.-H., Hu, C.-C., Lee, K.R. \& Lai, J.-Y. (2019), 'Improved performance of thin-film nanocomposite nanofiltration membranes as induced by embedded polydopamine-coated silica nanoparticles', Separation and Purification Technology 224, 113 - 120.

Anis, S. F., Lalia, B. S., Mostafa, A. O. \& Hashaikeh, R. (2017), 'Electrospun nickel-tungsten oxide composite fibers as active electrocatalysts for hydrogen evolution reaction', Journal of Materials Science 52(12), 7269-7281.

URL: https://doi.org/10.1007/s10853-017-0964-2

Asiah, M. N., Mamat, M. H., Khusaimi, Z., Abdullah, S., Rusop, M. \& Qurashi, A. (2015), 'Surfactant-free seed-mediated large-scale synthesis of mesoporous TiO2 nanowires', Ceramics International 41(3, Part A), 4260-4266.

Atchudan, R., Edison, T. N. J. I., Perumal, S., Karthikeyan, D. \& Lee, Y. R. (2016), 'Facile synthesis of zinc oxide nanoparticles decorated graphene oxide composite via simple solvothermal route and their photocatalytic activity on methylene blue degradation', Journal of Photochemistry and Photobiology B: Biology 162, 500-510.

\section{Abbreviations \\ AFM Atomic Force Microscopy \\ AL-DS Active layer - draw side \\ AL-FS Active layer - feed side \\ BSA Bovine Serum Albumin \\ CDs Carbon dots \\ CECP Cake-enhanced concentration polarisation \\ CNT Carbon Nanotubes \\ CTA Cellulose acetate \\ DMF Dimethylformamide \\ DS Draw side}

DSARO Draw solution assisted reverse osmosis

ECP External concentration polarisation

EPS Extracellular polymeric substances

FESEM Field emission scanning electron microscope

FO Forward osmosis

FS Feed side

GO Graphene oxide

ICP Internal concentration polarisation

LDH Layer double hydroxyl

MPD M-phenylenediamine

MVC Mechanical vapour compression

NIPS Non-solvent Induced Phase Separation

NM Nanomaterial

NP Nanoparticle

OARO Osmotically assisted reverse osmosis

OED Osmotically-enhanced dewatering

PA Polyamide

PAFO Pressure assisted FO

PANI Polyaniline

PDA Ploydopamine

PEG Polyethylene glycol

PEI Polyethylenimine

PRO Pressure retarded osmosis

PSF Polysulfone

PVA Polyvinyl alcohol

ROS Regenerated oxidative substances

RST Reverse solute transport

SEC Specific energy consumption

SEM Scanning electronmicroscopy

SFRO Split feed reverse osmosis

TEM Transmission electron microscope

TFC Thin-film composite

TMC Trimesoylchloride

TNT Titanium nanotubes

UF Ultrafiltration

UV Ultraviolet

XRD X-ray diffraction 


\begin{tabular}{|ll|}
\hline Nomenclature \\
$A$ & Water permeability coefficient, \\
& $L \cdot m^{-2} \cdot s^{-1} \cdot$ bar $^{-1}$ \\
& Salt permeability coefficient, \\
& $L \cdot m^{-2} \cdot h^{-1}$ \\
& Salt flux, $g \cdot m^{-2} \cdot h^{-1}$ \\
$J_{S}$ & Water flux, $L \cdot m^{-2} \cdot h^{-1}$ \\
$J_{W}$ & $L \cdot m^{-2} \cdot h^{-1}$ \\
& $L \cdot m^{-2} \cdot h^{-1}$ \\
& $L \cdot m^{-2} \cdot h^{-1}$ \\
& FO feed pressure, bar \\
$P_{F O}$ & OARO feed pressure, bar \\
$P_{O A R O}$ & PAFO feed pressure, bar \\
$P_{P A F O}$ & RO feed pressure, bar \\
$P_{R O}$ & Draw flowrate, $m^{3} \cdot s^{-1}$ \\
$Q_{D}$ & Feed flowrate, $m^{3} \cdot s^{-1}$ \\
$Q_{F}$ & Structural parameter, $m$ \\
$S$ & RO system recovery, $\%$ \\
$Y_{R O}$ & Second law efficiency \\
$\eta_{I I}$ & Transmembrane pressure difference, bar \\
$\Delta P$ & Osmotic pressure difference, bar \\
$\Delta \pi$ & Osmotic pressure of brine solution, bar \\
$\pi_{B}$ & Osmotic pressure of draw solution, bar \\
$\pi_{D}$ & Osmotic pressure of feed solution, bar \\
$\pi_{F}$ & \\
& \\
\hline & \\
\hline
\end{tabular}

Bacchin, P., Aimar, P. \& Field, R. W. (2006), 'Critical and sustainable fluxes: Theory, experiments and applications', Journal of Membrane Science 281(1), 42-69.

Badruzzaman, M., Voutchkov, N., Weinrich, L. \& Jacangelo, J. G. (2019), 'Selection of pretreatment technologies for seawater reverse osmosis plants: A review', Desalination 449, 7891.

Bartholomew, T. V., Mey, L., Arena, J. T., Siefert, N. S. \& Mauter, M. S. (2017), 'Osmotically assisted reverse osmosis for high salinity brine treatment', Desalination 421, 3-11.

Bazazi, S., Arsalani, N., Khataee, A. \& Tabrizi, A. G. (2018), 'Comparison of ball milling-hydrothermal and hydrothermal methods for synthesis of $\mathrm{ZnO}$ nanostructures and evaluation of their photocatalytic performance', Journal of Industrial and Engineering Chemistry 62, 265-272.

Behnajady, M. A., Eskandarloo, H., Modirshahla, N. \& Shokri, M. (2011), 'Investigation of the effect of solgel synthesis variables on structural and photocatalytic properties of $\mathrm{TiO} 2$ nanoparticles', Desalination 278(1), 10-17.

Ben-Dov, E., Ben-David, E., Messalem, R., Herzberg, M. \& Kushmaro, A. (2016), 'Biofilm formation on RO membranes: the impact of seawater pretreatment', Desalination and $\mathrm{Wa}$ ter Treatment 57(11), 4741-4748.

Ben-Sasson, M., Lu, X., Bar-Zeev, E., Zodrow, K. R., Nejati, S., Qi, G., Giannelis, E. P. \& Elimelech, M. (2014), 'In situ formation of silver nanoparticles on thin-film composite reverse osmosis membranes for biofouling mitigation', Water Research 62, 260-270.

Bethi, B., Sonawane, S. H., Bhanvase, B. A. \& Gumfekar, S. P. (2016), 'Nanomaterials-based advanced oxidation processes for wastewater treatment: A review', Chemical Engineering and Processing: Process Intensification 109, 178-189.

Bhalla, V. \& Tyagi, H. (2018), 'Parameters influencing the performance of nanoparticles-laden fluid-based solar thermal collectors: A review on optical properties', Renewable and Sus-
Boretti, A., Al-Zubaidy, S., Vaclavikova, M., Al-Abri, M., Castelletto, S. \& Mikhalovsky, S. (2018), 'Outlook for graphene-based desalination membranes', npj Clean Water $\mathbf{1}(1), 5-$.

Bouma, A. T. \& Lienhard, J. H. (2018), 'Split-feed counterflow reverse osmosis for brine concentration', Desalination 445, 280-291.

Bououdina, M., Al-Najar, B., Falamarzi, L., Judith Vijaya, J., Shaikh, M. N. \& Bellucci, S. (2019), 'Effect of annealing on phase formation, microstructure and magnetic properties of $\mathrm{MgFe} 2 \mathrm{O} 4$ nanoparticles for hyperthermia', The European Physical Journal Plus 134(3), 84.

URL: https://doi.org/10.1140/epjp/i2019-12485-5

Bououdina, M., Alwqyan, T. S., Khezami, L., Al-Najar, B., Shaikh, M. N., Gill, R., Modwi, A., Taha, K. K. \& Lemine, O. M. (2019), 'Fabrication and characterization of nanostructured $\mathrm{MgO} \cdot \mathrm{Fe} 2 \mathrm{O} 3$ composite by mechanical milling as efficient adsorbent of heavy metals', Journal of Alloys and Compounds 772, 1030-1039.

Bozorgi, M., Abbasizadeh, S., Samani, F. \& Mousavi, S. E. 2085 (2018), 'Performance of synthesized cast and electrospun PVA/chitosan/ZnO-NH2 nano-adsorbents in single and simultaneous adsorption of cadmium and nickel ions from wastewater', Environmental Science and Pollution Research 25(18), 17457-17472.

URL: https://doi.org/10.1007/s11356-018-1936-z

Bui, N.-N. \& McCutcheon, J. R. (2016), 'Nanoparticle-embedded nanofibers in highly permselective thin-film nanocomposite membranes for forward osmosis', Journal of Membrane Science 518, 338-346.

Cai, Y. \& Hu, X. M. (2016), 'A critical review on draw solutes development for forward osmosis', Desalination 391, 16-29.

Chan, W.-F., Marand, E. \& Martin, S. M. (2016), 'Novel zwitterion functionalized carbon nanotube nanocomposite membranes for improved RO performance and surface anti-biofouling resistance', Journal of Membrane Science 509, 125-137.

Chen, D., Ai, S., Liang, Z. \& Wei, F. (2016), 'Preparation and photocatalytic properties of zinc oxide nanoparticles by microwave-assisted ball milling', Ceramics International 42(2, Part B), 3692-3696.

Chen, K., Xiao, C., Huang, Q., Liu, H. \& Tang, Y. (2018), 'Fabrication and properties of graphene oxide-embedded cellulose triacetate RO composite membrane via melting method', Desalination 425, 175-184.

Chen, X. \& Yip, N. Y. (2018), 'Unlocking High-Salinity Desalination with Cascading Osmotically Mediated Reverse Osmosis: Energy and Operating Pressure Analysis', Environmental Science \& Technology 52(4), 2242-2250.

Chesters, S. P., Pena, N., Gallego, S., Fazel, M., Armstrong, M. W. \& del Vigo, F. (2013), 'Results from 99 seawater RO membrane autopsies', IDA Journal of Desalination and Water Reuse 5(1), 40-47.

Chong, T. H., Wong, F. S. \& Fane, A. G. (2008), 'Implications of critical flux and cake enhanced osmotic pressure (CEOP) on colloidal fouling in reverse osmosis: Experimental observations', Journal of Membrane Science 314(1), 101-111.

Cohen-Tanugi, D. \& Grossman, J. C. (2012), 'Water Desalination across Nanoporous Graphene', Nano Lett. 12(7), 36023608 .

Cohen-Tanugi, D., McGovern, R. K., Dave, S. H., Lienhard, J. H. \& Grossman, J. C. (2014), 'Quantifying the potential of ultra-permeable membranes for water desalination', Energy Environ. Sci. 7(3), 1134-1141. 
Combernoux, N., Schrive, L., Labed, V., Wyart, Y., Carretier, E. \& Moulin, P. (2017), 'Treatment of radioactive liquid effluents by reverse osmosis membranes: From lab-scale to pilot-scale', Water Research 123, 311-320.

Corry, B. (2008), 'Designing Carbon Nanotube Membranes for Efficient Water Desalination', J. Phys. Chem. B $112(5), 1427-1434$.

Daer, S., Kharraz, J., Giwa, A. \& Hasan, S. W. (2015), 'Recent applications of nanomaterials in water desalination: A critical review and future opportunities', Desalination 367, 37-48.

Da'na, E. (2017), 'Adsorption of heavy metals on functionalizedmesoporous silica: A review', Microporous and Mesoporous Materials 247, 145-157.

Darabi, R. R., Peyravi, M. \& Jahanshahi, M. (2019), 'Modified forward osmosis membranes by two amino-functionalized zno nanoparticles: A comparative study', Chemical Engineering Research and Design 145, 85 - 98.

Darezereshki, E., khodadadi Darban, A., Abdollahy, M. \& Jamshidi-Zanjani, A. (2018), 'Influence of heavy metals on the adsorption of arsenate by magnetite nanoparticles: Kinetics and thermodynamic', Environmental Nanotechnology, Monitoring \& Management 10, 51-62.

Dong, H., Zhao, L., Zhang, L., Chen, H., Gao, C. \& Winston Ho, W. S. (2015), 'High-flux reverse osmosis membranes incorporated with $\mathrm{NaY}$ zeolite nanoparticles for brackish water desalination', Journal of Membrane Science 476, 373-383.

Du, H., Thompson, A. \& Wang, X., eds (2018), Osmotically Driven Membrane Processes, IntechOpen.

Elimelech, M. \& Phillip, W. A. (2011), 'The Future of Seawater Desalination: Energy, Technology, and the Environment', Science 333(6043), 712-717.

Eyvaz, M., Aslan, T., Arslan, S., Yuksel, E. \& Koyuncu, I. (2016), 'Recent developments in forward osmosis membrane bioreactors: a comprehensive review', Desalination and Water Treatment 57(59), 28610-28645.

F de Roever, E. W., Fazel, M. \& Hallsby, A. (2009), 'Permeate Spacer Imprints on SWRO Membranes: Evidence for Intrusion and Compaction', IDA Wolrd Congress (January).

Fane, A. G. T. (2018), 'A grand challenge for membrane desalination: More water, less carbon', Desalination 426, 155-163.

Fathizadeh, M., Tien, H. N., Khivantsev, K., Song, Z., Zhou, F. \& Yu, M. (2019), 'Polyamide/nitrogen-doped graphene oxide quantum dots (n-goqd) thin film nanocomposite reverse osmosis membranes for high flux desalination', Desalination 451, 125 - 132. Nanomaterials for Water Desalination: Recent Advances and Future Challenges.

Franken, A. C. M. (2009), 'Prevention and control of membrane fouling: Practical implications and examining recent innovations', Membraan Applicatie Centrum Twente b.v.

Fu, Y., Liu, X. \& Chen, G. (2019), 'Adsorption of heavy metal sewage on nano-materials such as titanate/TiO2 added lignin', Results in Physics 12, 405-411.

Gajanan, K. \& Tijare, S. N. (2018), 'Applications of nanomaterials', Materials Today: Proceedings 5(1, Part 1), 1093-1096.

Galizia, P., Cernea, M., Mihalache, V., Diamandescu, L., Maizza, G. \& Galassi, C. (2017), 'Easy batch-scale production of cobalt ferrite nanopowders by two-step milling: Structural and magnetic characterization', Materials \& Design 130, 327 335.

Gallo, A., Bianco, C., Tosco, T., Tiraferri, A. \& Sethi, R. (2019), 'Synthesis of eco-compatible bimetallic silver/iron nanoparticles for water remediation and reactivity assessment on bromophenol blue', Journal of Cleaner Production 211, 13671374 .
Ge, L., Wang, W., Peng, Z., Tan, F., Wang, X., Chen, J. \& Qiao, X. (2018), 'Facile fabrication of Fe@MgO magnetic nanocomposites for efficient removal of heavy metal ion and dye from water', Powder Technology 326, 393-401.

Ge, Q., Amy, G. L. \& Chung, T.-S. (2017), 'Forward osmosis for oily wastewater reclamation: Multi-charged oxalic acid complexes as draw solutes', Water Research 122, 580-590.

Ghosh, A. K. \& Hoek, E. M. V. (2009), 'Impacts of support membrane structure and chemistry on polyamide-polysulfone interfacial composite membranes', Journal of Membrane Science 336(1), 140-148.

Ghosh, B. K., Hazra, S., Naik, B. \& Ghosh, N. N. (2015), 'Preparation of $\mathrm{Cu}$ nanoparticle loaded SBA-15 and their excellent catalytic activity in reduction of variety of dyes', Powder Technology 269, 371-378.

Giwa, A., Akther, N., Dufour, V. \& Hasan, S. W. (2016), 'A critical review on recent polymeric and nano-enhanced mem- 2210 branes for reverse osmosis', RSC Adv. 6(10), 8134-8163.

Harvey, D. (2000), Modern analytical chemistry, McGraw-Hill Companies, Inc., Boston.

Hasnidawani, J. N., Azlina, H. N., Norita, H., Bonnia, N. N., Ratim, S. \& Ali, E. S. (2016), 'Synthesis of ZnO Nanostructures 2215 Using Sol-Gel Method', Procedia Chemistry 19, 211-216.

Ho, J. S., Sim, L. N., Gu, J., Webster, R. D., Fane, A. G. \& Coster, H. G. L. (2016), 'A threshold flux phenomenon for colloidal fouling in reverse osmosis characterized by transmembrane pressure and electrical impedance spectroscopy', Journal of Membrane Science 500, 55-65.

Hoek, E. M. V. \& Elimelech, M. (2003), 'Cake-Enhanced Concentration Polarization: A New Fouling Mechanism for SaltRejecting Membranes', Environ. Sci. Technol. 37(24), 55815588 .

Hu, D., Zhao, F., Zhang, Z., Miao, L., Ma, R., Zhao, W., Ren, L., Zhang, G., Zhai, L., Wang, D. \& Dou, S. (2018), 'Synthesis and magnetic properties of monodisperse $\mathrm{CoFe} 2 \mathrm{O} 4$ nanoparticles coated by SiO2', Ceramics International 44(18), 2246222466 .

Hu, Z., Antony, A., Leslie, G. \& Le-Clech, P. (2014), 'Real-time monitoring of scale formation in reverse osmosis using electrical impedance spectroscopy', Journal of Membrane Science 453, 320-327.

Jamdagni, P., Khatri, P. \& Rana, J. S. (2018), 'Green synthesis of zinc oxide nanoparticles using flower extract of Nyctanthes arbor-tristis and their antifungal activity', Journal of King Saud University - Science 30(2), 168-175.

Jia, H., Wu, Z. \& Liu, N. (2017), 'Effect of nano-zno with different particle size on the performance of pvdf composite membrane', Plastics, Rubber and Composites 46(1), 1-7. URL: https://doi.org/10.1080/14658011.2016.1245032

Jiang, S., Li, Y. \& Ladewig, B. P. (2017), 'A review of reverse osmosis membrane fouling and control strategies', Science of The Total Environment 595, 567-583.

Jithendra Kumara, K. S., Krishnamurthy, G., Sunil Kumar, N., Naik, N. \& Praveen, T. M. (2018), 'Sustainable synthesis of magnetically separable $\mathrm{SiO} 2 / \mathrm{Co} @ \mathrm{Fe} 2 \mathrm{O} 4$ nanocomposite and its catalytic applications for the benzimidazole synthesis', Journal of Magnetism and Magnetic Materials 451, 808-821.

Kaplan, R., Erjavec, B., Dražić, G., Grdadolnik, J. \& Pintar, A. (2016), 'Simple synthesis of anatase/rutile/brookite TiO2 nanocomposite with superior mineralization potential for photocatalytic degradation of water pollutants', Applied Catalysis B: Environmental 181, 465-474. 15 
Karimi, A., Khataee, A., Vatanpour, V. \& Safarpour, M. (2019), 'High-flux pvdf mixed matrix membranes embedded with sizecontrolled zif-8 nanoparticles', Separation and Purification Technology 229, 115838.

Karkooti, A., Yazdi, A. Z., Chen, P., McGregor, M., Nazemifard, N. \& Sadrzadeh, M. (2018), 'Development of advanced nanocomposite membranes using graphene nanoribbons and nanosheets for water treatment', Journal of Membrane Science 560, 97 - 107.

Kaur, P., Chawla, S. K., Meena, S. S., Yusuf, S. M. \& Narang, S. B. (2016), 'Synthesis of Co-Zr doped nanocrystalline strontium hexaferrites by sol-gel auto-combustion route using sucrose as fuel and study of their structural, magnetic and electrical properties', Ceramics International 42(13), 1447514489 .

Khajouei, M., Jahanshahi, M. \& Peyravi, M. (2018), 'Biofouling mitigation of TFC membrane by in-situ grafting of PANI/Cu couple nanoparticle', Journal of the Taiwan Institute of Chemical Engineers 85, 237-247.

Khan, M. F., Ansari, A. H., Hameedullah, M., Ahmad, E., Husain, F. M., Zia, Q., Baig, U., Zaheer, M. R., Alam, M. M., Khan, A. M., AlOthman, Z. A., Ahmad, I., Ashraf, G. M. \& Aliev, G. (2016), 'Sol-gel synthesis of thorn-like ZnO nanoparticles endorsing mechanical stirring effect and their antimicrobial activities: Potential role as nano-antibiotics', Scientific Reports 6, 27689.

URL: https://doi.org/10.1038/srep27689

Khin, M. M., Nair, A. S., Babu, V. J., Murugan, R. \& Ramakrishna, S. (2012), 'A review on nanomaterials for environmental remediation', Energy Environ. Sci. 5(8), 8075-8109.

URL: $h t t p: / / d x$.doi.org/10.1039/C2EE21818F

Khot, A. C., Desai, N. D., Khot, K. V., Salunkhe, M. M., Chougule, M. A., Bhave, T. M., Kamat, R. K., Musselman, K. P. \& Dongale, T. D. (2018), 'Bipolar resistive switching and memristive properties of hydrothermally synthesized TiO2 nanorod array: Effect of growth temperature', Materials 8 Design 151, 37-47.

Kim, J., Kim, D. I. \& Hong, S. (2018), 'Analysis of an osmotically-enhanced dewatering process for the treatment of highly saline (waste)waters', Journal of Membrane Science 548, 685-693.

Kim, S. G., Hyeon, D. H., Chun, J. H., Chun, B.-H. \& Kim, S. H. (2013), 'Nanocomposite poly(arylene ether sulfone) reverse osmosis membrane containing functional zeolite nanoparticles for seawater desalination', Journal of Membrane Science 443, 10-18.

Kim, Y. C. \& Elimelech, M. (2012), 'Adverse Impact of Feed Channel Spacers on the Performance of Pressure Retarded Osmosis', Environ. Sci. Technol. 46(8), 4673-4681.

Kombaiah, K., Vijaya, J. J., Kennedy, L. J., Bououdina, M., Ramalingam, R. J. \& Al-Lohedan, H. A. (2018), 'Okra extractassisted green synthesis of $\mathrm{CoFe} 2 \mathrm{O} 4$ nanoparticles and their optical, magnetic, and antimicrobial properties', Materials Chemistry and Physics 204, 410-419.

Kumar, R., Umar, A., Kumar, G. \& Nalwa, H. S. (2017), 'Antimicrobial properties of $\mathrm{ZnO}$ nanomaterials: A review', $\mathrm{Ce}$ ramics International 43(5), 3940-3961.

Le, N. L. \& Nunes, S. P. (2016), 'Materials and membrane technologies for water and energy sustainability', Sustainable Materials and Technologies 7, 1-28.

Lee, J., Kook, S., Lee, C. \& Kim, I. S. (2017), 'Effect of intermittent pressure-assisted forward osmosis (I-PAFO) on organic fouling', Desalination 419, 60-69.
Lee, K. P., Arnot, T. C. \& Mattia, D. (2011), 'A review of reverse osmosis membrane materials for desalination: Development to date and future potential', Journal of Membrane Science $\mathbf{3 7 0}(1), 1-22$.

Lee, S., Boo, C., Elimelech, M. \& Hong, S. (2010), 'Comparison of fouling behavior in forward osmosis (FO) and reverse osmosis (RO)', Journal of Membrane Science 365(1), 34-39.

Lee, T. H., Oh, J. Y., Hong, S. P., Lee, J. M., Roh, S. M., Kim, S. H. \& Park, H. B. (2019), 'Zif-8 particle size effects on reverse osmosis performance of polyamide thin-film nanocomposite membranes: Importance of particle deposition', Journal of Membrane Science 570-571, 23 - 33.

Li, K., Lee, B. \& Kim, Y. (2019), 'High performance reverse osmosis membrane with carbon nanotube support layer', Journal of Membrane Science 592, 117358.

Li, Q., Yang, D., Shi, J., Xu, X., Yan, S. \& Liu, Q. (2016), 'Biomimetic modification of large diameter carbon nanotubes and the desalination behavior of its reverse osmosis membrane', Desalination 379, 164 - 171.

Li, Y., Li, S. \& Zhang, K. (2017), 'Influence of hydrophilic carbon dots on polyamide thin film nanocomposite reverse osmosis membranes', Journal of Membrane Science 537, 42-53.

Li, Z., Valladares Linares, R., Bucs, S., Fortunato, L., HélixNielsen, C., Vrouwenvelder, J. S., Ghaffour, N., Leiknes, T. \& Amy, G. (2017), 'Aquaporin based biomimetic membrane in forward osmosis: Chemical cleaning resistance and practical operation', Desalination 420, 208-215.

Liao, Y., Jiang, H., Wei, N., Laiho, P., Zhang, Q., Khan, S. A. \& Kauppinen, E. I. (2018), 'Direct Synthesis of Colorful SingleWalled Carbon Nanotube Thin Films', Journal of the American Chemical Society 140(31), 9797-9800.

Lingamdinne, L. P., Choi, Y.-L., Kim, I.-S., Yang, J.-K., Koduru, J. R. \& Chang, Y.-Y. (2017), 'Preparation and characterization of porous reduced graphene oxide based inverse spinel nickel ferrite nanocomposite for adsorption removal of radionuclides', Journal of Hazardous Materials 326, 145-156.

Lisjak, D. \& Mertelj, A. (2018), 'Anisotropic magnetic nanoparticles: A review of their properties, syntheses and potential applications', Progress in Materials Science 95, 286-328.

Liu, C., Lee, J., Small, C., Ma, J. \& Elimelech, M. (2017), 'Comparison of organic fouling resistance of thin-film composite membranes modified by hydrophilic silica nanoparticles and zwitterionic polymer brushes', Journal of Membrane Science $\mathbf{5 4 4}, 135-142$.

Liu, K.-K., Shan, C.-X., Zhou, R., Zhao, Q. \& Shen, D.-Z. (2017), 'Large-scale synthesis of $\mathrm{ZnO}$ nanoparticles and their application as phosphors in light-emitting devices', Optical Materials Express 7(7), 2682-2690.

Liu, L., Xie, X., Qi, S., Li, R., Zhang, X., Song, X. \& Gao, C. (2019), 'Thin film nanocomposite reverse osmosis membrane incorporated with uio-66 nanoparticles for enhanced boron removal', Journal of Membrane Science 580, 101 - 109.

Liu, Q., Xu, Y.-R., Wang, A.-J. \& Feng, J.-J. (2016), 'A single-step route for large-scale synthesis of coreshell palladium@platinum dendritic nanocrystals/reduced graphene oxide with enhanced electrocatalytic properties', Journal of Power Sources 302, 394-401.

Lotfi, F., Chekli, L., Phuntsho, S., Hong, S., Choi, J. Y. \& Shon, H. K. (2017), 'Understanding the possible underlying mechanisms for low fouling tendency of the forward osmosis and pressure assisted osmosis processes', Desalination 421, 89-98.

Lu, P., Liang, S., Qiu, L., Gao, Y. \& Wang, Q. (2016), 'Thin film nanocomposite forward osmosis membranes based on layered double hydroxide nanoparticles blended substrates', Journal of Membrane Science 504, 196-205. 
Lu, P., Liang, S., Zhou, T., Xue, T., Mei, X. \& Wang, Q. (2017), 'Layered double hydroxide nanoparticle modified forward osmosis membranes via polydopamine immobilization with significantly enhanced chlorine and fouling resistance', Desalination 421, 99-109.

Lu, X., Feng, X., Yang, Y., Jiang, J., Cheng, W., Liu, C., Gopinadhan, M., Osuji, C. O., Ma, J. \& Elimelech, M. (2019), 'Tuning the permselectivity of polymeric desalination membranes via control of polymer crystallite size', Nature Communications 10(1), 2347.

Ma, W., Soroush, A., Van Anh Luong, T., Brennan, G., Rahaman, M. S., Asadishad, B. \& Tufenkji, N. (2016), 'Sprayand spin-assisted layer-by-layer assembly of copper nanoparticles on thin-film composite reverse osmosis membrane for biofouling mitigation', Water Research 99, 188-199.

Maddinedi, S. B., Mandal, B. K. \& Anna, K. K. (2017), 'Environment friendly approach for size controllable synthesis of biocompatible Silver nanoparticles using diastase', Environmental Toxicology and Pharmacology 49, 131-136.

Madsen, H. T., Nissen, S. S., Muff, J. \& Søgaard, E. G. (2017), 'Pressure retarded osmosis from hypersaline solutions: Investigating commercial FO membranes at high pressures', Desalination 420, 183-190.

Mahy, J. G., Lambert, S. D., Léonard, G. L. M., Zubiaur, A., Olu, P.-Y., Mahmoud, A., Boschini, F. \& Heinrichs, B. (2016), 'Towards a large scale aqueous sol-gel synthesis of doped TiO2: Study of various metallic dopings for the photocatalytic degradation of p-nitrophenol', Journal of Photochemistry and Photobiology A: Chemistry 329, 189-202.

Mansournia, M. \& Ghaderi, L. (2017), 'CuO@ZnO core-shell nanocomposites: Novel hydrothermal synthesis and enhancement in photocatalytic property', Journal of Alloys and Compounds 691, 171-177.

Mayyahi, A. A. (2018), 'Thin-film composite (TFC) membrane modified by hybrid $\mathrm{ZnO}$-graphene nanoparticles $(\mathrm{ZnO}-$ Gr NPs) for water desalination', Journal of Environmental Chemical Engineering 6(1), 1109-1117.

McGinnis, R. L., Hancock, N. T., Nowosielski-Slepowron, M. S. \& McGurgan, G. D. (2013), 'Pilot demonstration of the NH3/CO2 forward osmosis desalination process on high salinity brines', Desalination 312, 67-74.

Mezher, T., Fath, H., Abbas, Z. \& Khaled, A. (2011), 'Technoeconomic assessment and environmental impacts of desalination technologies', Desalination 266(1), 263-273.

Mi, B. \& Elimelech, M. (2010), 'Gypsum Scaling and Cleaning in Forward Osmosis: Measurements and Mechanisms', Environ. Sci. Technol. 44(6), 2022-2028.

Mitra, P., Chakraborty, P. K., Saha, P., Ray, P. \& Basu, S. (2014), 'Antibacterial efficacy of acridine derivatives conjugated with gold nanoparticles', International Journal of Pharmaceutics 473(1), 636-643.

Modwi, A., Taha, K. K., Khezami, L., Bououdina, M. \& Houas, A. (2019), 'Silver decorated $\mathrm{Cu} / \mathrm{ZnO}$ photocomposite: efficient green degradation of malachite', Journal of Materials Science: Materials in Electronics 30(4), 3629-3638.

Morillo, J., Usero, J., Rosado, D., Bakouri, H. E., Riaza, A. \& Bernaola, F.-J. (2014), 'Comparative study of brine management technologies for desalination plants', Desalination 336, 32-49.

Mujeeb Rahman, P., Abdul Mujeeb, V. M., Muraleedharan, K. \& Thomas, S. K. (2018), 'Chitosan/nano ZnO composite films: Enhanced mechanical, antimicrobial and dielectric properties', Arabian Journal of Chemistry 11(1), 120-127.
Mutuma, B. K., Shao, G. N., Kim, W. D. \& Kim, H. T. (2015), 'Solgel synthesis of mesoporous anatasebrookite and anatasebrookiterutile $\mathrm{TiO} 2$ nanoparticles and their photocatalytic properties', Journal of Colloid and Interface Science 442, 17.

Nahas, M. N., Jilani, A. \& Salah, N. (2016), 'Microwave synthesis of ultrathin, non-agglomerated $\mathrm{CuO}$ nanosheets and their evaluation as nanofillers for polymer nanocomposites', Journal of Alloys and Compounds 680, 350-358.

Nasir, A., Masood, F., Yasin, T. \& Hameed, A. (2019), 'Progress in polymeric nanocomposite membranes for wastewater treatment: Preparation, properties and applications', Journal of Industrial and Engineering Chemistry 79, 29 - 40.

Nguyen, A., Zou, L. \& Priest, C. (2014), 'Evaluating the antifouling effects of silver nanoparticles regenerated by $\mathrm{TiO} 2$ on forward osmosis membrane', Journal of Membrane Science 454, 264-271.

Nguyen, T.-T., Kook, S., Lee, C., Field, R. W. \& Kim, I. S. (2019), 'Critical flux-based membrane fouling control of forward osmosis: Behavior, sustainability, and reversibility', Journal of Membrane Science 570-571, 380-393.

Niksefat, N., Jahanshahi, M. \& Rahimpour, A. (2014), 'The effect of SiO2 nanoparticles on morphology and performance of thin film composite membranes for forward osmosis application', Desalination 343, 140-146.

Oh, Y., Lee, S., Elimelech, M., Lee, S. \& Hong, S. (2014), 'Effect of hydraulic pressure and membrane orientation on water flux and reverse solute flux in pressure assisted osmosis', Journal of Membrane Science 465, 159-166.

Ong, C. S., Goh, P. S., Lau, W. J., Misdan, N. \& Ismail, A. F (2016), 'Nanomaterials for biofouling and scaling mitigation of thin film composite membrane: A review', Desalination 393, 2-15.

Orge, C. A., Soares, O. S. G. P., Faria, J. L. \& Pereira, M. F. R. (2017), 'Synthesis of TiO2-Carbon Nanotubes through ballmilling method for mineralization of oxamic acid (OMA) by photocatalytic ozonation', Journal of Environmental Chemical Engineering 5(6), 5599-5607.

Ostovari Moghaddam, A., Shokuhfar, A., Cabot, A. \& Zolriasatein, A. (2018), 'Synthesis of bornite Cu5FeS4 nanoparticles via high energy ball milling: Photocatalytic and thermoelectric properties', Powder Technology 333, 160-166.

Padaki, M., Emadzadeh, D., Masturra, T. \& Ismail, A. F. (2015), 'Antifouling properties of novel PSf and TNT composite membrane and study of effect of the flow direction on membrane washing', Desalination 362, 141-150.

Palla, R., Karade, S. R., Mishra, G., Sharma, U. \& Singh, L. P. (2017), 'High strength sustainable concrete using silica nanoparticles', Construction and Building Materials 138, 285-295.

Pattnaik, S. P., Behera, A., Martha, S., Acharya, R. \& Parida, K. (2018), 'Synthesis, photoelectrochemical properties and solar light-induced photocatalytic activity of bismuth ferrite nanoparticles', Journal of Nanoparticle Research 20(1), 10.

Pendergast, M. M., Nowosielski-Slepowron, M. S. \& Tracy, J. (2016), 'Going big with forward osmosis', Desalination and Water Treatment 57(55), 26529-26538.

Peters, C. \& Hankins, N. (2019), 'Osmotically assisted reverse osmosis (OARO): Five approaches to dewatering saline brines using pressure-driven membrane processes', Desalination .

Petrović, S., Rožić, L., Jović, V., Stojadinović, S., Grbić, B., Radić, N., Lamovec, J. \& Vasilić, R. (2018), 'Optimization of a nanoparticle ball milling process parameters using the response surface method', Advanced Powder Technology 29(9), 2129-2139. . 
Pineda-Reyes, A. M. \& Olvera, M. d. l. L. (2018), 'Synthesis of $\mathrm{ZnO}$ nanoparticles from water-in-oil (w/o) microemulsions', Materials Chemistry and Physics 203, 141-147.

Pinjari, D. V., Prasad, K., Gogate, P. R., Mhaske, S. T. \& Pandit, A. B. (2015), 'Synthesis of titanium dioxide by ultrasound assisted solgel technique: Effect of calcination and sonication time', Ultrasonics Sonochemistry 23, 185-191.

Politano, A., Profio, G. D., Fontananova, E., Sanna, V., Cupolillo, A. \& Curcio, E. (2019), 'Overcoming temperature polarization in membrane distillation by thermoplasmonic effects activated by ag nanofillers in polymeric membranes', Desalination 451, 192 - 199. Nanomaterials for Water Desalination: Recent Advances and Future Challenges. 'A new nanocomposite forward osmosis membrane customdesigned for treating shale gas wastewater', Scientific Reports 5, 14530

Qu, Y., He, F., Yu, C., Liang, X., Liang, D., Ma, L., Zhang, Q., Lv, J. \& Wu, J. (2018), 'Advances on graphene-based nanomaterials for biomedical applications', Materials Science and Engineering: $C$ 90, 764-780.

Rabiee, H., Vatanpour, V., Farahani, M. H. D. A. \& Zarrabi, H. (2015), 'Improvement in flux and antifouling properties of PVC ultrafiltration membranes by incorporation of zinc oxide $(\mathrm{ZnO})$ nanoparticles', Separation and Purification Technology 156, 299-310.

Rajabi, H., Ghaemi, N., Madaeni, S. S., Daraei, P., Astinchap, B., Zinadini, S. \& Razavizadeh, S. H. (2015), 'Nano-zno embedded mixed matrix polyethersulfone (pes) membrane: Influence of nanofiller shape on characterization and fouling resistance', Applied Surface Science 349, 66 - 77.

Rastgar, M., Shakeri, A., Bozorg, A., Salehi, H. \& Saadattalab, V. (2017), 'Impact of nanoparticles surface characteristics on pore structure and performance of forward osmosis membranes', Desalination 421, 179-189.

Roy, Y., Warsinger, D. M. \& Lienhard, J. H. (2017), 'Effect of temperature on ion transport in nanofiltration membranes: Diffusion, convection and electromigration', Desalination 420, 241-257.

Saad, A. H. A., Azzam, A. M., El-Wakeel, S. T., Mostafa, B. B. \& Abd El-latif, M. B. (2018), 'Removal of toxic metal ions from wastewater using $\mathrm{ZnO@Chitosan} \mathrm{core-shell} \mathrm{nanocomposite',}$ Environmental Nanotechnology, Monitoring \& Management 9, 67-75.

Saikia, L., Bhuyan, D., Saikia, M., Malakar, B., Dutta, D. K. \& Sengupta, P. (2015), 'Photocatalytic performance of $\mathrm{ZnO}$ nanomaterials for self sensitized degradation of malachite green dye under solar light', Applied Catalysis A: General 490, 42-49.

Salavati-Niasari, M., Soofivand, F., Sobhani-Nasab, A., Shakouri-Arani, M., Yeganeh Faal, A. \& Bagheri, S. (2016), 'Synthesis, characterization, and morphological control of ZnTiO3 nanoparticles through sol-gel processes and its photocatalyst application', Advanced Powder Technology 27(5), 20662075.

Saleh, T. A. \& Gupta, V. K. (2012), 'Synthesis and characterization of alumina nano-particles polyamide membrane with enhanced flux rejection performance', Separation and Purification Technology 89, 245-251.

Santhosh, C., Velmurugan, V., Jacob, G., Jeong, S. K., Grace, A. N. \& Bhatnagar, A. (2016), 'Role of nanomaterials in water treatment applications: A review', Chemical Engineering Journal 306, 1116-1137.
Shafi, H. Z., Matin, A., Akhtar, S., Gleason, K. K., Zubair, S. M. \& Khan, Z. (2017), 'Organic fouling in surface modified reverse osmosis membranes: Filtration studies and subsequent morphological and compositional characterization', Journal of Membrane Science 527, 152-163.

Shafiq, M., Sabir, A., Islam, A., Khan, S. M., Gull, N., Hussain, S. N. \& Butt, M. T. Z. (2018), 'Cellulose acetate based thin film nanocomposite reverse osmosis membrane incorporated with TiO2 nanoparticles for improved performance', Carbohydrate Polymers 186, 367-376.

Shao, F., Xu, C., Ji, W., Dong, H., Sun, Q., Yu, L. \& Dong, L. (2017), 'Layer-by-layer self-assembly TiO2 and graphene oxide on polyamide reverse osmosis membranes with improved membrane durability', Desalination 423, 21-29.

Sharma, N., Ojha, H., Bharadwaj, A., Pathak, D. P. \& Sharma, R. K. (2015), 'Preparation and catalytic applications of nanomaterials: a review', $R S C$ Advances 5(66), 53381-53403.

Shende, S., Gade, A. \& Rai, M. (2017), 'Large-scale synthesis and antibacterial activity of fungal-derived silver nanoparticles', Environmental Chemistry Letters 15(3), 427-434.

Tatarchuk, T., Peter, A., Al-Najar, B., Vijaya, J. \& Bououdina, M. (2018), Photocatalysis: Activity of Nanomaterials, in 'Nanotechnology in Environmental Science', Vol. 1-2, WileyVCH Verlag, pp. 209-292.

Teimouri, M., Khosravi-Nejad, F., Attar, F., Saboury, A. A., Kostova, I., Benelli, G. \& Falahati, M. (2018), 'Gold nanoparticles fabrication by plant extracts: synthesis, characterization, degradation of 4-nitrophenol from industrial wastewater, and insecticidal activity A review', Journal of Cleaner Production 184, 740-753.

Teow, Y. H. \& Mohammad, A. W. (2019), 'New generation nanomaterials for water desalination: A review', Desalination 451, 2-17. Nanomaterials for Water Desalination: Recent Advances and Future Challenges.

Tian, M., Qiu, C., Liao, Y., Chou, S. \& Wang, R. (2013) 'Preparation of polyamide thin film composite forward osmosis membranes using electrospun polyvinylidene fluoride (PVDF) nanofibers as substrates', Separation and Purification Technology 118, 727-736.

Tian, M., Wang, Y.-N., Wang, R. \& Fane, A. G. (2017), 'Synthesis and characterization of thin film nanocomposite forward osmosis membranes supported by silica nanoparticle incorporated nanofibrous substrate', Desalination 401, 142-150.

Tong, T. \& Elimelech, M. (2016), 'The Global Rise of Zero Liquid Discharge for Wastewater Management: Drivers, Technologies, and Future Directions', Environmental Science $\mathcal{G} 2620$ Technology 50(13), 6846-6855.

Truppi, A., Petronella, F., Placido, T., Margiotta, V., Lasorella, G., Giotta, L., Giannini, C., Sibillano, T., Murgolo, S., Mascolo, G., Agostiano, A., Curri, M. L. \& Comparelli, R. (2019), 'Gram-scale synthesis of UVvis light active plasmonic photocatalytic nanocomposite based on $\mathrm{TiO} 2 / \mathrm{Au}$ nanorods for degradation of pollutants in water', Applied Catalysis B: Environmental 243, 604-613.

Tsai, J.-H., Macedonio, F., Drioli, E., Giorno, L., Chou, C.Y., Hu, F.-C., Li, C.-L., Chuang, C.-J. \& Tung, K.-L. (2017), 'Membrane-based zero liquid discharge: Myth or reality?', Journal of the Taiwan Institute of Chemical Engineers 80, 192-202.

Ulbricht, M. (2006), 'Advanced functional polymer membranes', Polymer 47(7), 2217-2262.

UNESCO (2018), United Nations World Water Development Report: Nature-based Solutions for Water, Vol. 1, UNESCO World Water Assessment Programme. 
Urgessa, Z. N., Talla, K., Dobson, S. R., Oluwafemi, O. S., Olivier, E. J., Neethling, J. H. \& Botha, J. R. (2013), 'Mechanisms of self-assembly in solution grown $\mathrm{ZnO}$ nanorods', $\mathrm{Ma}$ terials Letters 108, 280-284.

Vivar Mora, L., Taylor, A., Paul, S., Dawson, R., Wang, C., Taleb, W., Owen, J., Neville, A. \& Barker, R. (2018), 'Impact of silica nanoparticles on the morphology and mechanical properties of sol-gel derived coatings', Surface and Coatings Technology 342, 48-56.

Voutchkov, N. (2018), 'Energy use for membrane seawater desalination: Current status and trends', Desalination 431, 2-14.

Wadley, S., Brouckaert, C. J., Baddock, L. A. D. \& Buckley, C. A. (1995), 'Modelling of nanofiltration applied to the recovery of salt from waste brine at a sugar decolourisation plant', Journal of Membrane Science 102, 163-175.

Wan Azelee, I., Goh, P. S., Lau, W. J., Ismail, A. F., Rezaei-DashtArzhandi, M., Wong, K. C. \& Subramaniam, M. N. (2017), 'Enhanced desalination of polyamide thin film nanocomposite incorporated with acid treated multiwalled carbon nanotube-titania nanotube hybrid', Desalination 409, 163-170.

Wang, J., Dlamini, D. S., Mishra, A. K., Pendergast, M. T. M., Wong, M. C. Y., Mamba, B. B., Freger, V., Verliefde, A. R. D. \& Hoek, E. M. V. (2014), 'A critical review of transport through osmotic membranes', Journal of Membrane Science 454, 516-537.

Wang, L., Gu, W., An, Z. \& Cai, Q. (2018), 'Shape-controllable synthesis of silica coated core/shell upconversion nanomaterials and rapid imaging of latent fingerprints', Sensors and Actuators B: Chemical 266, 19-25.

Wang, P. (2016), Smart Materials for Advanced Environmental Applications, Smart Materials Series, The Royal Society of Chemistry.

Wang, R.-y., Zhang, W., Zhang, L.-y., Hua, T., Tang, G., Peng, X.-q., Hao, M.-h. \& Zuo, Q.-t. (2019), 'Adsorption characteristics of $\mathrm{Cu}(\mathrm{II})$ and $\mathrm{Zn}$ (II) by nano-alumina material synthesized by the sol-gel method in batch mode', Environmental Science and Pollution Research 26(2), 1595-1605.

Wang, X., Ding, B., Liu, Y., Zhu, X., Li, H., Xia, M., Fu, H. $\&$ Li, M. (2018), 'Synthesis of 3D flower-like ZnSnO3 and improvement of ethanol-sensing properties at room temperature based on nano-TiO2 decoration and UV radiation', Sensors and Actuators B: Chemical 264, 119-127.

Werber, J. R., Deshmukh, A. \& Elimelech, M. (2016), 'The Critical Need for Increased Selectivity, Not Increased Water Permeability, for Desalination Membranes', Environmental Science \& Technology Letters 3(4), 112-120.

Xia, M., Tang, Z., Kim, W.-S., Yu, T. \& Park, B. J. (2017), 'Morphological evolution of copper nanoparticles: Microemulsion reactor system versus batch reactor system', Journal of Crystal Growth 469, 31-35.

Xiao, Q., Sun, Y., Zhang, J. \& Li, Q. (2015), 'Size-dependent of chromium (VI) adsorption on nano $\alpha$-Fe2O3 surface', Applied Surface Science 356, 18-23.

Xu, G.-R., Xu, J.-M., Su, H.-C., Liu, X.-Y., Lu-Li, Zhao, H.L., Feng, H.-J. \& Das, R. (2019), 'Two-dimensional (2d) nanoporous membranes with sub-nanopores in reverse osmosis desalination: Latest developments and future directions', Desalination 451, 18 - 34. Nanomaterials for Water Desalination: Recent Advances and Future Challenges.

Xu, J., Cao, Z., Zhang, Y., Yuan, Z., Lou, Z., Xu, X. \& Wang, X. (2018), 'A review of functionalized carbon nanotubes and graphene for heavy metal adsorption from water: Preparation, application, and mechanism', Chemosphere 195, 351-364.
Xu, J., Wang, Z., Yu, L., Wang, J. \& Wang, S. (2013), 'A novel reverse osmosis membrane with regenerable anti-biofouling and chlorine resistant properties', Journal of Membrane Sci- 2705 ence 435, 80-91.

Xue, W., Sint, K. K. K., Ratanatamskul, C., Praserthdam, P. \& Yamamoto, K. (2018), 'Binding TiO2 nanoparticles to forward osmosis membranes via MEMOPMMABr monomer chains for enhanced filtration and antifouling performance', 2710 $R S C$ Advances 8(34), 19024-19033.

Yang, Z., Guo, H., Yao, Z.-k., Mei, Y. \& Tang, C. Y. (2019), 'Hydrophilic silver nanoparticles induce selective nanochannels in thin film nanocomposite polyamide membranes', Environmental Science \&6 Technology 53(9), 5301-5308. PMID: 30973224 .

URL: https://doi.org/10.1021/acs.est.9b00473

Yi, H., Huang, D., Qin, L., Zeng, G., Lai, C., Cheng, M., Ye, S., Song, B., Ren, X. \& Guo, X. (2018), 'Selective prepared carbon nanomaterials for advanced photocatalytic application in environmental pollutant treatment and hydrogen production', Applied Catalysis B: Environmental 239, 408-424.

Yip, N. Y. \& Elimelech, M. (2011), 'Performance Limiting Effects in Power Generation from Salinity Gradients by Pressure Retarded Osmosis', Environmental Science \& Technology 45(23), 10273-10282.

Zaidi, S., Fadhillah, F., Khan, Z. \& Ismail, A. F. (2015), 'Salt and water transport in reverse osmosis thin film composite seawater desalination membranes', Desalination 368, 202213.

Zhang, J.-c., Tang, Y.-j., Yi, Y., Ma, K.-f., Zhou, M.-j., Wu, W.-d. \& Wang, C.-y. (2016), 'Large-scale synthesis of novel vertically-aligned helical carbon nanotube arrays', New Carbon Materials 31(6), 568-573.

Zhang, J., Wang, Z., Wang, Q., Pan, C. \& Wu, Z. (2017), 'Comparison of antifouling behaviours of modified pvdf membranes by tio2 sols with different nanoparticle size: Implications of casting solution stability', Journal of Membrane Science 525, $378-386$.

Zhao, Y., Qiu, C., Li, X., Vararattanavech, A., Shen, W., Torres, J., Hélix-Nielsen, C., Wang, R., Hu, X., Fane, A. G. \& Tang, C. Y. (2012), 'Synthesis of robust and highperformance aquaporin-based biomimetic membranes by interfacial polymerization-membrane preparation and RO performance characterization', Journal of Membrane Science 423-424, 422-428.

Zhu, K., Ju, Y., Xu, J., Yang, Z., Gao, S. \& Hou, Y. (2018), 'Magnetic Nanomaterials: Chemical Design, Synthesis, and Potential Applications', Accounts of Chemical Research 51(2), 404-413.

Zhu, L., Li, Y. \& Zeng, W. (2018), 'Hydrothermal synthesis of hierarchical flower-like $\mathrm{ZnO}$ nanostructure and its enhanced ethanol gas-sensing properties', Applied Surface Science 427, 281-287.

Zielińska-Jurek, A., Wei, Z., Wysocka, I., Szweda, P. \& Kowalska, E. (2015), 'The effect of nanoparticles size on photocatalytic and antimicrobial properties of $\mathrm{Ag}-\mathrm{Pt} / \mathrm{TiO} 2$ photocatalysts', Applied Surface Science 353, 317-325.

Zirehpour, A., Rahimpour, A., Seyedpour, F. \& Jahanshahi, M. (2015), 'Developing new CTA/CA-based membrane containing hydrophilic nanoparticles to enhance the forward osmosis desalination', Desalination 371, 46-57. 